\title{
Recent Advances and Perspectives of Carbon-Based Nanostructures as Anode Materials for Li-ion Batteries
}

\author{
L. Selva Roselin ${ }^{1, *}$, Ruey-Shin Juang ${ }^{2,3, *}$, , Chien-Te Hsieh ${ }^{4}$, Suresh Sagadevan ${ }^{5}$,
} Ahmad Umar ${ }^{6}$, Rosilda Selvin ${ }^{7}$ and Hosameldin H. Hegazy ${ }^{8,9}$

1 Department of Chemistry, Faculty of Science and Arts, King Abdulaziz University, Rabigh, 21911 Rabigh, Saudi Arabia

2 Department of Chemical and Materials Engineering, Chang Gung University, Guishan, Taoyuan 33302, Taiwan

3 Division of Nephrology, Department of Internal Medicine, Chang Gung Memorial Hospital, Linkou-33305, Taiwan

4 Department of Chemical Engineering and Materials Science, Yuan Ze University, Chungli, Taoyuan-32003, Taiwan; cthsieh@saturn.yzu.edu.tw

5 Nanotechnology \& Catalysis Research Centre, University of Malaya, Kuala Lumpur-50603, Malaysia; drsureshnano@gmail.com

6 Department of Chemistry, Faculty of Science and Arts and Promising Centre for Sensors and Electronic Devices, Najran University, Najran 11001, Saudi Arabia; ahmadumar786@gmail.com

7 Department of Chemistry, School of Science, Sandip University, Trimbak Road, Mahiravani, Nashik, Maharashtra 422213, India; selvinrosilda@yahoo.com

8 Department of Physics, Faculty of Science, King Khalid University, Abha -61421, Saudi Arabia; hhegazy@kku.edu.sa

9 Department of Physics, Faculty of Science, Al-Azhar University, Assiut 71524, Egypt

* Correspondence: dr.roselin@gmail.com (L.S.R.); rsjuang@mail.cgu.edu.tw (R.-S.J.)

Received: 14 December 2018; Accepted: 8 April 2019; Published: 15 April 2019

\begin{abstract}
Rechargeable batteries are attractive power storage equipment for a broad diversity of applications. Lithium-ion (Li-ion) batteries are widely used the superior rechargeable battery in portable electronics. The increasing needs in portable electronic devices require improved Li-ion batteries with excellent results over many discharge-recharge cycles. One important approach to ensure the electrodes' integrity is by increasing the storage capacity of cathode and anode materials. This could be achieved using nanoscale-sized electrode materials. In the article, we review the recent advances and perspectives of carbon nanomaterials as anode material for Lithium-ion battery applications. The first section of the review presents the general introduction, industrial use, and working principles of Li-ion batteries. It also demonstrates the advantages and disadvantages of nanomaterials and challenges to utilize nanomaterials for Li-ion battery applications. The second section of the review describes the utilization of various carbon-based nanomaterials as anode materials for Li-ion battery applications. The last section presents the conclusion and future directions.
\end{abstract}

Keywords: Li-ion batteries; an anode; carbon-based nanomaterials

\section{Introduction}

Environmentally friendly renewable energy sources have been explored for a sustainable future [1]. The present major energy sources are fossil fuel and nuclear energy. These nonrenewable energy sources have their own disadvantages. Fossil fuels are finite and will be depleted. Recent research has shown that fossil fuel energy sources emit greenhouse gases and carcinogenic substances [2]. 
Nonrenewable nuclear energy sources produce nuclear waste and are radioactive. Now, there is evidence of global warming and researchers from many fields are focusing on alternative energy sources; e.g., fuel cells, photovoltaic cells, and photoelectrochemical cells [3]. The energy produced from the green techniques requires storage devices. An electrochemical device such as a battery can store electricity inside a closed energy system as chemical energy and can be recharged and re-used as a power source in small electrical appliances, large machinery, and inaccessible locations [4]. Electrical energy is obtained by an electrochemical redox chemical reaction. Many electronic types of equipment cannot work without batteries [5]. There is increased usage of portable electronic systems of personal use. These developments have resulted in a massive demand for batteries [6]. In the near future, all electronic devices will be turned into portable and flexible ones. In addition, the use of rechargeable battery technology has many benefits for armed forces, such as in missiles, ships, submarines and aircraft, satellites, space stations, etc. In industry, where handheld devices are replacing clipboards and paperwork, and it provides higher levels of accuracy in tests once performed by hand [7]. Therefore, various electronic devices are driving the battery market to greater growth than ever before, especially the growth of rechargeable batteries.

The chemical unit inside a battery is called a cell. Many cells connected in series to form one battery. Every cell has three important portions; a positive electrode, a negative electrode, and a liquid or solid electrolyte [8]. While charging the battery with electric current, a chemical reaction happens in the electrolyte, making ions move through it one way, with electrons moving through the external circuit the other way [9]. This development of electric charge makes an electric current flow through the cell [10].

Although there are different kinds of batteries available, based on their working function they are classified into two types: primary (disposable) and secondary (non-disposable) batteries [11]. Primary cells, for the most part, have a better shelf life and are simple to use, but they cannot be recharged and discarded. These primary batteries are simple and helpful versatile power sources for different applications including medical devices, defense components, and so on [12]. Zinc-carbon batteries and alkaline batteries are a sort of disposable batteries [13]. Alkaline Zn-Mn batteries have assumed control a large portion of the current primary battery market, and their generation and utilization keep on developing in light of their invaluable expense and execution [14]. Generally, the energy densities of these alkaline $\mathrm{Zn}-\mathrm{Mn}$ batteries are higher than the secondary batteries. The secondary batteries are designed for recharging and reuse. The benefits achieved by secondary cells over primary cells are their reusability, higher power density, and higher discharge rate with excellent performance at low-temperature [15]. Various kinds of commercial battery systems are available in the market, including lead-acid battery, nickel-cadmium, nickel-metal hydride, nickel-zinc, zinc-air, zinc-bromine, and lithium batteries. Jürgen Garche discussed the characteristics of these battery systems in detail [16]. Much advancement has additionally been attempted in creating essential metal-air and lithium batteries, which utilize light metals as the anode. Lithium is a light metal and may convey a theoretical limit up to $3860 \mathrm{mAh} / \mathrm{g}$. Since lithium plating may cause hampering in batteries, magnesium is an elective lightweight component with lower cost, lower toxicity, and higher security [17]. Likewise, $\mathrm{Mg}$ is rich in both the earth's crust and seawater. Correspondingly, other active metals incorporate aluminum and zinc are alluring electrode materials with a high limit (theoretically 2980 and $820 \mathrm{mAh} / \mathrm{g}$ for $\mathrm{Al}$ and $\mathrm{Zn}$, respectively). In any case, the practical capacity of the utilized active materials for primary batteries remains are restricted because of the low use efficiency of the conventional bulk form [18].

Lithium is the first choice for negative electrode material as it is the lightest, most electropositive metal with high power density energy. Theoretically, the specific capacity for lithium is higher than zinc and lead [19]. The specific capacity values for lithium, zinc, and lead are 3860, 820, and $260 \mathrm{Ah} / \mathrm{kg}$, respectively [20]. In 1949, Hajek first suggested the use of lithium in a battery. In the 1960s, research on lithium batteries began and the concept of "lithium secondary batteries" was presented [21]. At the beginning of the 1980s, the researchers showed interest in secondary lithium batteries that reversibly 
incorporate lithium ions in their structure. Using lithium as the anode created a series of problems. Corrosion of lithium occurred, which led to dendrite formation and thus a high-volume change of the anode during cycling that resulted in a low cycling efficiency of less than 200 cycle life [22]. More importantly, the highly reactive lithium raised mainly safety concerns about the type of cell. The high reactivity of lithium made an electrolyte impossible. Two methodologies were proposed later in 1980 to overcome this issue. The main methodology comprised of utilizing a strong polymer electrolyte, which is less reactive with lithium; prompting all-solid-state lithium metal rechargeable batteries. The second conceivable approach to remove the issue related with Li metal is to supplant it with material ready to intercalate lithium ions reversibly at a low voltage, prompting the so-called "lithium-ion", "rocking chair", or "swing" lithium rechargeable batteries [23]. In the first approach, it was necessary to find a suitable electrolyte medium and a reversible positive electrode material to avoid lithium reacting with the electrolyte. Therefore, a nonaqueous slid electrolyte is needed for the lithium metal anode. $\mathrm{LiCl}-\mathrm{AlCl}_{3}$ electrolyte mixed and dissolved with propylene carbonate was proposed by Chilton and Cook [21]. As for the cathode, different halides, such as $\mathrm{AgCl}, \mathrm{CuF}_{2}, \mathrm{CuCl}, \mathrm{CuCl}_{2}$, and $\mathrm{NiF}_{2}$, were examined initially in the prototype cells. During discharging, these halides are converted into lithium halide and their corresponding metal. The formation of soluble complexes of the cathode leads to a high self-discharge rate. The alloys of lithium with other metals such as $\mathrm{Al}$ were studied to substitute the Li metal [24].

\subsection{Industrial Use of Lithium-Ion Battery Technology}

Sony Energetic of Japan utilized the Li-ion secondary battery for the first time. Li-ion batteries have many advantages over other rechargeable batteries [25]. First, they have a higher output voltage; the voltage of a single cell is $\sim 4.1 \mathrm{~V}$, approximately three times higher than that of $\mathrm{NiCd}$ and NiMH cells and two times higher than that of lead-acid batteries. Because of the higher voltage, less lithium-ion cells are required in a battery of a given voltage [26]. Also, higher energy density results in smaller and lighter batteries. Different advantages are low self-discharge, (2-10\% every month, amazing cycle life (more noteworthy than 1000 cycles) wide employed temperature extend $\left(-20\right.$ to $60^{\circ} \mathrm{C}$ ), long time spans of usability (up to five years), and low upkeep [18]. The cells do not show memory impact (where utilization time is condensed by repeated shallow discharge cycles) which is a component of NiCd batteries [27]. The gravimetric vitality thickness $(\sim 150 \mathrm{Wh} / \mathrm{kg})$ of lithium-particle cells is twice that of NiMH cells and the volumetric energy density $(\sim 400 \mathrm{Wh} / \mathrm{L})$ is four times more noteworthy than that of NiCd cells [28]. Moreover, lithium-ion cells give high rate ability: $5 \mathrm{C}$ persistent discharge rates and $25 \mathrm{C}$ consistent discharge rates have been reported in the literature [29]. These properties make lithium-ion technology appealing to different applications. Hardly any disadvantages observed incorporate moderately high costs, long charging times, capacity loss, and poor cyclability. These issues will, in general, begin from the electrode-electrolyte interfaces.

\subsection{Working Principles of Li-Ion Batteries}

A battery is a device that changes chemical energy into electric energy by means of electrochemical oxidation-reduction reaction (redox) reaction. The essential electrochemical unit achieving such energy change is known as a "cell" [30]. A battery contains a group of interconnected cells. The number of cells utilized relies upon the desired capacity and voltage for a specific application. A few electrochemical cells are associated with the arrangement as well as in parallel to acquire a lithium-ion battery of indicated voltage and capacity [31]. Each cell contains the following parts: a negative terminal (anode), where electrochemical oxidation happens during discharge; a positive terminal (cathode), where electrochemical decrease happens; an electrolyte, which encourages the transportations of ions from one electrode to another electrode; a separator, which gives electronic segregation between the electrodes; and a casing, which contains the other cell parts [32]. Lithium-ion cells use a solid reductant as an anode and a solid oxidant as a cathode. The cathode materials used in most of the commercial Li-ion batteries are $\mathrm{LiCoO}_{2}$ or $\mathrm{LiNiO}_{2}$ and the anode materials are carbonaceous [33]. During cell charging, 
the cathode material releases $\mathrm{Li}$ ions to the electrolyte and electrons are removed from the cathode by applying an external field and are then transferred to the anode. The charge-compensating Li ions are attracted by the negative electrode and then inserted into it. During cell discharge, the reverse reaction occurs [8]. That is, the anode supplies intercalated $\mathrm{Li}$ ions into the electrolyte and provides electrons to the external circuit. At the cathode, the Li ions intercalate from the electrolyte and satisfy the charge of electrons from an external circuit [34]. Common carbon anode materials are graphite or coke-type or both combined; common cathode materials include $\mathrm{LiMn}_{2} \mathrm{O}_{4}, \mathrm{LiCoO}_{2}$, and $\mathrm{LiNiO}_{2}$. The electrolyte can be either solid or liquid. The liquid electrolyte is usually a nonaqueous solution of $\mathrm{Li}$ salts and various solvents including ethers, esters, and carbonates [35]. The cell reactions that occur at the cathode and anode during cell charging and discharging are represented as follows (Equations (1)-(4)) [36-38]:

during charging

$$
\begin{gathered}
\text { At cathode: } \mathrm{LiMO}_{2} \rightarrow \mathrm{Li}_{1-x} \mathrm{MO}_{2}+\mathrm{xLi}^{+}+\mathrm{xe}^{-} \\
\text {At anode: } \mathrm{xLi}^{+}+\mathrm{xe}^{-}+\mathrm{C} \rightarrow \mathrm{Li}_{\mathrm{x}} \mathrm{C}
\end{gathered}
$$

during discharging

$$
\begin{gathered}
\text { At cathode: } \mathrm{Li}_{1-x} \mathrm{MO}_{2}+\mathrm{xLi}^{+}+\mathrm{xe}^{-} \rightarrow \mathrm{LiMO}_{2} \\
\text { At anode: } \mathrm{Li}_{x} \mathrm{C} \rightarrow \mathrm{xLi}^{+}+\mathrm{xe}^{-}+\mathrm{C}
\end{gathered}
$$

Connecting the electrodes to an external load results in electron flow in the external circuit and the ions move through the electrolyte [39]. The charge flows result from electrochemical (or redox) reactions at the electrodes that include chemical species and electrons and occur at various voltages [40]. The output voltage of the battery is given by the voltage difference between the two redox reactions. In a primary battery, the redox reactions can't be turned around and the system must be discharged once, while in a secondary (or rechargeable) battery, the redox reactions are reversible, which results in multiple charging and discharging cycles [41]. Energy storage and conversion materials with lightweight active materials involving $\mathrm{H}^{+}$and $\mathrm{OH}^{-}$ionic transport in an electrochemical reaction are being developed which facilitate miniature electronic devices. However, most conventional batteries have a lower kinetic rate of ion diffusion and migration [42]. This leads to low electrode performance compared to the theoretical value. Hence, scientists and engineers are involved in developing new electrode materials to improve the battery performance of current batteries. Current research on battery technologies is focused on (i) developing new anode/cathode materials with high-energy storage capacity and cyclability, (ii) investigation of liquid-free solid electrolyte materials with higher ionic conductivities, which addresses the flammability of organic solvents, and (iii) optimization of the electrode-electrolyte interface to improve cell safety and lifetime. Apart from these, simple battery fabrication methods utilizing thin, lightweight, and cost-effective materials are sought for next-generation batteries [43].

\subsection{Utilization of Nanomaterials for Li-Ion Batteries}

To improve the electrode performance of a battery, it is necessary to improve the (i) specific charge and charge density, cell voltage, and reversibility of cathode and anode electrochemical reactions [44]. Improvisation in lithium batteries can be done by using different materials for the cathode, anode, and electrolyte. In general, the electrochemical properties of electrode materials depend on crystallinity, phase purity, particle size and grain size of materials, and particle size distribution [45]. Both the size of the particles and size of grains within these particles play important roles, in which electrodes having smaller particles and grains show better cyclability. The power density of the microsized particle is relatively low due of a high polarization at a high charge-discharge rates [46] and is caused by moderate diffusion in the active material and rises in the resistance of the electrolyte. This issue can be resolved by planning active nanostructure materials that give high surface area and short diffusion ways for ionic transport and electronic conduction. Therefore, the use of nanoparticles as active materials dispersed in a lithium oxide or lithium salt matrix could decrease the diffusion path length for lithium insertion and 
decreases the charge transfer resistance of the electrode, thereby increasing the rate (power) capability of the battery [47]. Nanoparticles prevent aggregation and formation of large particles (thus avoiding the cracks). It has been confirmed in many studies that the cycling performance of alloy anodes can be improved by reducing the active particle size to the nanometer range $(<100 \mathrm{~nm})$ and by circumventing agglomeration of the particles by composite electrode materials [48]. The improved cycling stability can be attributed primarily to nanosized particles to accommodate large stress and strain without any cracking.

\subsection{Advantages of Nanomaterials for Li-Ion Batteries}

Micrometer-sized electrode materials are mostly used in commercial batteries, which are limited by their kinetics, lithium-ion intercalation capacities, and structural stability, resulting in low specific energy and energy density with low reversibility of electrochemical reactions. Many benefits are observed for lithium ion batteries when using nanomaterials:

(i) Since the nanostructured materials provide smaller diffusion length and higher surface/volume ratio than bulk materials, the diffusion of $\mathrm{Li}^{+}$ions are faster and thus the rate of charging is faster. The electrochemical redox reaction in Li-ion batteries proceeded in three stages; diffusion of the Li-ion inside the electrode materials, a charge transfer effect between the boundary of the electrode and the electrolyte, and Li-ion progress in the electrolyte [31]. Amongst these, the diffusion of Li ions is generally considered to be the rate-determining step of Li-ion batteries. Literature revealed that the diffusion kinetics could be improved by two approaches [49]. In one approach, doped electrode materials are used [50]. Nevertheless, the introduction of impurities sometimes causes an unstable crystal lattice which leads to lesser improvement in rate-performance. The second approach involves utilizing nanostructured materials which could minimize the diffusion length of $\mathrm{Li}^{+}$and $\mathrm{e}^{-}$[36]. The use of nanomaterials significantly shortens the $\mathrm{Li}+$ and $\mathrm{e}^{-}$diffusion lengths to the nanometer scale within the electrode materials and hence increases the rate (power) capability of the battery.

(ii) Li surface storage due to nanosize may play an important role in the overall capacity. The use of nanomaterials enhances the electrode/electrolyte contact area resulting from the larger surface area thereby enhances the electrode capability of Li storage [51]. The storage of lithium could be possible at its lattices, surface, interface, and in its nanopores. In addition to the large surface area, enhanced electrode capacity resulted in a new Li-ion storage mechanism [52]. The classical mechanism involves either a $\mathrm{Li}$ insertion/de-insertion process or a Li alloy formation. To understand the role of nanoparticles in the mechanism of Li reactivity, Poizot et al. [37] constructed $\mathrm{LiMn}_{2} \mathrm{O}_{4} / \mathrm{CoO}$ cells and studied the structural properties during charging and discharging. The $\mathrm{CoO}$ materials form a rock-salt structure which does not occupy Li-ions for insertion [53]. Also, it does not form an alloy with Li. It was observed that during charging and discharging, there were a reversible formation and decomposition of $\mathrm{Li}_{2} \mathrm{O}$. This new type of mechanism is called as 'conversion mechanism' (Equation (5)).

$$
\mathrm{MX}+\mathrm{yLi}^{+}+\mathrm{ye}^{-} \leftrightarrow \mathrm{LiX}+\mathrm{M}
$$

In the case of $\mathrm{Cu}_{3} \mathrm{~N}$ as a negative electrode, a conversion mechanism is likely to happen, wherein $\mathrm{Cu}$ metal is oxidized into $\mathrm{Cu}^{2+}$ to form $\mathrm{CuO}$ and its reduction contributes to the increase in capacity with cycle number. The additional Li storage capacity in nanosize transition metal oxide at low potential could also be explained by another mechanism, called the interfacial Li storage mechanism [38]. As per this concept, $\mathrm{Li}^{+}$ions are stored in the subsurface or surface of $\mathrm{Li}_{2} \mathrm{O}$ or $\mathrm{LiF}$, while the electrons are suited in the transition metal, resulting in charge separation. In nanostructured solids, such interfacial effects show the dominant role because of their significant ratio of interfaces with respect to the bulk [54]. It is significant to take note that interfacial storage is seen in the $\mathrm{Me} / \mathrm{LiX}, \mathrm{X}=\mathrm{O}, \mathrm{F}$ nanocomposites, in which no compound reactions occur between the transition metal and Li. The two parts, Me and LiX network, can't store Li in their bulk. It is the synergistic two-phase effect that allows additional storage at low potential [55]. This concept highlights the significance of synergistic attentions in composite systems 
and it forms the bridge between the capacitor and electrode function [56]. For example, in the case of $\mathrm{LiCoO}_{2}$, as the crystallite size decreased from 17 to $8 \mathrm{~nm}$, the capacity contribution increased from 2.6 to $6.4 \mathrm{mAh} / \mathrm{g}$. Interestingly, the charging (deintercalation) potentials decreased with size. The lower potentials suggest the effect of nanosize on the electrochemical performance of $\mathrm{LiCoO}_{2}$ [57].

(iii) In conventional bulk materials, there is considerable volume change occur during the $\mathrm{Li}$ insertion and de-insertion process, which causes cracking in the anode that leads to the capacity loss in batteries. It is believed that nanosized anode materials can overcome the volume change during the $\mathrm{Li}$ insertion and de-insertion process and so the stress and strain could be surmounted. This problem is mostly observed in silicon anodes. The theoretical capacity of silicon anode is $4200 \mathrm{mAh} \mathrm{g}^{-1}$, which is ten times higher than that of graphite anodes. However, there is a huge amount of capacity loss was observed in these silicon anodes. This is due to the higher number of $\mathrm{Li}$ atoms (4.4 $\mathrm{Li}$ atoms) could be inserted for one $\mathrm{Si}$ atom during $\mathrm{Li}$ insertion, which leads to higher volume expansion. On the other hand, during the Li de-insertion process, huge volume contraction is observed. This type of volume change causes cracking of $\mathrm{Si}$ anodes. The loss in electrical contact leads to capacity loss. When the particle size of anode materials is small, the volume of the anode is maintained, and the capacity loss can be avoided. Comparison of nanoscale single crystalline $\mathrm{SnO}$ and conventional bulky $\mathrm{SnO}$ electrode showed that the nanoscale single crystalline $\mathrm{SnO}$ exhibited higher specific capacity with better cycle performance [58]. In the SnO meshed plate nanostructure with nanosized ribbons, the nanoribbons provide a space to maintain the volume extension. Similarly, in layered $\mathrm{Li}_{x} \mathrm{Mn}_{1-y} \mathrm{Co}_{\mathrm{y}} \mathrm{O}_{2}$ cathodes, spinel-like phases are formed, with every crystallite being made of a mosaic of nanodomains. The strain is overcome at the domain wall boundaries, leading to facile cycling of these nanostructured materials compared to the spinels obtained at high-temperature without nanodomains [59].

(iv) Electrochemical reactions of the irreversible bulk materials can be made reversible when it comes to the nanoscale. These results with higher specific capacity than compared to that of the theoretical value. For example, in tin-based Li storage compounds, for example, tin oxide, it is irreversibly converted to tin according to the equation given below (Equations (6) and (7)). The second reaction involves the formation of several phases in the LixSn system, which is reversible.

$$
\begin{gathered}
\mathrm{SnO}_{2}+4 \mathrm{Li}^{+}+4 \mathrm{e}^{-} \rightarrow \mathrm{Sn}+2 \mathrm{Li}_{2} \mathrm{O} \\
\mathrm{Sn}+\mathrm{xLi}^{+}+x \mathrm{e}^{-} \leftrightarrow \mathrm{Li}_{\mathrm{x}} \mathrm{Sn}((0 \leq \mathrm{x} \leq 4.4)
\end{gathered}
$$

when pure $\mathrm{SnO}_{2}$ nanomaterial was used, the irreversible first reaction (Equation (6)) could be more reversible, resulting in higher specific capacity than the theoretical value.

(v) Nanotubes and nanowires can enhance electrical percolation and mechanical properties by entanglement [60].

Nanomaterials with a high surface-to-volume ratio increase the area of contact between the electrolyte and the electrode, resulting in more exposed redox sites providing higher power and energy density. The mechanically strong, low-dimensional nanomaterials offer high resistance to any structural damage. In addition, their structure can be easily tuned to overcome changes in the volume of lithium-based battery electrodes. Nanomaterials offer new lithium storage mechanisms irrespective of the simple ion accumulation at insertion sites, such as surface redox reactions, lithium storage at interfaces, and nanopores inherently present in nanostructures. Most electrode materials have successfully applied the strategy that enhances the rate capability with nanosized particles. Combining the advantage of low cost, low toxicity, and the ability to be manufactured as a nanomaterial that delivers fast lithium-ion intercalation, a great deal of attention has recently been given to titanium oxides [61,62]. However, "nanosize" can only effectively shorten the path length for electronic transport in practical application. In Figure 1a, where a carbon additive is used to improve the conductivity of the total electrode, the electronic transport in a nanomaterial-based electrode is shown schematically. Since nanosized particles have a very high specific surface area and high surface energy and tend to form agglomerates, they are hard to disperse and are mixed with a carton additive (see Figure 1a) [63]. 
The electronic transport length (Le) is therefore still much higher than the particle size (r) because only a small amount of nanoparticles can contact the carbon additive directly and obtain electrons (see Figure 1b). In addition, there is still a large interface resistance, particularly if the particle size is within a typical nanoscale [63]. If each nanoparticle is fully covered with an electronic conductive layer, it would effectively shorten the electronic transport length (Le) in an electrode. In this case, the electronic transport length (Le) throughout the active material is equal to (or less than) the nanomaterial particle size (r) (as shown in Figure 1b). This is because every nanoparticle's outer surface can be completely passed by electrons. Being nanosized can effectively reduce the electronic transport length (Le) across the active material with a thin electronic conductive coating layer. In addition, the electronic conductive layer of coating can reduce the resistance of the interface.

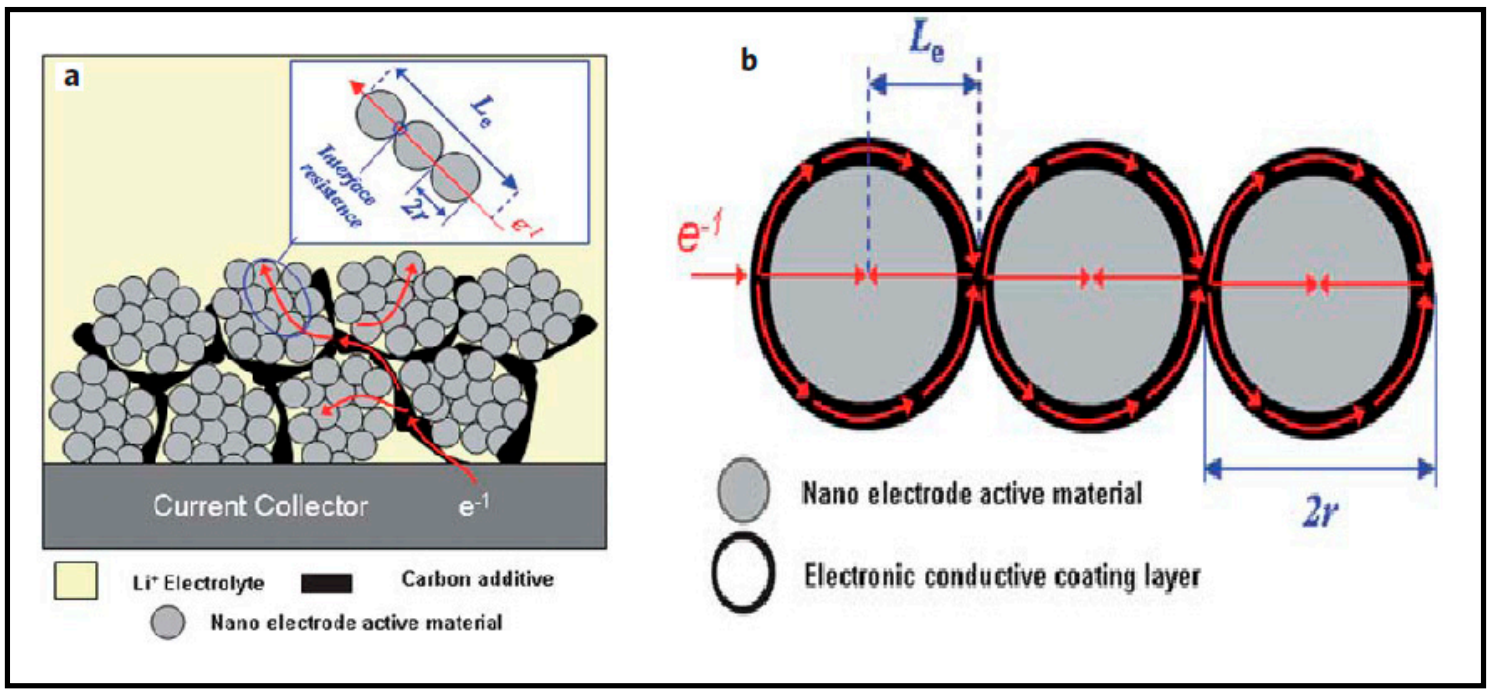

Figure 1. (a) Schematic representation showing the electronic transport length $\left(\mathrm{L}_{\mathrm{e}}\right)$ in the nanoparticles-based electrode (b) Schematic illustration of the electronic transport length for nanoparticles with a full conductive coating [63].

\subsection{Disadvantages of Nanomaterials for Li-Ion Batteries}

Because of their reduced particle size, the use of nanomaterials can cause many new challenges, such as high surface area, low packing density, and high cost. Rational design of nanomaterials must compensate for these associated disadvantages while addressing the problems of materials of micrometer size. During battery cycling, the formation of the SEI layer on the electrode surface consumes the cathode electrolyte and lithium. Compared to electrodes made up of micrometer-sized materials, the SEI forms part of the surface of nanostructured electrodes, due to the much higher electrode-electrolyte interfacial area, consumes more electrolyte and lithium, resulting in low initial Coulombic efficiency and significantly reduced overall battery capacity and energy density. A stable SEI is critical to the electrode's long cycle life while controlling the specific SEI (electrode/electrolyte surface area) plays an important role in achieving high initial Coulombic efficiency. The problems of SEI's large volume expansion and instability for high-capacity electrode materials are solved by engineering nanostructures with an electrolyte-blocking layer and an internal void space. However, due to their high surface area, the problem of low initial Coulombic efficiency arises for these nanostructures. The high surface area of electrode/electrolyte increases the risk of severe side reactions involving decomposition of electrolytes and consumption of lithium. High surface area is an inherent feature of nanomaterials, but by engineering their secondary structures, the electrode/electrolyte surface area can be adjusted. Figure 2a shows the calculation of a specific area of SEI for a secondary particle of a micrometer scale consisting of assembled nanoparticles. The specific SEI area can be reduced significantly with an electrolyte-blocking layer outside the assembled secondary particles [64]. Thus, 
the use of micrometer-scale secondary particles, compared to primary nanoparticles, can help to reduce deferred side reactions between the electrolyte and the electrode and achieve higher initial Coulombic efficiency. Of noteworthy success are $\mathrm{Si}$ anode materials with a nanoscale design inspired by grenades with the following characteristics (Figure $2 b$ ): micrometer-sized Si secondary particles composed of primary Si nanoparticles; each primary Si nanoparticle has a carbon shell with void space, and each secondary particle has an outer carbon layer as an electrolyte-blocking layer [64].

In addition to the reduced specific SEI, the interconnected carbon framework provides fast electron transport pathways. Vacuum space can mitigate Si's volume expansion on lithiation. These primary particles also allow for high tap density and volumetric mass loading, which are important parameters for electrode evaluations. Decreasing the particle size to the nanometer scale creates a lot of interparticle space, which usually results in low tap density for materials and therefore the low volumetric capacity for an electrode. Because of their significantly high surface energy, nanoparticles tend to bridge/aggregate strongly into secondary microparticles. In addition to the interparticle space between secondary microparticles, there is a large interparticle space within the aggregation of nanoparticles, resulting in a higher overall porosity compared to that of the interparticle space materials between individual microparticles. Meanwhile, the reduced particle size also induces large resistance of interparticle (relative to the same mass loading), which creates barriers in the electrode for electron transport. Thus, using nanostructured materials, achieving electrodes with high mass loading and areal capacity is challenging. Because of the reduced interparticle space, the tap density of micrometer-sized particles is generally higher than that of free nanoparticles. As such, by engineering a micrometer-scale secondary particle/cluster densely assembled by small primary nanoparticles, the tap density of nanomaterials can be significantly improved (Figure 2c) [64].

With several advantages, the nanomaterials also possess some disadvantages in the Li-ion battery applications, such as:

(i) This increase in surface area will also increase the undesirable side-reactions and potentially decrease the safety of the cells. For example, when nanomaterials are utilized as the cathode in lithium-ion batteries, their increased surface area increases reactions between electrode and electrolyte, which results in increased irreversibility but to compromise with the poor cycle life. In addition, the high surface reactivity of nanoelectrode materials causes poor cycle life. For example, in olivine $\mathrm{LiFePO}_{4}, \mathrm{Fe}^{2+}$ is quite unstable in the atmosphere where $\mathrm{O}_{2}$ and a small amount of $\mathrm{H}_{2} \mathrm{O}$ coexist. The stability of $\mathrm{LiFePO}_{4}$ in air atmosphere decreases with the reduction of particle-size since nanosize increases the number of molecules exposed in the air [65]. Okubo et al. demonstrated the good high-rate performance of nanocrystalline $\mathrm{LiCoO}_{2}$ up to $100^{\circ} \mathrm{C}$, although extreme size reduction (below $15 \mathrm{~nm}$ ) proved detrimental to cathode performance [57]. The cycling performance of nanosized $\mathrm{LiCoO}_{2}$ was, however, much inferior to that of a bulk sample, which they attributed to the enhanced reactivity of the high surface area material.

(ii) The volumetric energy density of lithium-ion batteries is quite lower in nanoelectrode materials compared to microsized materials [51].

\subsubsection{Comparison of Bulk and Nanomaterials for LIBs}

The micrometer-sized $\mathrm{LiNi}_{1-\mathrm{x}} \mathrm{MxO}_{2}$ secondary particles composed of aligned needle-like nanosized primary particles [66] and $\mathrm{LiFePO}_{4}$ secondary particles containing nanoscale carbon-coated primary particles [67] are two examples of the most successful designs for intercalation-type cathode materials. Unlike these cathode insertion materials, however, engineering the void space for each primary particle is crucial to achieving the long cycle life of high-capacity electrode materials due to their large volume lithiation expansion. Based on the principles of secondary cluster design, we have recently shown that high tap density can be achieved for powders made up of micrometer-sized Si secondary particles with a pomegranate-like a nanostructure and Si secondary clusters made using a mechanical approach (Figure 2d) $[64,68]$. The Si secondary cluster tap density produced by the mechanical approach is $0.91 \mathrm{~g} \mathrm{~cm}^{-3}$, six times the primary nanoparticles density $\left(0.15 \mathrm{~g} \mathrm{~cm}^{-3}\right)$. 
Important aspects to note here are the integration of carbon nanotubes into the Si clusters, which helps improve the electrical conductivity of the inter-cluster in the electrode, while the interconnected carbon network provides the pathways for fast electron transport within a secondary cluster. High areal mass loading is thus achieved for the as-obtained electrodes due to the good conductivity. As expected, for the as-prepared Si clusters [68], stable cycling with a high areal capacity of $\sim 3.5 \mathrm{mAh} \mathrm{cm}^{-2}$ at a high areal mass load ( $>2 \mathrm{mg} \mathrm{cm}^{-2}$ ) is achieved. Therefore, both high tap density and mass loading were achieved due to space-efficient packing of nanometer-sized primary nanoparticles within the micrometer-scale secondary particles and the interconnected carbon frame within each secondary particle. The current strategy of engineering micrometer-scale secondary particles and an interconnected conductive network is both easy and effective in solving the critical issue of low tap density and nanomaterial mass loading, and it can be extended to prepare various high-capacity electrode materials.

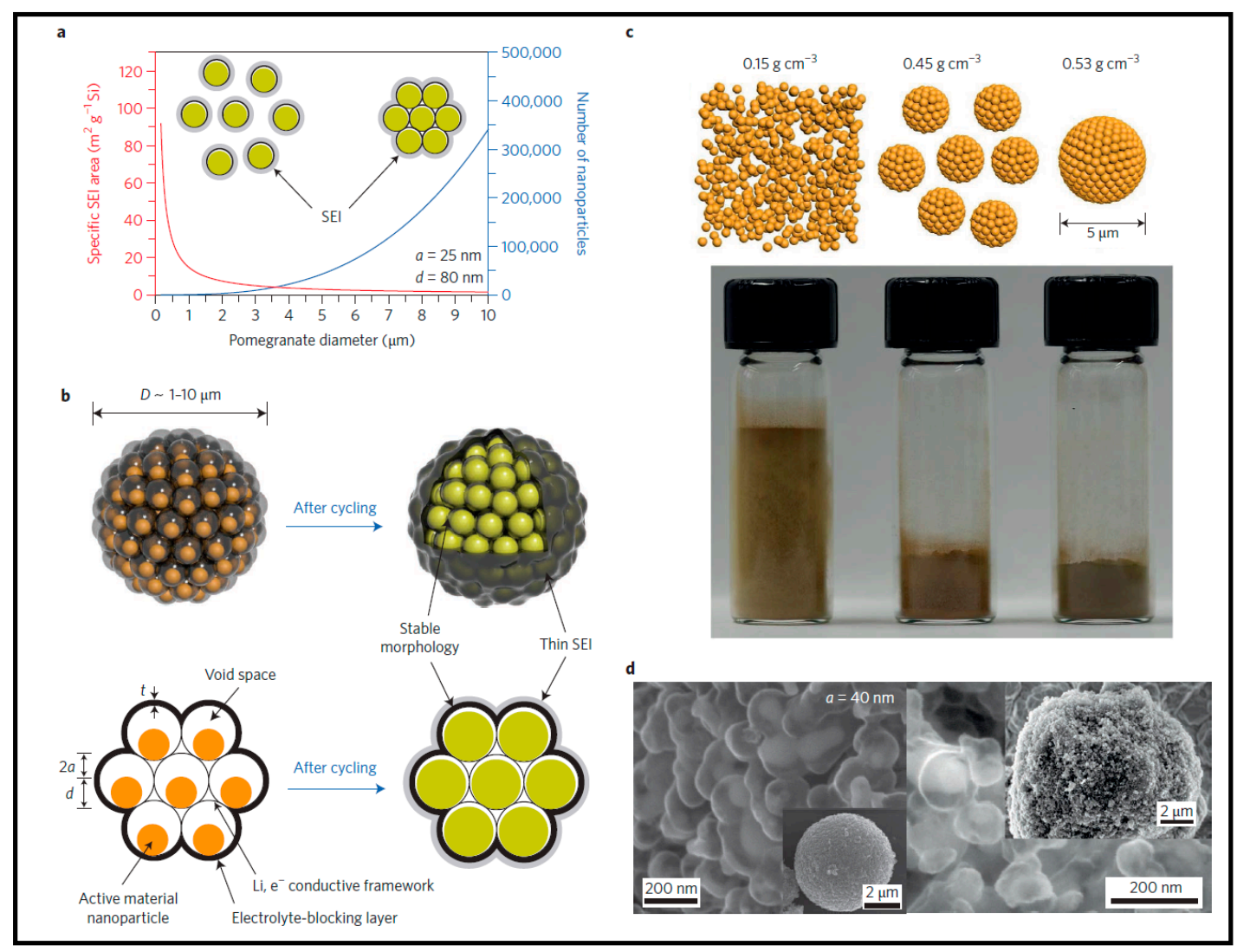

Figure 2. (a) Calculated surface area in contact with the electrolyte (specific SEI area). (b) Schematic of a pomegranate microparticle before and after electrochemical cycling (in the lithiated state). (c) Schematics and pictures of free Si nanoparticles $(\sim 80 \mathrm{~nm})$, small secondary particles $(\sim 1-2 \mu \mathrm{m})$ and large secondary particles $(\sim 5 \mu \mathrm{m})$ of the same Si nanoparticles. (d) SEM images of micrometer-sized Si secondary particles prepared via a microemulsion approach $[64,68]$.

\subsection{Challenges for the Utilization of Nanomaterials for Li-Ion Batteries}

Even though nanostructured anode materials exhibit better electrode performance, there are some limitations for commercial applications. The coulombic efficiency and reversible capacities of nanostructured anode materials are much lower than the bulk samples. For example, in nanosized $\mathrm{LiCoO}_{2}$, the coulombic efficiency was decreased to $26 \%$ and reversible capacities were decreased to $65 \mathrm{mAh} / \mathrm{g}$ from $>140 \mathrm{mAh} / \mathrm{g}$ [57]. Since the coulombic efficiency and reversible capacities are decisive factors for electrodes in commercial applications, a great focus can be placed on how to obtain more stable surfaces and better crystallinity of nanomaterials for their practical utilization in batteries. Therefore, it is essential to use the nanomaterials into smart nanostructures with tailored properties, 
which specifically improve the desired reaction. Choi et al. [69] deduced a novel method to create anode and cathode materials with controlled properties. Another important challenge in synthesizing nanomaterials is the production cost. The new technology for large-scale production show cost low cost with lightweight materials. It is important to encourage utilizing renewable energy sources possessing low cost highly efficient batteries.

\section{Carbon-Based Nanostructures as Anode Materials for Li-Ion batteries}

In a battery, loss of electrons takes place in the anode. The electron extracted from the anode is utilized as electricity through an external electric circuit. In general, a negative electrode in a primary cell is called the anode and the positive electrode is called the cathode. The preferred characteristics of the anode materials are high reversible capacity pleasing charge profile, advantageous kinetics (rate capability), longer cycle life and longer calendar life, effortlessness of processing, safety, compatibility with the electrolyte solution, and cost-effective. In the initial ambient-temperature rechargeable lithium cells, the negative electrode was metallic lithium. The important capacity loss that results from the reaction of metallic lithium with the organic solvent liquid electrolyte and the severe safety problems that results from the periodic deposition and dissolution of metallic lithium during cycling sharply diminished the commercialization of these cells. Replacement of the metallic lithium by lithium-intercalation compounds enhanced both cell cycle life and safety [70].

\subsection{Carbonaceous Materials as Anode Materials for Li-Ion Batteries}

The lithium-ion cells that are commercially available utilize carbon-based materials for their negative electrode. A breakthrough occurred in 1983, where the Li metal anode was replaced by a graphite-based carbon material in which lithium was reversibly intercalated and deintercalated [71]. Carbon-based materials are preferred for the anode, because of their availability, low cost, and performance. In addition, carbon materials protect the lithium from dendrite formation while recharging the battery. Carbon materials are available in various forms, such as graphite, hard and soft carbons, carbon fibers, carbon nanotubes, etc. Usually, commercial Li-ion batteries use graphite as the anode material due to its outstanding stability. However, their theoretical maximum capacity is limited to $372 \mathrm{mAh} \mathrm{g}^{-1}$, corresponding to the formation of $\mathrm{LiC}_{6}$ [72]. Its poor cycling behavior, a consequence of the easy movement of the graphene planes along the a-axis direction during the intercalation and de-intercalation of lithium, in addition to the problem of solvated lithium intercalation, have since ruled this material out of practical lithium-ion battery applications. Other methods for modifying synthetic and natural graphites have been tested, e.g., gas-phase oxidation by oxidizing gases, for example, oxygen, air, and ozone, but it is difficult to obtain satisfactory anode materials on a tonnage scale since the uniformity of the product is not easy to control. The use of nanostructured materials as electrodes in cells, in place of conventional electrodes, was expected to give higher lithiation capacity and better execution due to the nanomaterials' high surface area compared to bulk materials. Henceforth, the abundant research effort was focused on choosing nanomaterials appropriate for this application. Carbon nanomaterials in various morphologies, such as carbon nanotubes, carbon nanofibers, carbon xerogel, carbon nanosprings, carbon nanorods, etc. were tested as anode materials.

\subsection{Carbon Nanotubes (CNTs) as Anode Materials for Li-Ion Batteries}

Since the discovery of carbon nanotubes in 1991 [73], scientific and technological interest has been stimulated intensively in the field of synthesis and applications of various CNTs and modified CNTs. CNTs are composed of rolled graphene sheets, which resemble building "bricks". The basic constitution of the nanotube lattice is the strong $\mathrm{C}-\mathrm{C}$ covalent bond (as in graphite planes). The perfect collection of atoms on the lattice along the tube axis and the closed topology endows nanotubes with in-plane properties of graphite, such as elevated conductivity, excellent mechanical strength, stiffness, chemical specificity, and most of all, its inert nature. Moreover, the nanosized structure gives a wide surface area which helps in enhancing the vast application in the field of mechanical and chemical engineering. 
Carbon nanotubes are classified in several ways based on their configuration, degree of graphitization, and structure. Based on configuration, it can be classified into an armchair, zig-zag, and chiral. Depending on the degree of graphitization, they can be classified into amorphous and graphitic. depending on the structure, they can be classified into single-walled (SWCNT) and multiwalled carbon nanotubes (MWCNT). The electrochemical properties of CNTs (both MWNTs [51-68] and SWNTs [51,57,65-68]) used as the anode materials for lithium-ion batteries were investigated extensively and it was found that lithium intercalation/deintercalation in the hosts was dependent upon the morphology and structure of the CNTs. A single graphene sheet rolled into a cylinder with an almost uniform diameter in the range of 1-2 nm and lengths of several micrometers form SWNTs. Each rope contains many tubes, ranging from 203 to several thousand. The surface of SWCNTs is much higher with a value of $2630 \mathrm{~m}^{2} / \mathrm{g}$. A lithium-ion battery with a graphene ink anode exhibited stable operation for over 80 charge-discharge cycles of $165 \mathrm{mAh} \mathrm{g}^{-1}$ with an energy density of around $190 \mathrm{Wh} \mathrm{kg}^{-1}$ (Figure 3) [74].
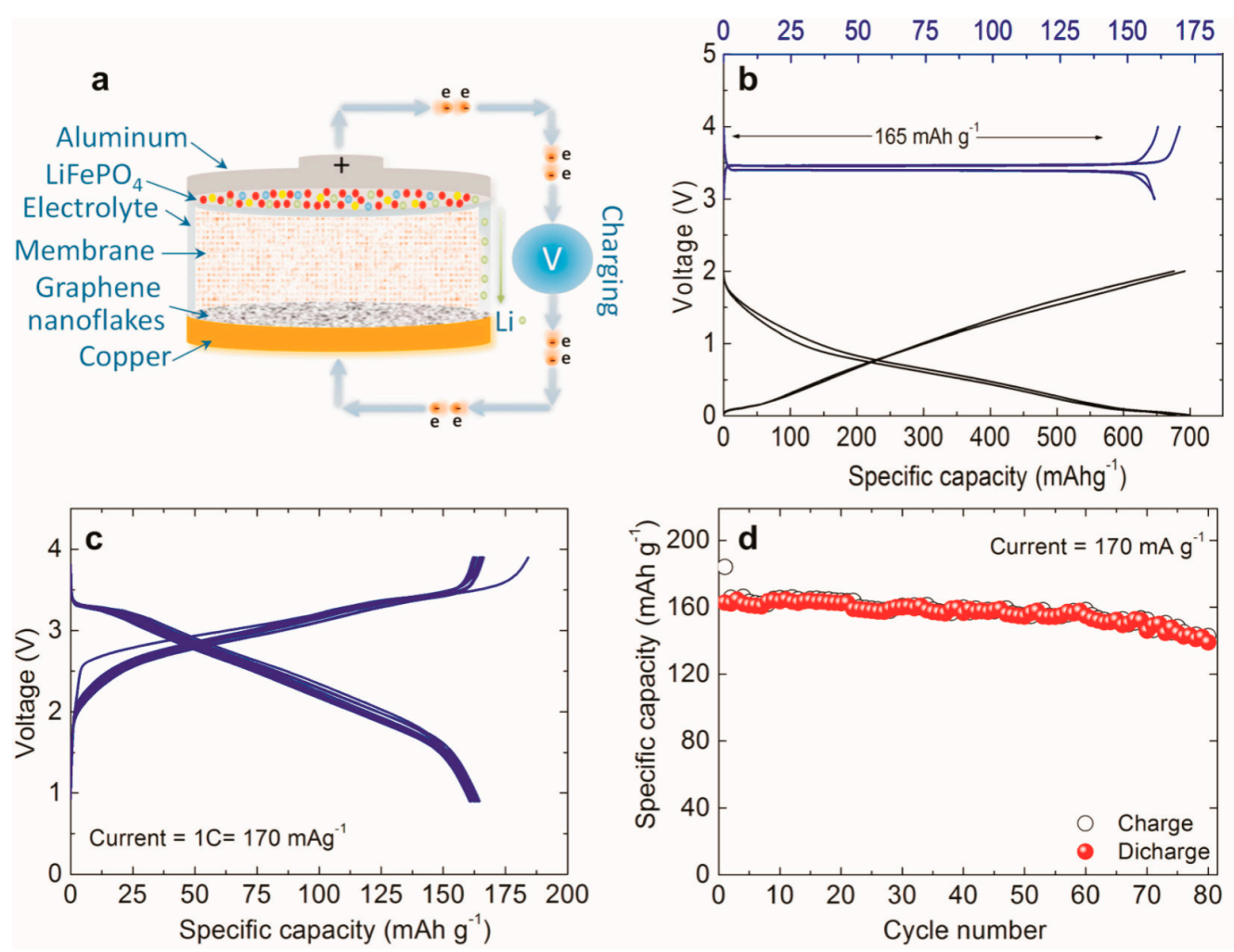

Figure 3. Electrochemical profile of graphene/lithium iron phosphate lithium ion cell. (a) Schematic diagram of graphene/lithium iron phosphate cell. (b) Charge-discharge voltage profiles of the single electrodes (c) Voltage profile of the graphene/ $/ \mathrm{LFePO}_{4}$ full cell. (d) Specific capacity versus cycle number of the cell [74].

Graphitic sheets are rolled into closed concentric cylinders to form MWCNTs [75-78]. These MWCNTs showed higher capacity than graphite. The conduction properties in MWNT are significant, and ballistic electron transport and the Aharnov-Bohm effect were observed in individual MWNTs [79]. The distinctive structural arrangement of MWCNTs resulted in a superior capacity to graphite. The aligned MWCNTs exhibited higher lithium storage $(980 \mathrm{mAh} / \mathrm{g})$ than in-aligned MWCNTs (158 $\mathrm{mAh} / \mathrm{g}$ ). After ten cycles, the capacity loss was observed in both cases, but the loss in capacity was much higher in nonaligned MWCNTs compared the that of aligned MWCNTs. The SWNTs showed reversible Li capacity on the order of $460 \mathrm{mAh} / \mathrm{g}$, which is higher than the theoretical value for graphite $(372 \mathrm{mAh} / \mathrm{g})$. Li insertion leads to irreversible structural disorder inside the CNT rope lattice. Figure 4 illustrates the Li adsorption mechanism on the CNT-C60 hybrid system [80]. 
(a)

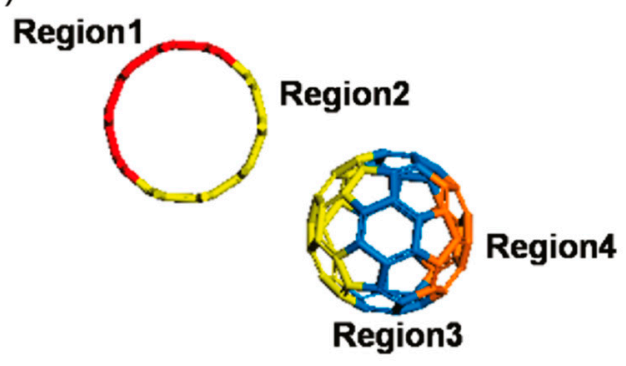

(b)

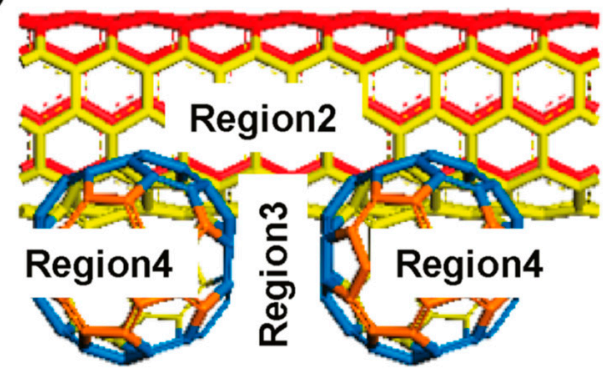

(d)

(c)

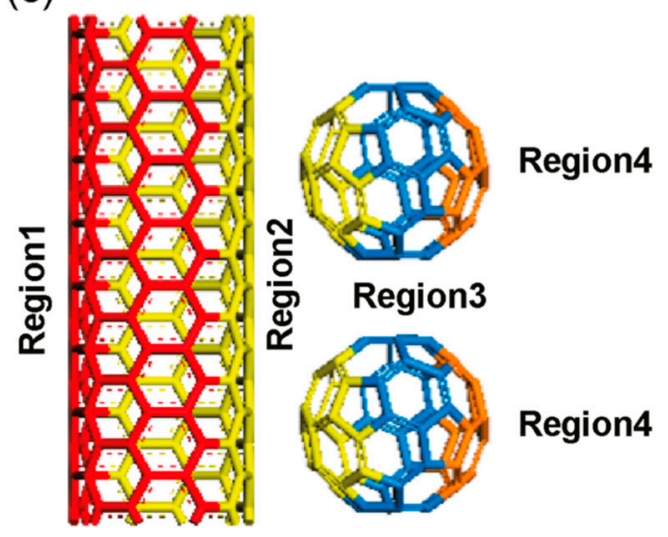

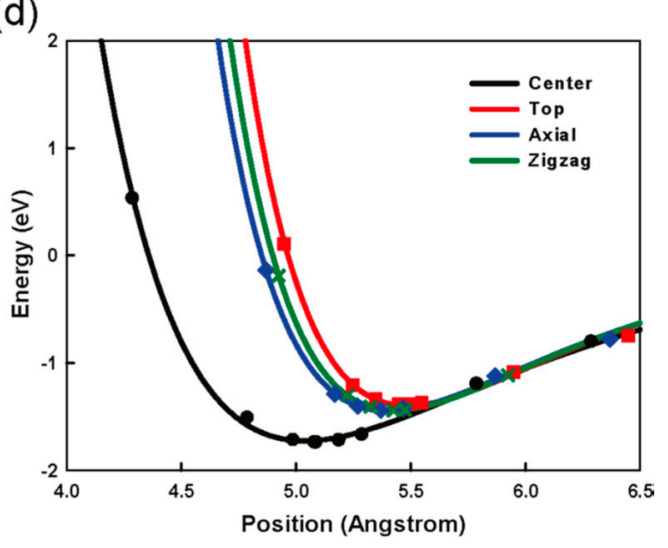

Figure 4. Elementary structure of $(5,5)$ CNT-C60 hybrid system: (a) front view; (b) side view; (c) top view; region 1-red, region 2-yellow, region 3-blue, and region 4-orange; (d) Single point energy calculation of the Li atom on the different positions of the hexagonal ring in the $(5,5)$ SWCNT [80].

This suggests that $\mathrm{Li}$ ions intercalate in the channels between nanotubes and disrupt the intertube binding, in contrast to the well-ordered doping superlattices observed in graphite, polyacetylene, and $\mathrm{C}_{60}$ hosts. For Li-ion battery applications, SWNT can be a promising material due to its high reversible capacity and high rate performance. The limiting factors of these nanotubes in battery application so far are the large irreversible capacity and the large voltage hysteresis. The electrochemical performance of CNTs depends on the presence of impurities, structural defects, and nature of graphitization, and these are controlled by their preparation methods and the treatment process. The further treatment process includes purification, ball milling, an etching process, acid treatment, etc. and can be adapted to enhance the electrochemical performance of the CNTs [81,82].

The electrochemical performance of CNT could be improved by modifying the CNT structure by adding additives. The porous carbon nanostructure $\alpha$-CNT showed a reversible capacity of $\sim 302 \mathrm{mAh} \mathrm{g}^{-1}$ and exhibit little hysteresis in the charge-discharge process [83]. CNT with quadrangular structure and one open end have higher reversible capacity compared to the common multiwalled carbon nanotubes [84]. The initial capacity of carbon nanotubes can be improved by constructing carbon nanotube networks onto carbon fiber (CNT/CFP) [83,84]. The improved performance is due to the electroactive area introduced by carbon fiber on CNT. To minimize the electrode weight and size, a simple paper electrode was prepared by using "free-standing" single wall carbon nanotubes (SWNT) [85]. These paper electrodes exhibited a slightly lower capacity compared to conventional electrodes. However, the capacity of this paper electrode could be improved by using carbon black additives. Comparison of electrochemical performance of the CNT in single-wall (SWCNT), double-wall (DWCNT), and multiwalled (MWCNTs) structures demonstrate that both SWCNT and DWCNT films exhibit more specific charge of $2390 \mathrm{mAh} \mathrm{g}^{-1}$ and $2110 \mathrm{mAh} \mathrm{g}^{-1}$ compared to the MWCNT film with a value of $750 \mathrm{mAh} \mathrm{g}^{-1}$ (Figure 5a). However, strong capacity fading was observed with SWCNT and DWCNT films. the MWCNT film has higher coulombic efficiency than both the SWCNT and 
DWCNT films. The active phase in CNT improves the electrochemical properties. By adding tin with CNT enhanced the charge capacity of CNY anode (Figure 5a). Figure 5b,c presents the TEM image of Sn@CNT electrode and Sn@C@CNT after 80 cycles, respectively [86].

Maurin et al. [87] examined the MWCNT gotten by an electric-arc method. The sample contains multiwalled carbon nanotubes MWNTs, onions, and amorphous carbon. The littlest nanotubes have two concentric graphitic shells. Diameters differ from 5 to $20 \mathrm{~nm}$ with a mean estimation of $15 \mathrm{~nm}$, and lengths are $>1 \mu \mathrm{m}$. The ends of the nanotubes are constantly capped. These carbon nanotubes display a reversible capacity of $180 \mathrm{Ah} / \mathrm{kg}$, contrasted with $372 \mathrm{Ah} / \mathrm{kg}$ in graphite. The reversibility concerns the amount of intercalated lithium that can be deintercalated and not the thermodynamically or kinetic parts of the intercalation procedure. This capacity is retained after ten cycles and the proportion discharge capacity-charge capacity is constant and is equal to $1.02 \pm 0.01$. The irreversible capacity is of $145 \mathrm{Ah} / \mathrm{kg}$. The low electrochemical specific capacity estimated is probably a result of both the confinement of the Li species that makes a 'bottleneck' which hinders the lithium dispersion and the low extent of MWNTs in the raw material. In the spectral changes of the Raman spectrum, the Raman $\mathrm{E}_{2 \mathrm{~g}}$ band defines the interlocked Li-ion between the graphene layers of the carbon nanotube without the progress of $\mathrm{n}$-staged phases with $\mathrm{n}$ higher than two and further proceeds by interlocking graphite compounds [88].

Gao et al. [89] compared single-walled carbon nanotube (SWNT) electrochemical performance for samples equipped by laser ablation technique and by further purification methods. It was observed that the SWNT exhibited a reversible saturation composition (RSC) of $450 \mathrm{mAh} \mathrm{g}^{-1}$ for $\mathrm{Li}_{1.2} \mathrm{C}_{6}$ by laser ablation technique. By further removing the impurity phases by filtration, the RSC raised to $600 \mathrm{mAh} \mathrm{g}^{-1}$ for $\mathrm{Li}_{1.6} \mathrm{C}_{6}$ which was apparently larger than the ideal value of $372 \mathrm{mAh} \mathrm{g}^{-1}$ for $\mathrm{LiC}_{6}$ in graphite. In the case of MWCNTs prepared by catalytic decomposition, the as-prepared MWCNTs without purification show high reversible capacity. After purification with a solution of hydrofluoric acid and then refluxing with nitric acid and heat treatment, irreversible capacity decreased. This change in the irreversible capacity was also associated with a decrease of the reversible capacity, from $390 \mathrm{~mA} \mathrm{~h} / \mathrm{g}$ for purified as-prepared MWNTs to $230 \mathrm{~mA} \mathrm{~h} / \mathrm{g}$ for the MWCNTs heat-treated at $2800{ }^{\circ} \mathrm{C}$. By comparison to graphite, such values correspond to $\mathrm{Li}_{1.04} \mathrm{C}_{6}$ and $\mathrm{Li}_{0.62} \mathrm{C}_{6}$, respectively [90].
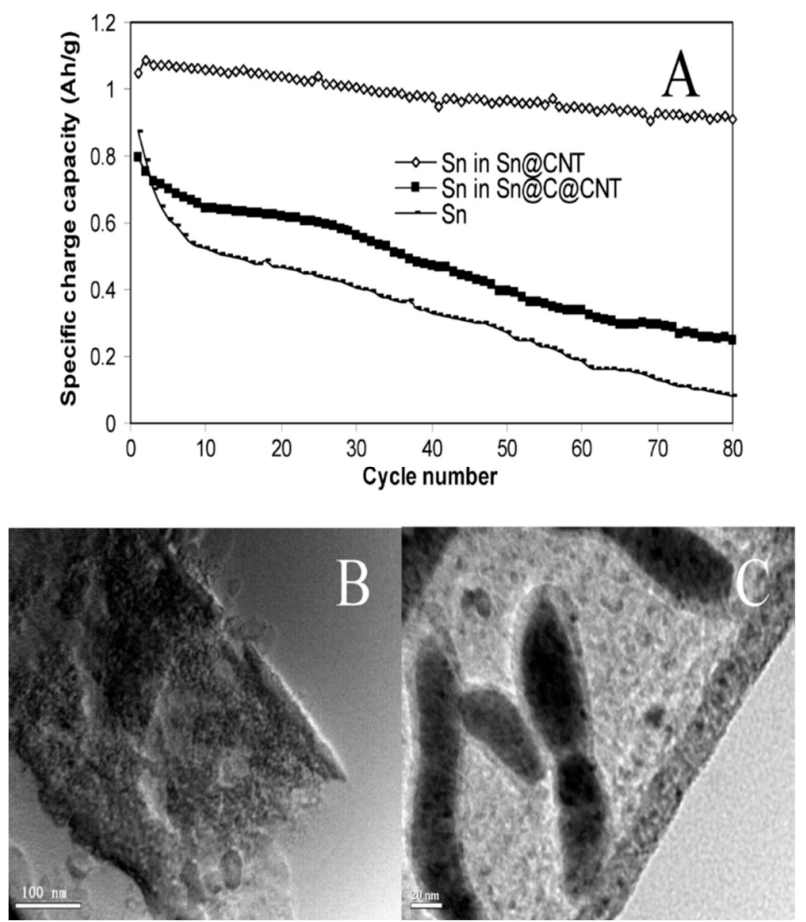

Figure 5. Electrochemical properties of Sn contributions in Sn@CNT and Sn@C@CNT (a); TEM image of Sn@CNT electrode after 80 cycles (b); TEM image of Sn@C@CNT electrode after 80 cycles (c) [86]. 
The raw carbon nanotubes were oxidized at a temperature of $130{ }^{\circ} \mathrm{C}$, using a mixture of nitric and sulfuric acid to improve its storage capacity. A total discharge capacity of approximately $660 \mathrm{~mA} \mathrm{hg}^{-1}$ was obtained after the initial discharge and in contrast, the storage capacity wads $200 \mathrm{~mA} \mathrm{hg}^{-1}$. This abrupt increase in the storage and leaching capacities were because of the effect of acid-oxidation on carbon nanotubes. This increased storage capacity is because of the intercalation procedure. Initially. The residuals in the acids caused them to react with the Li ions and cause the irreversible capacity. The nitric and sulfuric acid can easily infuse through the layers of the graphene sheets, creating defects such as pores in the graphene sheets and ultimately help in the expansion of graphite. Therefore, $\mathrm{Li}$ atoms can now easily diffuse into the graphite layers through defect sites produced by oxidation, hence increasing the reversible capacity [91].

The prepared nanotubes are subjected to the ball-milling process. The electrochemical properties and hence the battery performance was changed after ball-milling. The reversible capacity of lithium ion batteries was enhanced to $1000 \mathrm{mAh} \mathrm{g}^{-1}$ with $\mathrm{Li}_{2.7} \mathrm{C}_{6}$; at the same time, the irreversible capacity of lithium was diminished from $\mathrm{Li}_{3.2} \mathrm{C}_{6}$ to $\mathrm{Li}_{1.3} \mathrm{C}_{6}$ [92]. Efforts were taken up by various researchers to understand the causes for lower irreversible capacity in ball-milling nanotube and illustrate few models to enhance the electrochemical properties. Xing et al. [93] reported that in ball-milled sugar carbons, the reversible capacity of lithium is increased from $\mathrm{Li}_{1.5} \mathrm{C}_{6}$ to $\mathrm{Li}_{2} \mathrm{C}_{6}$. The lithium insertion in ball-milled sugar carbons is enhanced by carbon radicals present at the edges of graphene sheets with fractured structure. Disma et al. [94] studied that using $\mathrm{Li}_{1.9} \mathrm{C}_{6}$ that extended ball-milling time $(80 \mathrm{~h})$ to the sample produces a defect center along the graphite c-axis and breaks the graphene layers. The attributed large reversible capacity was designed due to the adsorption of $\mathrm{Li}$ ions on two sides of the separated graphene layers.

The development of the microtexture and the composition of the nanotubes with the thermal treatment, from 900 to $2800{ }^{\circ} \mathrm{C}$, permitted the investigation of the connection between the physical and the electrochemical behaviors of MWNT. The microtextural irregularities in the tube walls cause the catching of lithium at the edges of pseudographitic aromatic layers of MWNT and are completely responsible for the irreversible sorption phenomenon. Heat treatment of the nanotubes provided the excellent textural organization with a reduction of the surface area and gradual removal of the heteroatoms, leading to limited lithium inclusion, which is reversible as well as irreversible. The difference between the decrease and the oxidation overvoltage somewhat reduces for MWNT treated at $1600{ }^{\circ} \mathrm{C}$ and for MWNT $2000{ }^{\circ} \mathrm{C}$. Above $2500{ }^{\circ} \mathrm{C}$, that is, after almost full graphitization, the electrochemical storage in carbon nanotubes continues nearly without hysteresis; however, the value of the capacity is very low $\left(<100 \mathrm{mAh} \mathrm{g}^{-1}\right)$. It was expected that the central cores of MWNT play an important role in the cumulation of ions as well as for the creation of an electrical double layer. Henceforth, their closing with thermal treatment and the formation of continuous carbon layers is unfavorable for lithium sorption [95].

The CNT structure could also be modified by a chemical etching process which could at once change the electrochemical performance of CNT's. The shorter single-walled carbon nanotubes produced by chemical etching improve the Li diffusion into the interior of CNTs, thereby enhancing the reversible capacity of CNTs. Nevertheless, the coulombic efficiency was reduced by large structure defects [96]. The hysteresis could be reduced by using shorter single-walled carbon nanotubes [97]. Yang et al. [98] compared the electrochemical performance of long and short CNTs. The reversible capacities of short CNTs were twice those of long carbon nanotubes. Also, the charge-transfer resistance of short CNTs was much lower than those of long carbon nanotubes. As a result, the short CNTs revealed higher electrochemical performance during the charge and discharge process. With the aim of miniaturizing electrode devices, ultrashort CNTs were prepared by Wang et al. [99]. These micrometer-length CNTs showed much better electrochemical performance in Li-ion batteries. Introducing many defects and pores by etching increased CNT capacity [100-103]. The structural analysis of closed and opened carbon nanotubes showed that the closed carbon nanotubes possess pentagons and heptagons with capped tube end in which insertion of Li-ion is not possible into the inner core of the tubes. On the 
other hand, the Pentagon and heptagon structures were absent in open tubes and so Li-ion insertion into the inner core of the tubes is possible and this lithium cannot deintercalated. Therefore, the opened carbon nanotubes showed poorer cycling performance than the closed carbon nanotubes [104,105].

The degree of graphitization shows a significant role in the electrochemical behavior of MWCNTs. The charge capacity of the somewhat graphitized carbon nanotube is higher $(640 \mathrm{mAh} / \mathrm{g})$ than that of the well-graphitized carbon nanotube ( $282 \mathrm{mAh} \mathrm{g}^{-1}$ during the first cycle). The higher charge capacity of the slightly graphitized carbon nanotube sample could be related to Li being doped mostly into regions without organized graphitic structures, microcavities, edges of graphitic layers, and surfaces of single graphitic layers. Together, they showed a voltage hysteresis of about $1 \mathrm{~V}$, which is higher than for hydrogen-containing carbon. However, the graphitized MWNTs showed better cycle life and rate capability. The stable structure is because of the reduction in charge capacity $65.3 \%$ their initial value at 20 charges-discharge cycles. The well-graphitized samples sustained $91.5 \%$ of their original charge [106]. The CuO/MWCNTs, on the other hand, could supply $700 \mathrm{mAh} / \mathrm{g}$ [107]. Less graphitized MWCNT was compared with more graphitized MWCNT structure. It was inferred that the properties of specific capacity and cycle stability were enhanced in less graphitized MWCNT. Cycle stability and charge-discharge rates were enhanced in the more graphitized MWCNT structure [108].

The electrochemical performance of CNTs is improved by doping with various heteroatoms. For instance, boron-doped multiwalled carbon nanotubes (B-MWNTs) exhibit higher reversible capacity than undoped multiwalled carbon nanotubes [109]. The resistivity of bulk samples decreases by alkali doping [110]. The internal and external surfaces of the SWNT ropes were decorated by alkalis [111]. Tangential mode shifts result from electron transfer from alkali dopants to the SWNT [112]. Cobalt oxide nanoparticle coated on CNT surface exhibited good electrochemical performance through a conversion reaction [113].

All the electrochemical reactions occurring in a $\mathrm{CNTs}-\mathrm{Co}_{3} \mathrm{O}_{4}$ core-shell nanocomposite anode can be described as follows (Equations (8) and (9)):

$$
\begin{gathered}
8 \mathrm{Li}^{+}+\mathrm{Co}_{3} \mathrm{O}_{4} \leftrightarrow 4 \mathrm{Li}_{2} \mathrm{O}+3 \mathrm{Co} \text { (conversion reaction) } \\
\mathrm{xLi}^{+}+\mathrm{C}(\mathrm{CNT}) \leftrightarrow \mathrm{Li}_{\mathrm{x}} \mathrm{C} \text { (intercalation reaction) }
\end{gathered}
$$

Another example is carbon nanotubes coated with a layer of copper oxide $(\mathrm{CuO} / \mathrm{CNT})$ by a plating method followed by oxidation at $160{ }^{\circ} \mathrm{C}$ in air. They showed a reversible capacity of $700 \mathrm{mAh} \mathrm{g}{ }^{-1}$, corresponding to $1.88 \mathrm{Li}$ for $6 \mathrm{C}$, but the high capacity exhibits a larger potential hysteresis. The $\mathrm{Li}$ insertion properties of $\mathrm{CuO} /$ carbon nanotubes showed that $\mathrm{CuO}$ in $\mathrm{CuO} /$ carbon nanotubes can

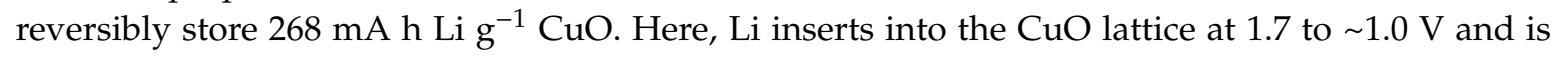
released at 2.3 to $\sim 2.5 \mathrm{~V}$ vs. $\mathrm{Li}$, according to the following equation (Equation (10))

$$
\mathrm{CuO}+\mathrm{xe}+\mathrm{xLi} \leftrightarrow \mathrm{CuOLi}
$$

The cycle life of $\mathrm{Li} / \mathrm{CuO} / \mathrm{CNT}$ cell is limited due to $\mathrm{CuOLix}$ decomposition to $\mathrm{Cu}, \mathrm{Cu}_{2} \mathrm{O}$, and $\mathrm{Li}_{2} \mathrm{O}$ and the microstructure of CNT was destroyed during $\mathrm{Li}$ insertion and release [114]. Yang et al. [115] confirmed the diffusion of $\mathrm{Cu}^{2+}$ ions into the pores and onto the exterior surface of the carbon nanotubes. The transformation of $\mathrm{Cu}^{2+}$ ions to $\mathrm{Cu}$ takes place at elevated temperatures in the carbon nanomaterial. Hence, the pores present the $\mathrm{CNT}$ and the exterior surfaces will be filled partially with $\mathrm{Cu}$ atoms until all the pores are occupied. Consequently, the carbon nanotubes doped with $\mathrm{Cu}$ will possess a lower specific capacity.

Metals such as $\mathrm{Al}, \mathrm{Sn}, \mathrm{Sb}, \mathrm{Pb}$ can store $\mathrm{Li}$ by means of combination development through electrochemical means, bringing about higher capacities than those of carbonaceous materials. A huge specific volume change likewise happens amid Li addition and extraction which cause the electrode to flop by pummeling. Accordingly, quick capacity blurring is observed [116]. Thus, to improve the structural stability, carbon nanotubes (CNTs) doped with $\mathrm{Sb}$ and $\mathrm{SnSb}$ particles were prepared by 
chemical methods using $\mathrm{SnCl}_{2}$ and $\mathrm{SbCl}_{3}$ as precursors along with CNTs. CNTs along with $\mathrm{Sb}$ and $\mathrm{SnSb}$ particles exhibited enhanced cyclability and reversible specific capacities in contrast with pure CNT's. The reversible capacities for CNT-36 wt. $\% \mathrm{Sb}$ were found to be $462 \mathrm{mAh} / \mathrm{g}$ and for CNT-56 wt.\% $\mathrm{SnSb}$ the reversible capacities were as high as $518 \mathrm{mAh} / \mathrm{g}$.

The enrichment in cyclability is connected to the nanoscale features of the metal nanoparticles and CNTs possess a unique role involved in the mechanical stress induced by specific volume changes in electrochemical Li addition and extraction reactions [117]. Sn/CNTs [118], Si/CNT [119], $\mathrm{SnO}_{2} / \mathrm{CNTs}$ [120], and $\mathrm{SnO}^{2} / \mathrm{CNTs}$ [121] composites possess larger capacity and enhanced cyclability than pure metals or metal oxides. Shu et al. [122] fabricated a cage-like CNTs/Si composite structure, exhibiting a large reversible capacity of $940 \mathrm{mAh} \mathrm{g}^{-1}$ and enhanced cycle performance. The Sn-encapsulated CNT nanostructure (Sn@CNT) exhibited high reversible capacity and good cyclability [86]. Both Sn@CNT and Sn@C@CNT anodes, even after 80 cycles of discharging and charging, retained their tubular structure and no significant growth in particle size was observed during the cycling period (Figure 5) [86].

It is predictable that in metal (oxide)-CNT composites, the volume variation that occurs in both metals or metal oxides can be more efficiently lodged in CNT during the process of charging and discharging. The encapsulation quantity of $\mathrm{SnO}_{2}$ in $\mathrm{CNTs}$ is directly related to reversible capacity and cycle performance of $\mathrm{SnO}_{2} / \mathrm{CNT}$ composite. Appropriate entrapping of $\mathrm{SnO}_{2}$ exhibits a reversible capacity as high as $383 \mathrm{mAh} \mathrm{g}^{-1}$ with subsequent cyclability with only $0.4 \%$ capacity loss/cycle. Appropriate entrapping of $\mathrm{SnO}_{2} / \mathrm{CNTs}$ could not only provide high electrical conductivity but also successfully accommodate the volume variations of $\mathrm{SnO}_{2}$ during the cycling processes [121].

For $\mathrm{MnO}_{2}$, a conventionally used cathode material, very few reports are available on its use as an anode material for Li-ion battery cells [123]; however, it has been reported to attain large reversible capacity as an anode material [124]. Furthermore, $\mathrm{MnO}_{2}-\mathrm{CNT}$ composite structures have been proved to be an efficient way to progress electron transfer for use in supercapacitors [125]. As stated by Reddy et al. [126] even though the $\mathrm{MnO}_{2} / \mathrm{CNT}$ composite electrodes can distribute a reversible capacity of about $500 \mathrm{mAh} \mathrm{g}^{-1}$ after 15 cycles, a faster decay capacity within 15 cycles was observed.

The Caterpillar-like nano flaky exhibits an Even larger reversible capacity of $801 \mathrm{mAhg}^{-1}$ was observed for $\mathrm{MnO}_{2}$ /carbon nanotube (CNT) nanocomposites [127], with $1000 \mathrm{mAhg}^{-1}$ contribution due to the $\mathrm{MnO}_{2}$ porous layer alone for the first cycle with a reasonable rate capability. The electrochemical performance when compared to the pure $\mathrm{MnO}_{2}$ electrode, unique hierarchy architecture in $\mathrm{MnO}_{2} /$ carbon nanotube (CNT) enhanced the property, thereby providing faster lithium ion and electron transport and to fulfill the large volume change during the conversion processes.

\subsection{Carbon Nanofibers as Anode Materials for Li-Ion Batteries}

An encouraging anodic material is carbon nanofiber due to its ability to highly graphitize at low temperatures and its reduced cost of bulk production. The rate of graphitization and their structure are greatly important for the anodic performances in Li-ion batteries. Yoon et al. [128] produced highly graphitized carbon nanofibers (CNFs) by $\mathrm{CVD}$ at $550-700{ }^{\circ} \mathrm{C}$ and could control the structure from platelet $(\mathrm{P})$ to tubular $(\mathrm{T})$ at such elevated temperatures. Such CNFs exhibit high capacity of about $297-431 \mathrm{mAh} / \mathrm{g}$, particularly in the low potential areas. The coulombic efficiency in the first cycle is nearly $60 \%$. Doping nitrogen is another approach to enhance the electrochemical properties of carbon materials. Wang et al. [129] observed that flexible CNF films with nitrogen or oxygen dopants had deformities in graphite structure and can display initial capacities of 2000 and $755 \mathrm{mAh} \mathrm{g}^{-1}$ corresponding to current densities of 5 and $10 \mathrm{Ag}^{-1}$, respectively. Even after 500 cycles, CNF800 retained capacities of about $1251,865,702$, and $305 \mathrm{mAh} \mathrm{g}^{-1}$ at $0.5,1,5$, and $10 \mathrm{Ag}^{-1}$, respectively (Figure 6). 
(a)

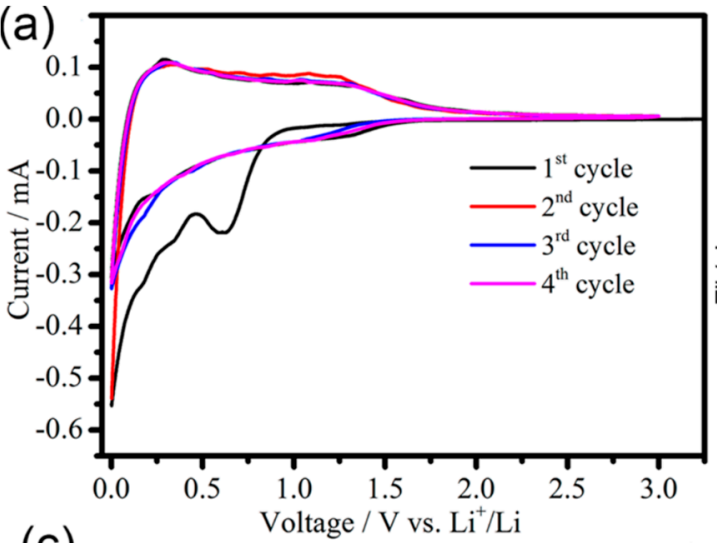

(c)

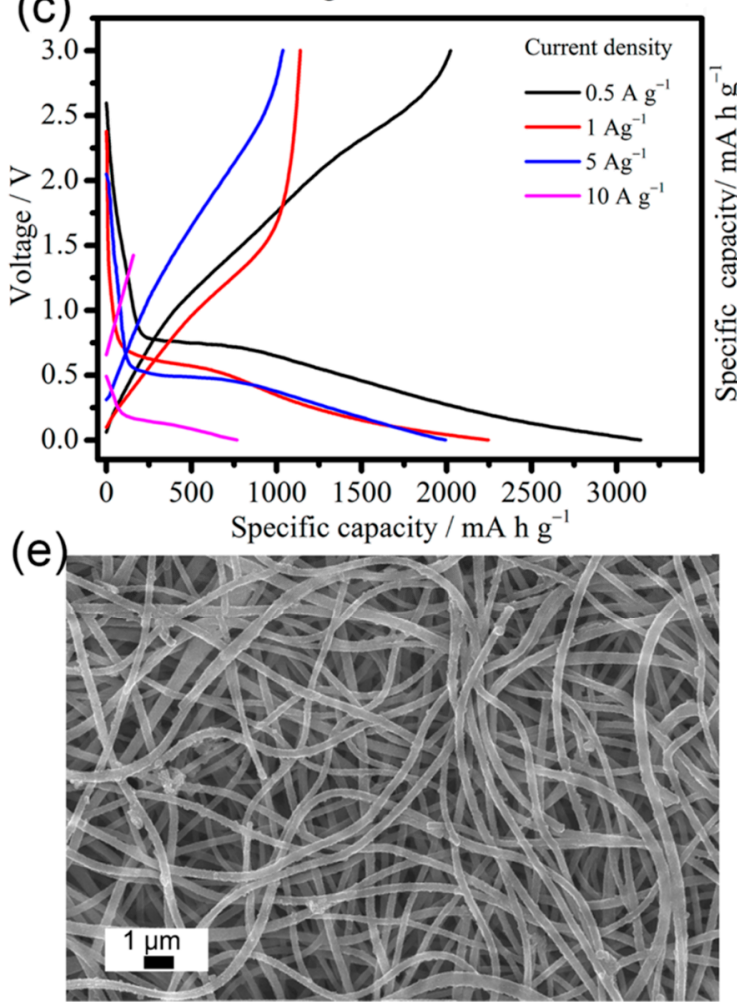

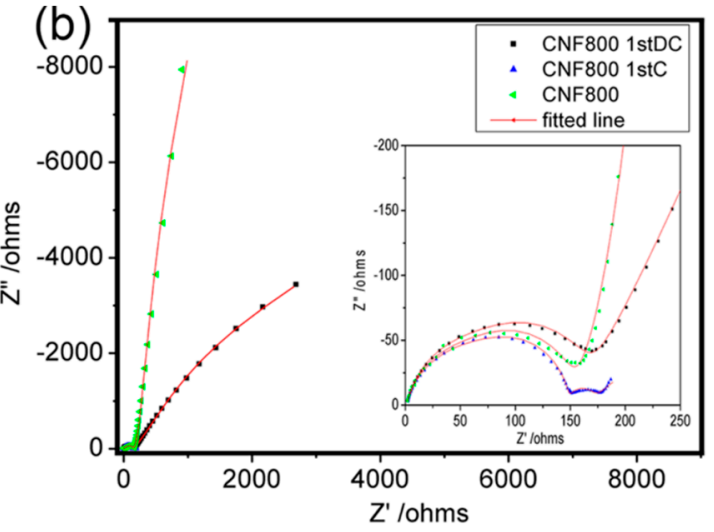
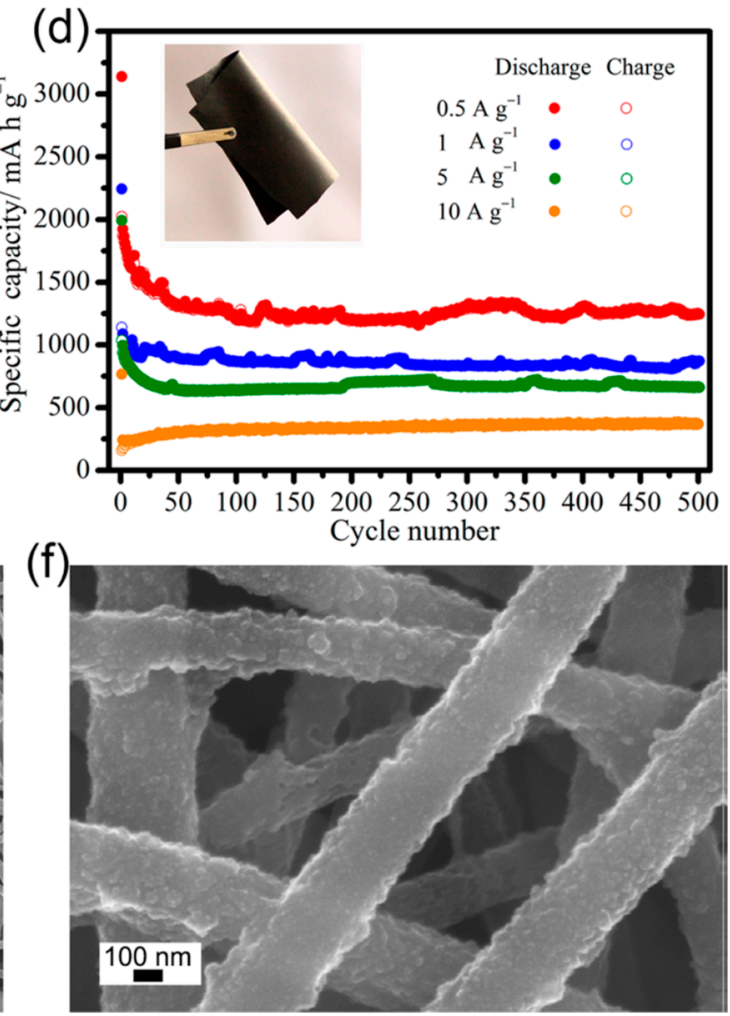

Figure 6. Cyclic voltammetry (CV) profiles (a) scan rate of $0.1 \mathrm{mV} \mathrm{s}^{-1}$ and EIS profiles (b) CNF800anode material in pure state (CNF800), the first discharging (CNF800 1stDC) and first charging state (1stC). The initial charge/discharge curves (c) and the cyclic performance (d) of CNF800 at many current densities (the inset is a digital photo of CNF800 film). The SEM images of CNF800 as anode film at the 500th discharge state (e,f) [129].

\subsection{Carbon Xerogel as Anode Materials for Li-Ion Batteries}

Carbon xerogel (CX) is a unique carbon based-material with a continuous nanoporous structure with low-density. The electrochemical measurements of $\mathrm{CX}$ and $\mathrm{CX}-\mathrm{SiO}$ were correlated by Yuan et al. [130]. CX-SiO consists of active C, graphite, $\mathrm{SiO}$, and dispersed $\mathrm{Si}$ crystals, while the CX is made up of only active $\mathrm{C}$ and graphite. $\mathrm{CX}-\mathrm{SiO}$ consists of uniformly dispersed particles in comparison with $\mathrm{CX}$ xerogel. The $\mathrm{SiO}$ in $\mathrm{CX}-\mathrm{SiO}$ xerogel can significantly raise the discharge capacity of the $\mathrm{CX}$ xerogel. The charge-discharge capacity of $\mathrm{CX}-\mathrm{SiO}$ comes primarily from the $\mathrm{Li}$ insertion-extraction in $\mathrm{Si}-\mathrm{SiO}$ in the sample. Figure 7 exhibits the typical FESEM image, charge-discharge profiles, and cyclic voltammograms of $\mathrm{CX}$ and $\mathrm{CX}-\mathrm{SiO}$ measured in the voltage range of $0-1.5 \mathrm{~V}$. Studies have confirmed that the prepared $\mathrm{CX}-\mathrm{SiO}$ composites present themselves as promising anode materials for high capacity rechargeable Li-ion batteries [130]. 

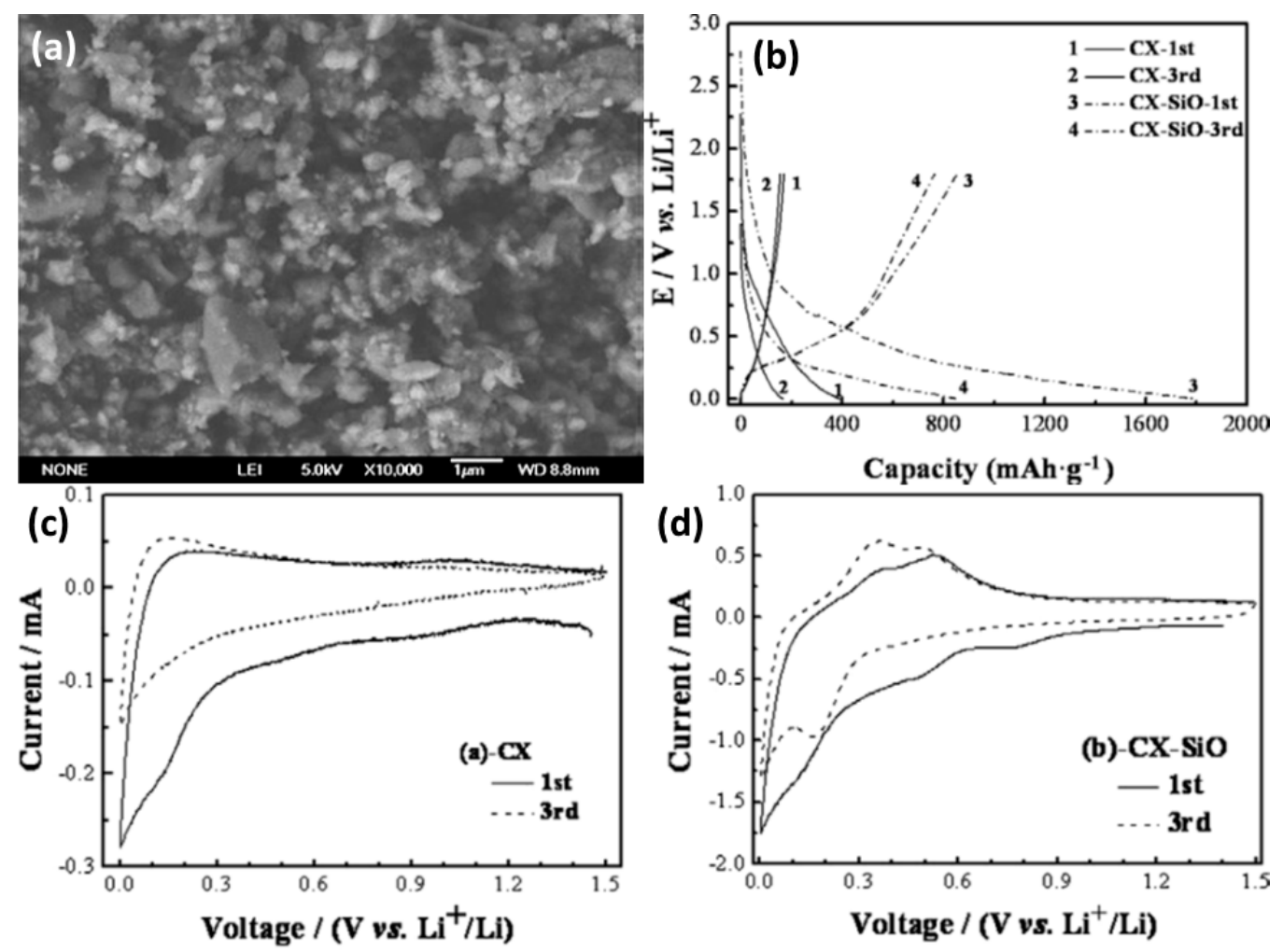

Figure 7. FESEM image of $\mathrm{CX}-\mathrm{SiO}$; (b) charge-discharge profiles, and (c,d) Cyclic voltammograms of $\mathrm{CX}$ and $\mathrm{CX}-\mathrm{SiO}$ measured in the voltage range of $0-1.5 \mathrm{~V}$ with a scan rate of $0.1 \mathrm{mV} \mathrm{s}^{-1}$ [130].

\subsection{Carbon Nanosprings as Anode Materials for Li-Ion Batteries}

A novel carbon nanospring (CNS) benefiting from the nanometer-sized carbon ring radius (ca. $50 \mathrm{~nm}$ ) was synthesized by Wu et al. [131]. The unusual spring-like morphology of CNSs with pitch distances of about $150 \mathrm{~nm}$ is a self-accommodating structure with excellent elasticity, which can effectively accommodate the strain of volume variation during $\mathrm{Li}$ insertion-extraction and, therefore, lead to excellent cycling performance. The CNSs show extraordinary potential as superior anode materials for rechargeable LIBs with both high rate capacity and long cycle life. At a present density as high as $3 \mathrm{Ag}^{-1}, \mathrm{CNSs}$ can give a reversible capacity of $160 \mathrm{mAh} \mathrm{g}^{-1}$, which is around six times bigger than that of graphite and three times bigger than that of multiwalled carbon nanotubes under a similar current density. After several cycles, there is no substantial capacity loss for CNSs at both low and high current densities. The enhanced electrochemical properties could be associated with the nanometer-sized building blocks and the unusual spring-like morphology (Figure 8).

In another approach, Shao et al. demonstrated the synthesis of a hematite@carbon nanospring $\left(\alpha-\mathrm{Fe}_{2} \mathrm{O}_{3} @ \mathrm{CNSs}\right)$ nanocomposite through precipitation followed by a heat treatment process [132]. The synthesized nanocomposites were examined by several techniques to investigate their various properties and were finally utilized as an electrode material to fabricate $\mathrm{Li}$-ion batteries. The authors observed that with increasing the amount of $\alpha-\mathrm{Fe}_{2} \mathrm{O}_{3}$ in the nanocomposite, the specific capacity of the fabricated device was increased, although the cyclic stability and rate capability of the device were degraded. The authors concluded that due to the strong network of CNSs and dispersed $\alpha-\mathrm{Fe}_{2} \mathrm{O}_{3}$ particles, the cycling performance, specific capacity, and rate capability of the fabricated device based on $\alpha-\mathrm{Fe}_{2} \mathrm{O}_{3} @ \mathrm{CNSs}$ were superior [132]. 

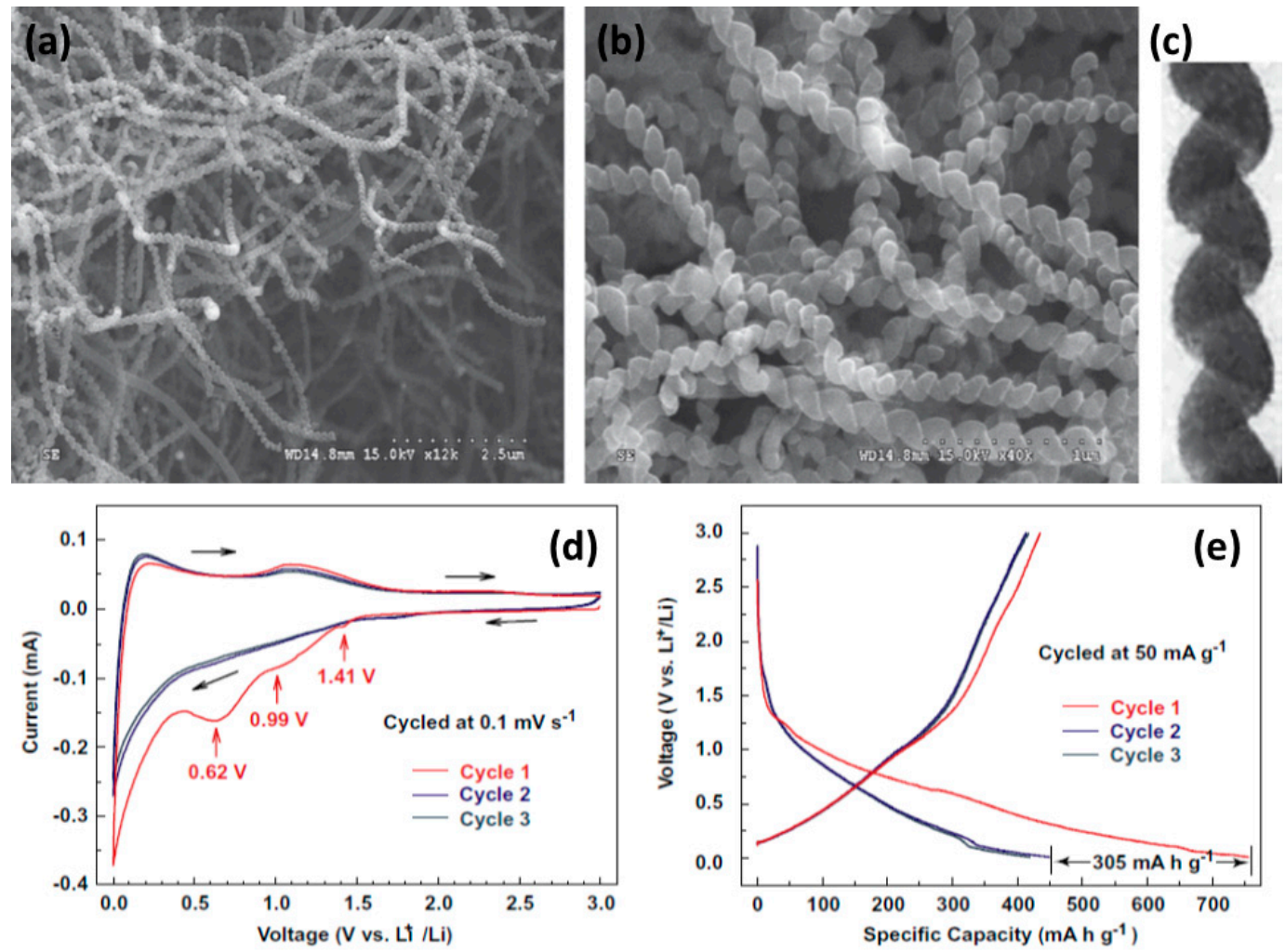

Figure 8. Typical (a,b) SEM and (c) TEM images of carbon nanosprings; (d,e) Charge-discharge curves of the fabricated device [131].

\subsection{Graphene-Based Nanocomposite Anodes for Li-Ion Batteries}

For the application of power source in the case of conveyable electronic device, high-capacity lithium ion batteries (LIBs) are being used. In the case of graphite, storage capacity as low as $372 \mathrm{mAh} \mathrm{g}^{-1}$ and reduced performance prevents them from being used as marketable anodes. Hence, researchers have continuously highlighted the preparation of innovative carbon-based anodic materials with advanced performance and storage capacity. Quite a few innovative carbon-based anodic materials, such as carbon-based nanotubes and graphene-based composite materials, have been introduced with high storage capacity, even beyond $1000 \mathrm{mAh} \mathrm{g}^{-1}$, with high performance [133-138]. Nevertheless, owing to their intrinsically larger surface area and despite suffering from lowered coulombic efficacy, they can attain a capacity exceeding $2 \mathrm{~V}$, which is not satisfactory for use in LIBs. The reason behind the elevated storage capacity in these carbon-based materials is not clearly understood, even though it has been proposed to be due to larger interlayer design, reduced diameter, and increased surface area, etc. $[139,140]$. Because the density of carbon-based materials is low they have poor storage capacity.

Incorporation of dopants is one method for controlling the physical and chemical characteristics of a material. With the swift evolution of elastic and wearable electronic devices, the need for stretchable anodes is increasing. Aerogels made of graphene [141-143], carbon nanotube foam/paper [144,145], and fiber cloth made of carbon $[146,147]$ were used as self-supported LIB electrodes. These flexible anodes still suffer from low flexibility. Therefore, this remains a challenge.

Establishing modern techniques for obtaining renewable energy by synthetic paths has been recognized as a new research area [148-153]. The proposal of transition metal oxides for energy storage [154-156] has been given a lot of attention. Superimposing transition metal oxides on carbonaceous materials, such as reduced graphene oxide (rGO), opens challenges of creating an efficient electrode possessing optimal material characteristics [157,158]. Superimposing $\mathrm{CeO}_{2}$ with carbonaceous material results in uniquely enhanced characteristics. Thus, the predicted new hybrid materials possess both the characteristics of the carbonaceous material (high power density and long 
cycle life) and the transition metal (large energy density) $[159,160]$. Doping of materials is therefore projected to yield hybrid electrode materials with enhanced power density, energy density, stable cycling, and cycle life.

Graphene nanoflakes are a good resource for advanced Li-ion batteries. A battery was tested in a semi cell using a graphene electrode doped with $\mathrm{Cu}$. The initial discharge voltage profile achieved a current rate of $700 \mathrm{~mA} \mathrm{~g}^{-1}$ (Figure 9a) [74]. The lithium ions on the graphene flakes form a passive film or solid electrolyte interphase (SEI) on the surface of the carbon [161]. Irreversible side reactions occur in lithium-based cells and are related to the electrode [161]. Figure 9b shows the resulting load-discharge cycle with fading initial capacity which then evens out at approximately $750 \mathrm{mAh} \mathrm{g}^{-1}$ [74].
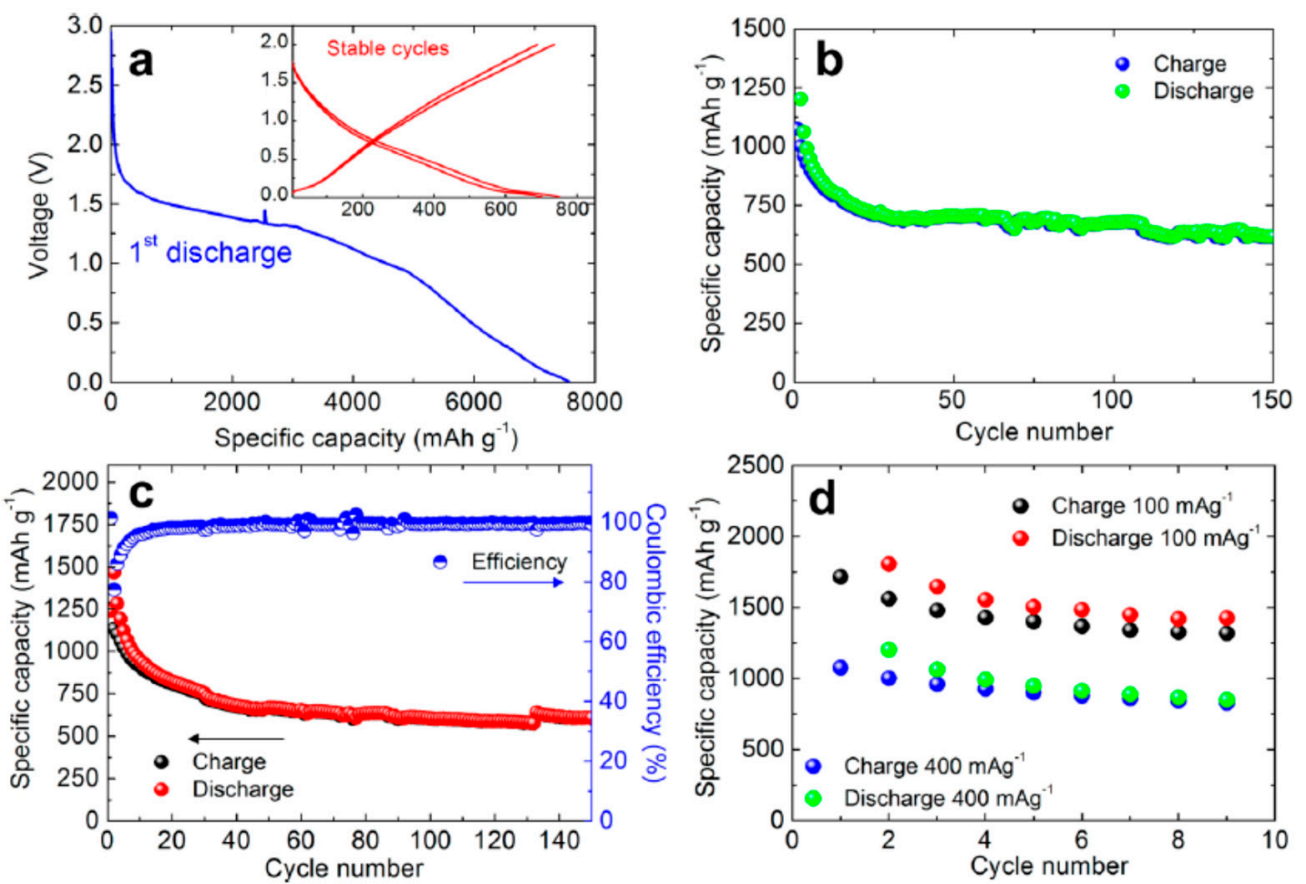

Figure 9. The electrochemical properties of a Cu-backed graphene electrode of a lithium cell. (a) Profile of initial discharge (inset: 50th cycle reversible steady-state profile) and (b) cycling response of the Li cell for; $700 \mathrm{mAg}^{-1}, 0.01-2 \mathrm{~V}$ voltage limit. (c) Coulombic productivity (blue dots) at $700 \mathrm{mAg}^{-1}$, voltage limits $0.01-2$ against long cycling (red dots) after ex situ lithiation (d) Specific capacity versus cycle number at rates of 100 and $400 \mathrm{mAg}^{-1}$ (Hassoun, et al. 2014 [74]).

For practical applications, a large initial irreversible capacity is undesirable, and this issue is addressed by an ex situ lithiation process carried out by direct contact with the Cu-supported graphene nanoflake electrode with a lithium metal foil, which is wet by the electrolyte. Initial irreversible capacity is of supreme importance to ensure the symmetry between the anode and cathode. Figure 9c illustrates the cycling report for $\mathrm{a} \sim 700 \mathrm{~mA} \mathrm{~g}^{-1}$ current discharge rate for the preheated electrode material. The irreversible capacity virtually disappears for the first cycle of Coulombic productivity, while a small decline is observed over a few subsequent cycles (almost ten), most likely connected with the residual SEI film creation process. In fact, at 150 load-discharge cycles, a steady revocable specific capacity of $\sim 650 \mathrm{mAh} \mathrm{g}^{-1}$ was detected. Figure $9 \mathrm{~d}$ confirms that the $\mathrm{Cu}$-supported graphene nanoflake electrode has a respectable rate capacity; i.e., 100 and $400 \mathrm{~mA} \mathrm{~g}^{-1}$, respectively. Figure $9 \mathrm{~d}$ likewise illustrates that the $\mathrm{Cu}$-decorated graphene nanoflake electrode has good rate capacity, as tested with two load-discharge rates. When cycled at a lowered rate $\left(100 \mathrm{mAg}^{-1}\right)$, the electrode has the capacity to dispense a very large alterable capacity exceeding $1500 \mathrm{mAh} \mathrm{g}^{-1}$, double the theoretical capacity of graphene [162]. These values are greater than those obtained with other C-based nanostructures, such as GNRs [163], delivering a reversible capacity of $~ 8825 \mathrm{mAh} \mathrm{g}^{-1}$ [163] with a density of $100 \mathrm{mAg}^{-1}$. 
Graphene in the framework performs an influential role in enhancing the anode's conductivity in diverse phases of the charge-discharge procedure. It also helps to generate a steady (SEI) plate shape that diminishes electrolyte decomposition and facilitates stable cycling performance. Figure 10a reveals the charge-discharge performance of $\mathrm{Mn}_{2} \mathrm{SnO}_{4} @ \mathrm{GS}$ for the initial 100 cycles. After the initial discharge, structural fluctuations occur which gradually become stable after a few cycles [164]. Figure $10 \mathrm{~b}$ shows the performance of long-term cycling and discharge at a current rate of $400 \mathrm{mAg}^{-1}$. Extraordinarily, $\mathrm{Mn}_{2} \mathrm{SnO}_{4} @ \mathrm{GS}$ showed a reversible capacity of $1069 \mathrm{mAh} \mathrm{g}^{-1}$ and $1041 \mathrm{mAh} \mathrm{g}^{-1}$ at a current density of $501 \mathrm{mAg}^{-1}$ at 200 and 500 cycles, correspondingly, which is larger than for $\mathrm{SnO}_{2}$ and $\mathrm{SnO}_{2} @ G S$. The electrochemical impedance spectroscopy (EIS) results supplies supplementary data regarding the conversion of charges during the electrochemical reaction intended for the anode in LIBs. The ideal Nyquist plot of $\mathrm{SnO}_{2}, \mathrm{SnO}_{2} @ G S$, and $\mathrm{Mn}_{2} \mathrm{SnO}_{4} @ G S$ electrodes are presented in Figure 10c. $\mathrm{Mn}_{2} \mathrm{SnO}_{4} @ \mathrm{GS}$ displayed a reduced semicircle at high frequency, corresponding to Rct $(\sim 60 \Omega)$ compared to $\mathrm{SnO}_{2} @ G S\left(\right.$ Rct $\sim 120 \Omega$ ) and $\mathrm{SnO}_{2}$ (Rct $\sim 250 \Omega$ ). This indicates upgraded dynamic transference for virtuous electrical interaction and electrode responses in the $\mathrm{Mn}_{2} \mathrm{SnO}_{4} @ G S$ anode. The sloped curve (Warburg impedance) is referred to as the ion diffusion which occurs at the lower frequency zone. The lower capacity could be responsible for greater Rct of $\mathrm{SnO}_{2}$ and $\mathrm{SnO}_{2} @ G S$. In Figure 10d, the working process of the battery through the charging and discharging of the ternary anode $\mathrm{Mn}_{2} \mathrm{SnO}_{4} @ G S$ might be due to the collaborative outcome. The $\mathrm{Mn}_{2} \mathrm{SnO}_{4} @ G S$ and the graphene substrate deliver a larger anode and electrolyte assemblage that constrains particle accumulation, signifying a larger tunable capacity. These ternary terminal substantials are anticipated to limit the distribution of $\mathrm{Li}^{+}$ions and the electrons $\left(\mathrm{e}^{-}\right)$between the $\mathrm{Mn}_{2} \mathrm{SnO}_{4} @ \mathrm{GS}$ and the collector current grounded on high electronic conductivity graphene sheets. The bouquet-like structure $\left(\mathrm{Mn}_{2} \mathrm{SnO}_{4} @ \mathrm{GS}\right)$ helps the electrolytes to be easily admitted and very quickly diffused, enabling superior and stable performance throughout the process [164].

One category of Li-ion capacitive storage deals with rapid Faradic external redox reaction to propose larger power for electrochemical submissions. Nevertheless, it is quite often restricted due to the condensed amount of energy involvement during the process of charge-discharge, thereby reducing the overall capacity of Li-ion loading in the electrodes $[165,166]$. Figure 11a shows the rate routine of $\mathrm{FeOOH} / \mathrm{rGO}$ composites and bare $\mathrm{FeOOH}$ with several current densities lying between 0.2 and $8 \mathrm{~A} / \mathrm{g}$ [167]. FeOOH/rGO composites display larger and steady measurements at diverse current densities with lesser capacity $(1156,1093,1015,872,786$, and $535 \mathrm{mAh} / \mathrm{g})$ for an increased current density $(0.2,0.5,1,2,5$, and $8 \mathrm{~A} / \mathrm{g})$ respectively [167]. It should be noted that the $\mathrm{FeOOH} / \mathrm{rGO}$ electrode upholds 61.1 percent of the initial reversible capacity at $0.2 \mathrm{~A} / \mathrm{g}$, even at a high current density of $5 \mathrm{~A} / \mathrm{g}$. In $\mathrm{FeOOH} / \mathrm{rGO}$ composites from 1263 to $1443 \mathrm{mAh} / \mathrm{g}$, increasing reversible capacity is tested when the current rate returned to $0.2 \mathrm{~A} / \mathrm{g}$ for 100 cycles. This performance at the initial reversible capacity reaches $112.2 \%$ retention of the primary reversible capacity. The observed capacitance of $547 \mathrm{mAh} / \mathrm{g}$ and $546 \mathrm{mAh} / \mathrm{g}$ was not appreciable and was weakened for current densities of 0.2 and $5 \mathrm{~A} / \mathrm{g}$, in the case of the bare FeOOH electrode. The capacitance was increased in a FeOOH-based system when rGO was added to the bare FeOOH electrode. Thus, the composite FeOOH maintained a firmer capacitance throughout the load-leaching process and upheld a faster load transfer rate with colossal energy storage under high current densities (Figure 11b). The outcome shows that after 200 cycles, $\mathrm{FeOOH} / \mathrm{rGO}$ maintained discharge of $1135 \mathrm{mAh} / \mathrm{g}$ - $97 \%$ of the primary capacity. This performance is obviously superior to that of the bare $\mathrm{FeOOH}$ electrode $(317 \mathrm{mAh} / \mathrm{g}$ after 100 cycles, retaining $40.2 \%$ of the initial reversible capacity). Encouraged by this outstanding performance, a larger current density $(5 \mathrm{~A} / \mathrm{g})$ of the $\mathrm{FeOOH} / \mathrm{rGO}$ electrode was additionally tested. It was still able to deliver nearly $83.9 \%$ of the reversible capacity of $783 \mathrm{mAh} / \mathrm{g}$. The coulombic effectiveness was maintained at $98.4 \%$ even after 200 cycles, although the $\mathrm{FeOOH} / \mathrm{rGO}$ composite showed reduced cycling capacity beyond 20 cycles. These outcomes confirm the good cycling performance of the $\mathrm{FeOOH} / \mathrm{rGO}$ electrode during the process of ultrafast load-discharge. Figure 11c,d illustrate the $\mathrm{FeOOH}$ and $\mathrm{FeOOH} / \mathrm{rGO}$ discharge profiles for various load-discharge rates. An inclined region $(1.0 \sim 0 \mathrm{~V})$ and a plateau region $(\sim 1.0 \mathrm{~V})$ are detected in 
these contours, corresponding to the Li-ion surface interface reaction and the $\mathrm{Fe}(0)$ conversion reaction, respectively [165]. These contours were compared and examined for various reaction times with the composite material, such as $\mathrm{FeOOH}$ and $\mathrm{FeOOH} / \mathrm{rGO}$ electrodes, and correlated with their capacity performance. The contour for the $\mathrm{FeOOH}$ and $\mathrm{FeOOH} / \mathrm{rGO}$ composite was found in the sloping and plateau region; the performance forcefully ceases for 0.2 to $5 \mathrm{~A} / \mathrm{g}$ charge-discharge rate as illustrated in Figure 11. Further, the decay indicates that the bare $\mathrm{FeOOH}$ electrode fails to maintain both the interfacial and the Li-ion conversion reaction. In addition, mostly the sloping zones in the $\mathrm{FeOOH} / \mathrm{rGO}$ electrode (Figure 11d) are almost the same for various load-discharge rates with equivalent capacities exceeding $400 \mathrm{mAh} / \mathrm{g}$, signifying their almost unchanged Li-ion storage performance at different reaction rates [166]. Further, the above profiles in Figure 11c,d estimate the gap amongst the charging and discharge process for an individual electrode in the plateau voltages. Thus, changing the gap for various current densities gives a suggestion of the range of polarization in $\mathrm{FeOOH}$ and $\mathrm{FeOOH} / \mathrm{rGO}$ electrodes. As shown in Figure 11e, the FeOOH electrode material apparently expands the potential with the increasing the current rate from 0.2 to $5 \mathrm{~A} / \mathrm{g}$. The composite $\mathrm{FeOOH} / \mathrm{rGO}$ electrode material presents an almost unaffected potential, representing an enhanced electrochemical process at different current densities without noticeable polarization in this electrode. Thus, in general, the overall results demonstrate that the $\mathrm{FeOOH} / \mathrm{rGO}$ electrode conceivably will not able to deliver enhanced interfacial Li-ion storage on the exterior of $\mathrm{FeOOH}$ rods, but at the same time, maintains an ultrafast load transfer rate to promote their performance for various current densities. Furthermore, this performance is cost-effective compared to other FeOOH-based electrode materials. Thus, $\mathrm{FeOOH} / \mathrm{rGO}$ electrodes show great potential as anodes in LIBs [167].
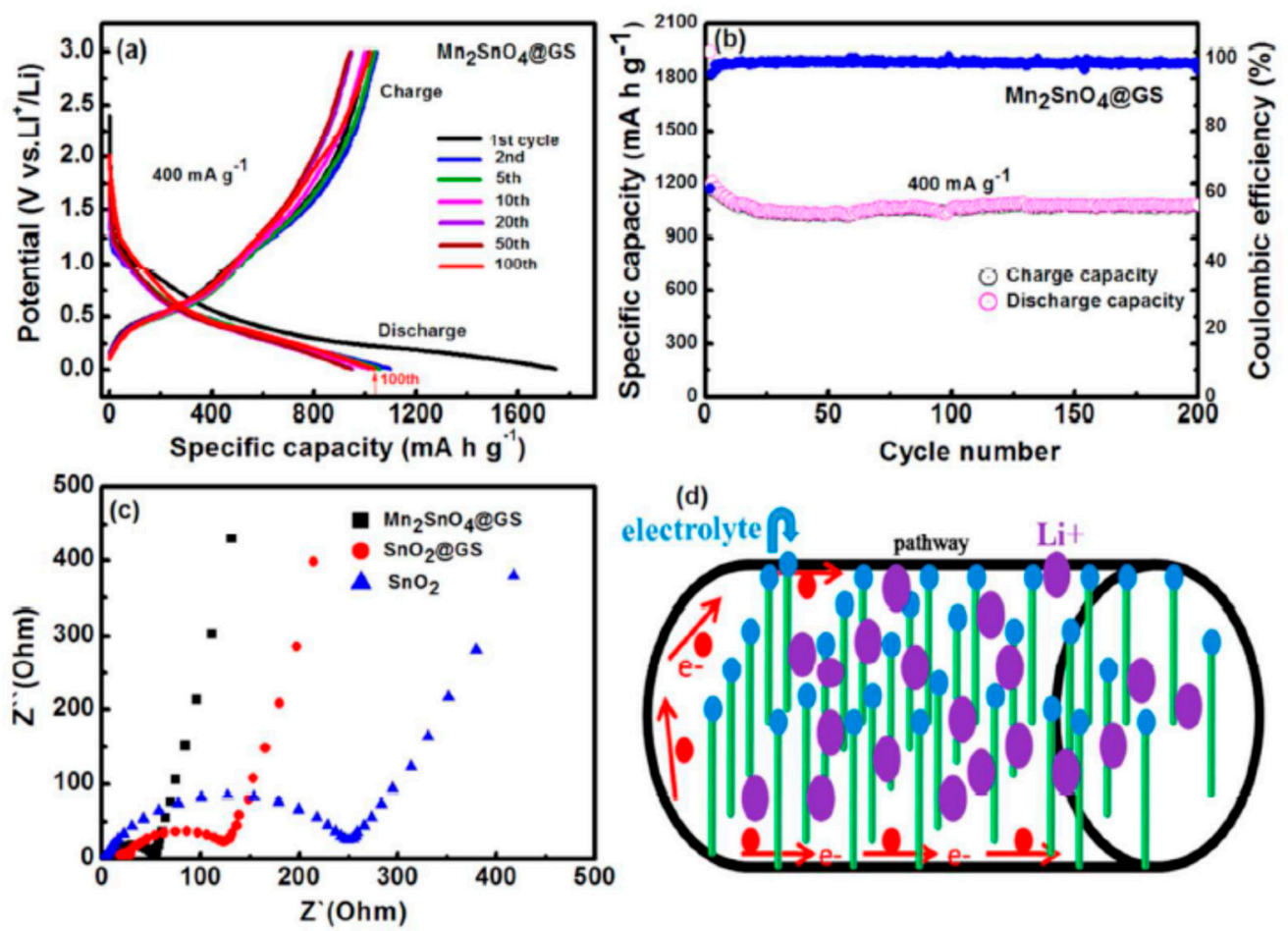

(d)

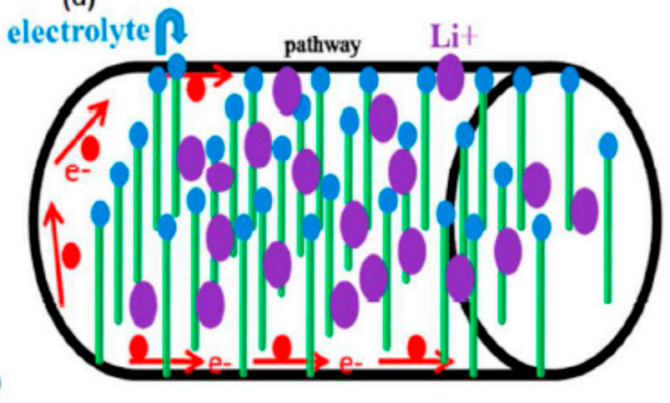

Figure 10. Li loading assets of $\mathrm{Mn}_{2} \mathrm{SnO}_{4} @ \mathrm{GS}$ composite; (a) first 100 cycles of expulsion profiles; (b) cyclic behavior of $\mathrm{Mn}_{2} \mathrm{SnO}_{4} @ G S$ at current density $400 \mathrm{mAg}^{-1}$ (c) Nyquist tin oxide EIS plots, $\mathrm{SnO}_{2} @ \mathrm{GS}$ and $\mathrm{Mn}_{2} \mathrm{SnO}_{4} @ \mathrm{GS}$, (d) representative diagram of $\mathrm{Li}^{+}$interaction with $\mathrm{e}^{-}$(Rehman et al. 2018 [164]). 
a

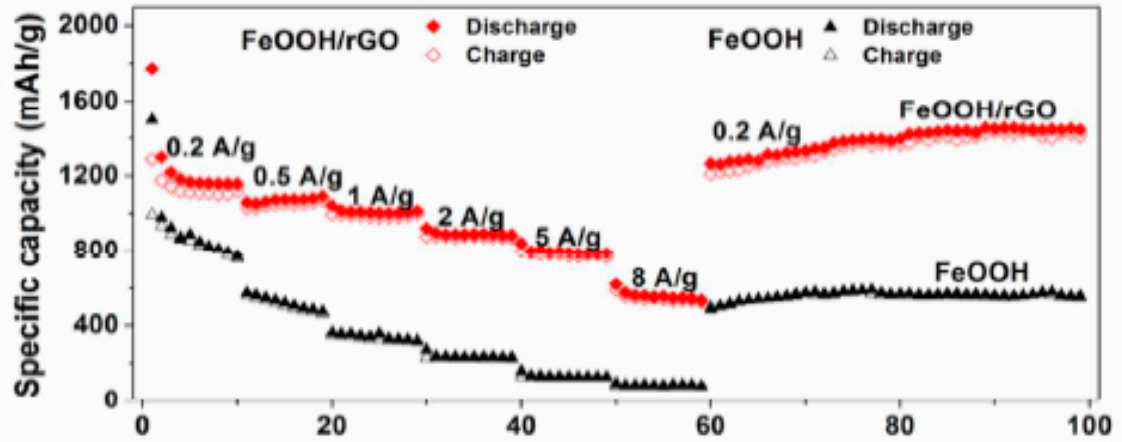

b

Cycle number
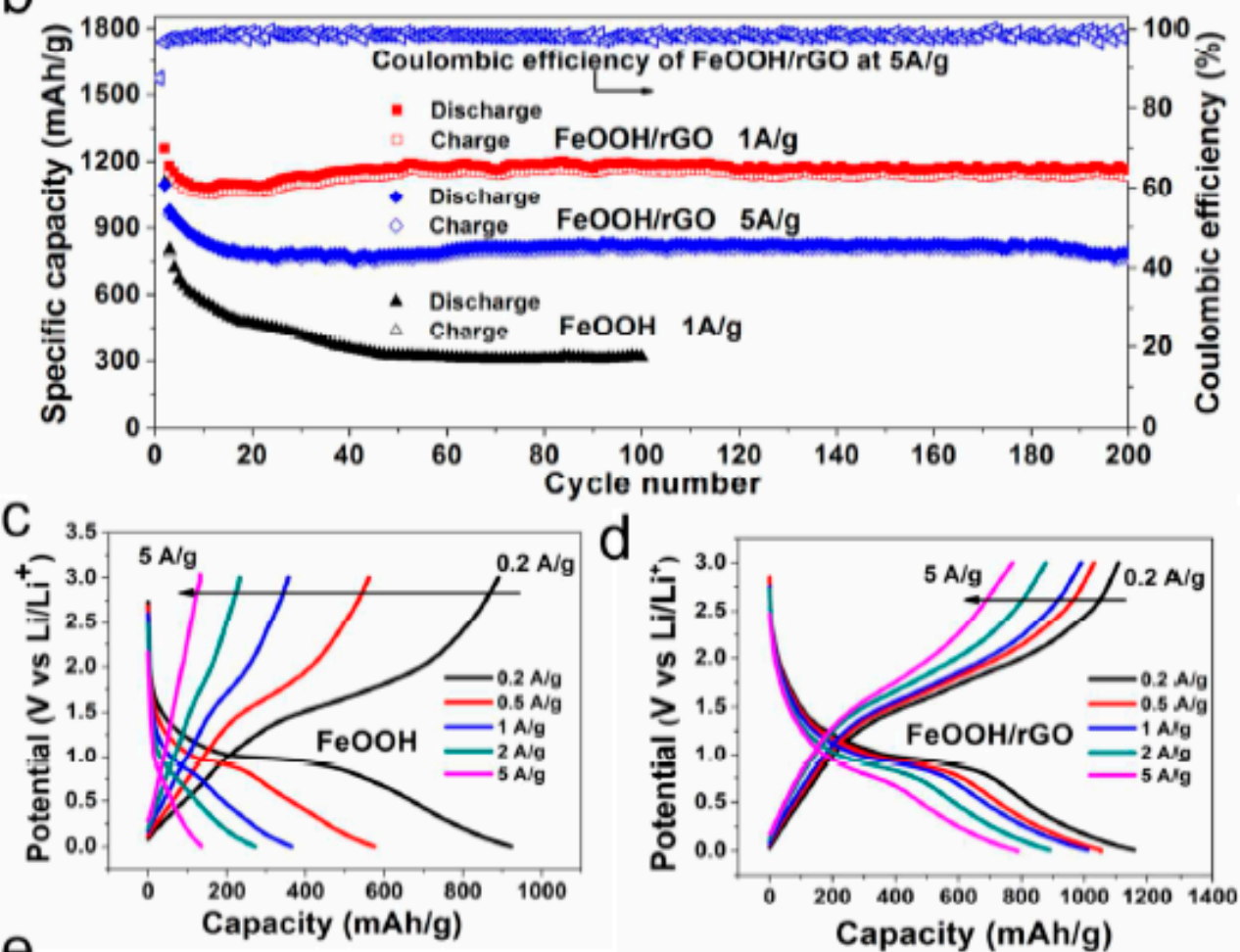

e

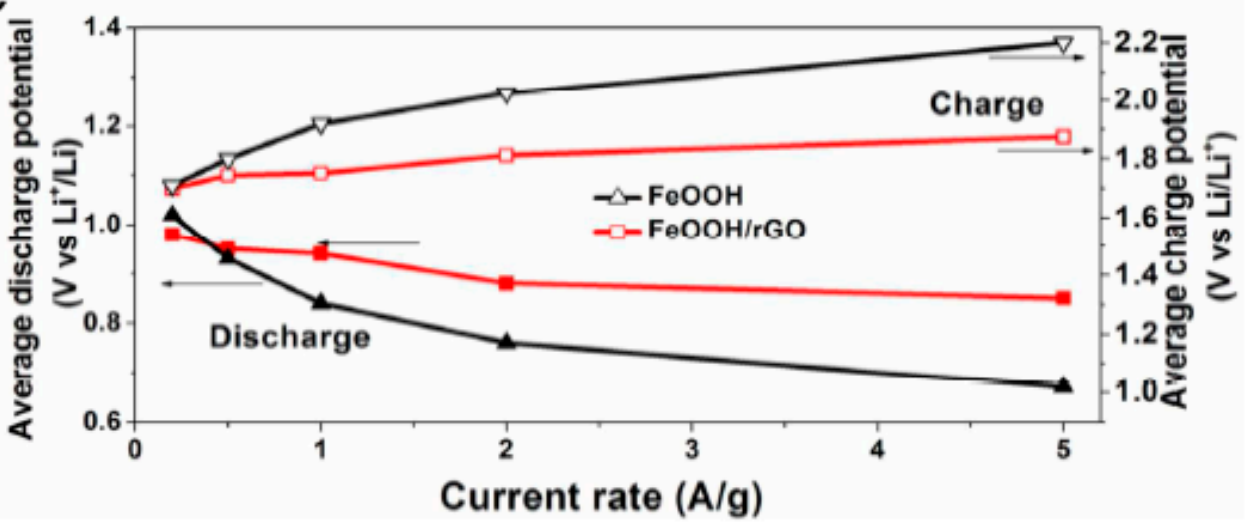

Figure 11. (a) Charge rates of unembellished $\mathrm{FeOOH}$ and $\mathrm{FeOOH} / \mathrm{rGO}$ composites for diverse rates $(0.2 \mathrm{~A} / \mathrm{g}$ to $8 \mathrm{~A} / \mathrm{g})$, (b) Cycling behavior of unembellished $\mathrm{FeOOH}$ and $\mathrm{FeOOH} / \mathrm{rGO}$ composites (first cycled at $0.2 \mathrm{~A} / \mathrm{g}$ in first cycle), load-discharge curves of (c) bare $\mathrm{FeOOH}$ and (d) $\mathrm{FeOOH} / \mathrm{rGO}$ composites at diverse rates, (e) Typical release and load potential of bare $\mathrm{FeOOH}$ and $\mathrm{FeOOH} / \mathrm{rGO}$ composites at diverse rates. (Hui et al. 2016 [167]). 
Graphene oxide (GO) reinforced by germanium oxide and lithium displays better processability. It was found that the charge capacity is a function of processing temperature: For temperatures up to $650^{\circ} \mathrm{C}$ (Figure 12), an elevated charge capacity was detected. In the case of GO-Ge composite, the larger crystalline germanium grains attached over the electrode improved their performance when treated at $900{ }^{\circ} \mathrm{C}$ [168]. This can be quantified due to modified upgraded electrical conductivity observed at a higher temperature in the case of graphene-based composite materials. The GO-Ge-650 electrode material's cycle achievement is good, with $250 \mathrm{mAg}^{-1}$ storage capacity even after 50 cycles (Figure 12a). Thus, the GO-Ge-650 electrode active material's rate performance is good, with a $2000 \mathrm{mAg}^{-1}$ current rate for about $740 \mathrm{mAh} \mathrm{g}^{-1}$ capacity (Figure 12b). This corresponds to a 20-min charge-discharge period. The close contact among the graphene and the germanium moieties affords the material increased capacity at a higher current rate. In Figure 12d, Nyquist plots of GO-Ge-80, GO-Ge-650, and GO-Ge-900 EIS studies are displayed. For all three electrodes, the Nyquist plots showed skewed semicircles opening with the electrolyte solution resistance (standardized to 20), but it is interrupted by almost linear curves before the semicircle is complete. The semicircle in the Nyquist plots can be attributed to the lithium ion migration through the electrolytic surface interface and the charge transfer resistance, which occurs at an intermediate frequency in this case. The slope of the line $\left(>45^{\circ}\right)$ shows an amalgamation of electrolyte diffusion (Warburg impedance) and lesser fluctuations in the Li film because of lithiation at lower frequencies. In the case of GO-Ge-650 anodes, the higher load bearing capability corresponded to the smallest Li-ion propagation.
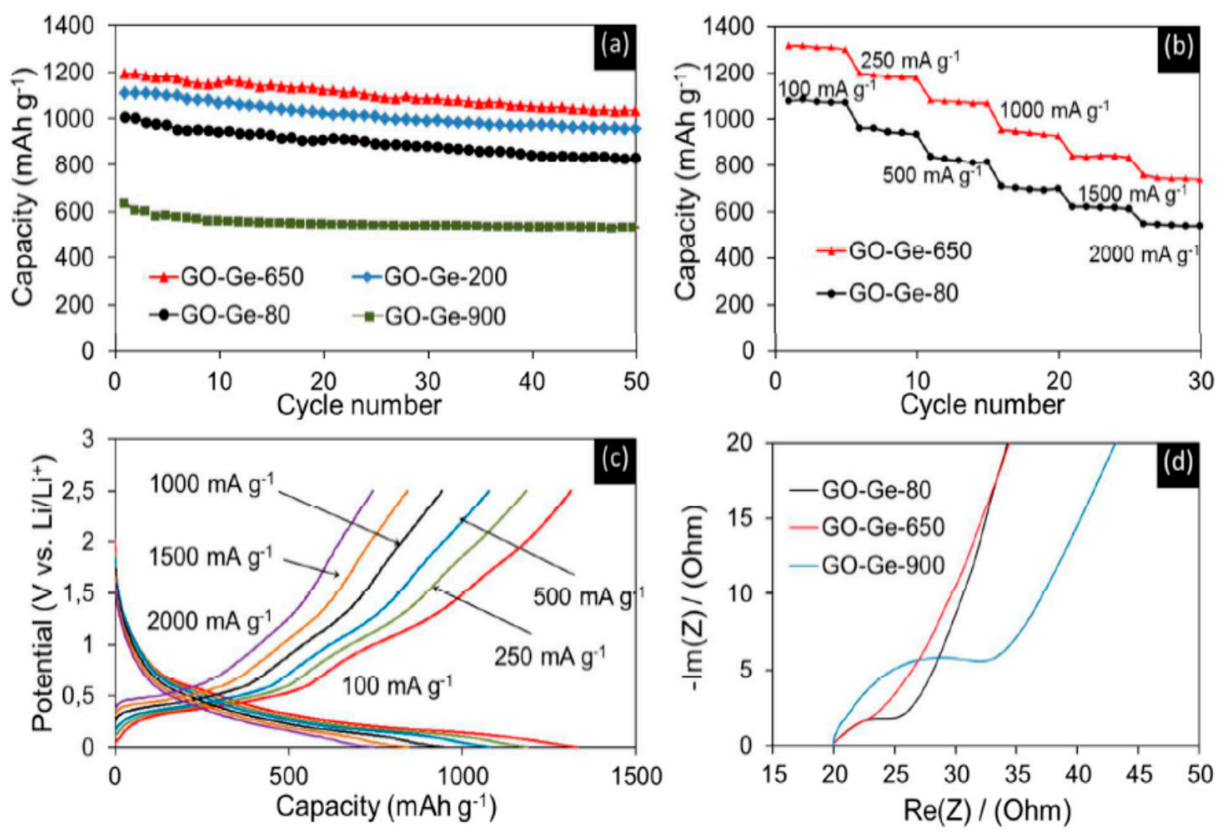

Figure 12. Evaluation of electrode behavior: (a) Charge capacities of GO-Ge-80, GO-Ge-200 GO-Ge-650, and GO-Ge-900 upon repeated cycling. The cycles were steered at a rate of $250 \mathrm{mAg}^{-1}$ among $0 \mathrm{~V}$ and $2.5 \mathrm{~V}$ vs. $\mathrm{Li} / \mathrm{Li}^{+}$(excluding GO-Ge-900 steered at $100 \mathrm{~mA} / \mathrm{g}$ ). (b) Charge capacities of GO-Ge-80 and GO-Ge-650 at diverse rates. (c) The charging-discharging curves for GO-Ge-650 composite for various current rates. (d) Nyquist plots of GO-Ge-80, GO-Ge-650, and GO-Ge-900 (Alexander et al. 2017) [168].

Graphene is an attractive carbonaceous material consisting of carbon atoms arranged in a hexagonal structure, which has added advantageous properties for use as an anode, such as being an excellent conductor of electricity and heat, having the high specific surface area, high diffusivity, strong mechanical strength with flexibility, and outstanding chemical stability. The high surface area, greater electrical conductivity and high diffusivity of graphene allow increased ionic transport for intercalation and thus higher power [169-172]. The theoretical capacity of a graphene anode is higher 
than a graphite anode and is in the range of $744 \mathrm{mAh} \mathrm{g}^{-1}$ to $1448 \mathrm{mAh} \mathrm{g}^{-1}$ depending on the graphene morphology. Challenging problems observed in graphene anode in LIB are high operating voltage, high initial irreversible capacity, low loading, low coulombic efficiency, low performance at high current densities, and poor cycle life $[173,174]$. The development of LIBs with graphene anodes is promoted by using graphene in various forms, such as thin, flexible, transparent graphene sheets. To enhance the electrochemical properties of the graphene sheet, various approaches have been put forward to develop a low-cost scalable method for large-scale production. Exfoliated graphite/graphene nanosheets (EGNs) obtained by ultrasonication and ultracentrifugation of graphite-based solution exhibited a capacity of about $500 \mathrm{mAh} \mathrm{g}^{-1}$, which is higher than that observed in blank graphite (BG) (300 mAh g $\left.{ }^{-1}\right)$ [175]. In EGNs, the graphene could accommodate lithium in two sides of the carbon layer and the electrochemical reaction is $\mathrm{Li}+3 \mathrm{C} \leftrightarrow \mathrm{LiC}_{3}$, with a theoretical specific capacity of $744 \mathrm{mAh} \mathrm{g}^{-1}$, which is higher than the theoretical specific capacity of a graphite anode ( $\left.372 \mathrm{mAh} \mathrm{g}^{-1}\right)$. The EGNs show an additional Li-insertion slope, which extends from $0.25 \mathrm{~V}$ to $3.00 \mathrm{~V}$ that was absent in blank graphite (Figure 13a). The galvanostatic cycling performance confirms the additional $\mathrm{Li}^{+}$ uptake in the graphene phase of the carbon material that was evidenced in the region between $0.9 \mathrm{~V}$ and $2.5 \mathrm{~V}$ (Figure 13b), having similar stability. It was proposed that the Li intercalation in EGNs involves a hybrid mechanism within the graphene nanosheets. Figure 13c shows the long-term cycling properties of the graphene nanocomposite.

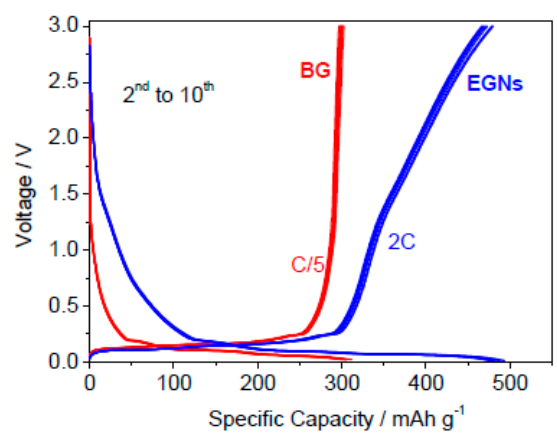

(a)

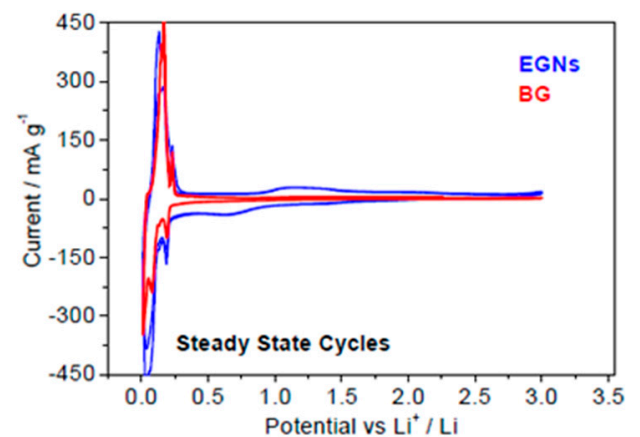

(b)

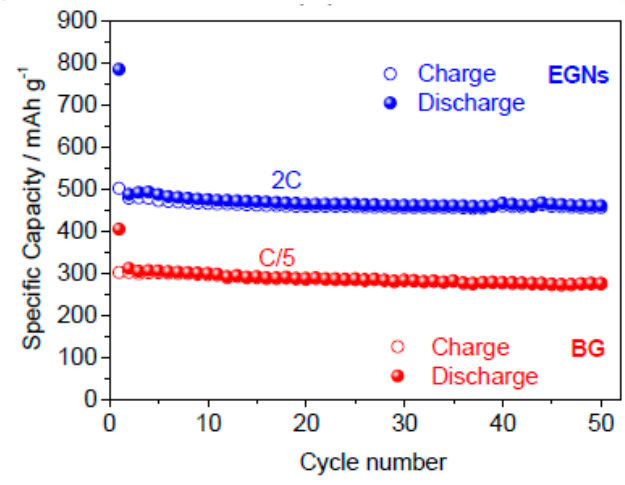

(c)

Figure 13. Galvanostatic voltage profiles from 2nd to 10th cycle (a), comparison of cyclic voltammetry at the steady state (b), and of the galvanostatic cycling performance (c) between the exfoliated graphite/graphene nanosheets (EGNs, blue line) and the blank graphite (BG, red line). Voltage range $0.01 \mathrm{~V}-3 \mathrm{~V}$. Galvanostatic current density in lithium half cell $474 \mu \mathrm{A} \mathrm{cm}{ }^{-2}$ (corresponding to $2 \mathrm{C}$ for the EGNS and $\mathrm{C} / 5$ for the $\mathrm{BG}$ ). The scan rate of the cyclic voltammetry in three electrodes lithium cell $0.05 \mathrm{mV} \mathrm{s}^{-1}$. Electrolyte LP30 (EC:DMC 1:1 v/v, LiPF6 1M) [175].

Some metals and metal oxides exhibit high theoretical gravimetric and volumetric capacities [176-178]. The drawback observed in these metals and metal oxides is low rate capability due to low electronic conductivity and poor cycling stability due to extreme volume expansion 
during cycling. These problems could be resolved by constructing hybrid materials with sandwiched architecture with highly conducting graphene and metal or metal oxide particles in layers to decrease the polarization effect and increase the electron/ion transfer kinetics [179-181]. The sandwich-like $\mathrm{Ni}_{2} \mathrm{P}$ nanoarray/nitrogen-doped graphene/ $\mathrm{Ni}_{2} \mathrm{P}$ nanoarray nanoarchitecture $\left(\mathrm{Ni}_{2} \mathrm{P} / \mathrm{NG} / \mathrm{Ni}_{2} \mathrm{P}\right)$ electrode constructed by involving solvation method followed by annealing and phosphorization treatment is shown in Figure 14 [182].

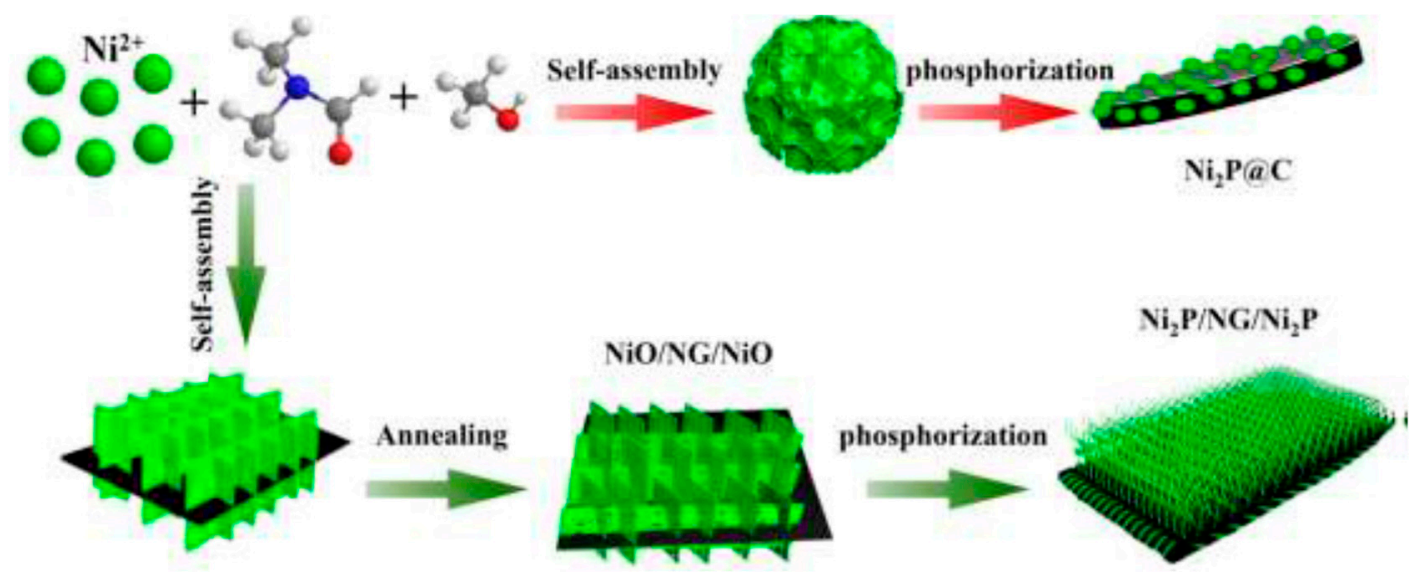

Figure 14. Schematic illustration of the synthesis of sandwich-like Ni2P/NG/Ni2P nanoarchitecture [182].

This $\mathrm{Ni}_{2} \mathrm{P} / \mathrm{NG} / \mathrm{Ni}_{2} \mathrm{P}$ anode exhibited a capacity of $417 \mathrm{mAh} \mathrm{g}^{-1}$ at a current density of $300 \mathrm{~mA} \mathrm{~g}^{-1}$ after 100 cycles. The volume expansion during discharging could be stabilized by the hybrid structure through the interaction between $\mathrm{Ni}_{2} \mathrm{P}$ and the graphene matrix incorporated with a nitrogen dopant that leads to higher cycling stability.

The anode metal with the highest theoretical capacity was recognized as silicon, but it exhibited large volume change during $\mathrm{Li}$ insertion and extraction, which causes sudden capacity fading. Wei et al. [183] constructed a hierarchical hollow structure, such as hierarchical copper silicate hydrate (CSH) hollow spheres encapsulated in reduced graphene oxide (RGO) (CSH/RGO composite) using silicates, copper precursor, and graphene, which can withstand the volume change during Li insertion and extraction, thereby improving the cycling performance. The CSH/RGO composite presented higher capacity, rate performance, and cycling stability than that of CSH and RGO. The author suggested that the synergistic effect of the hierarchical hollow structure and electrical conductivity of reduced graphene oxide provided excellent long-life electrochemical performance. The hierarchical hollow structure provides facile $\mathrm{Li}^{+}$diffusion with high-stress relaxation, effective electron transport, and excellent stability (Figure 15). These factors increased the capacity to a value of $890 \mathrm{mAh} / \mathrm{g}$ after 200 cycles at $200 \mathrm{~mA} / \mathrm{g}$ and a capacity of $429 \mathrm{mAh} / \mathrm{g}$ after 800 cycles at $1000 \mathrm{~mA} / \mathrm{g}$. However, there was still an irreversible capacity loss observed in the first cycle due to the formation of SEI film. Graphene/metal oxide composites with $\mathrm{Co}_{3} \mathrm{O}_{4}, \mathrm{MnO}_{2}, \mathrm{NiO}, \mathrm{Fe}_{3} \mathrm{O}_{4}$, and $\mathrm{TiO}_{2}$ showed high reversible capacity, good rate performance, and long cycle life [184-188]. In these graphene-based composites, graphene acts as a buffer to maintain the volume changes occurring in metal oxides [189]. 


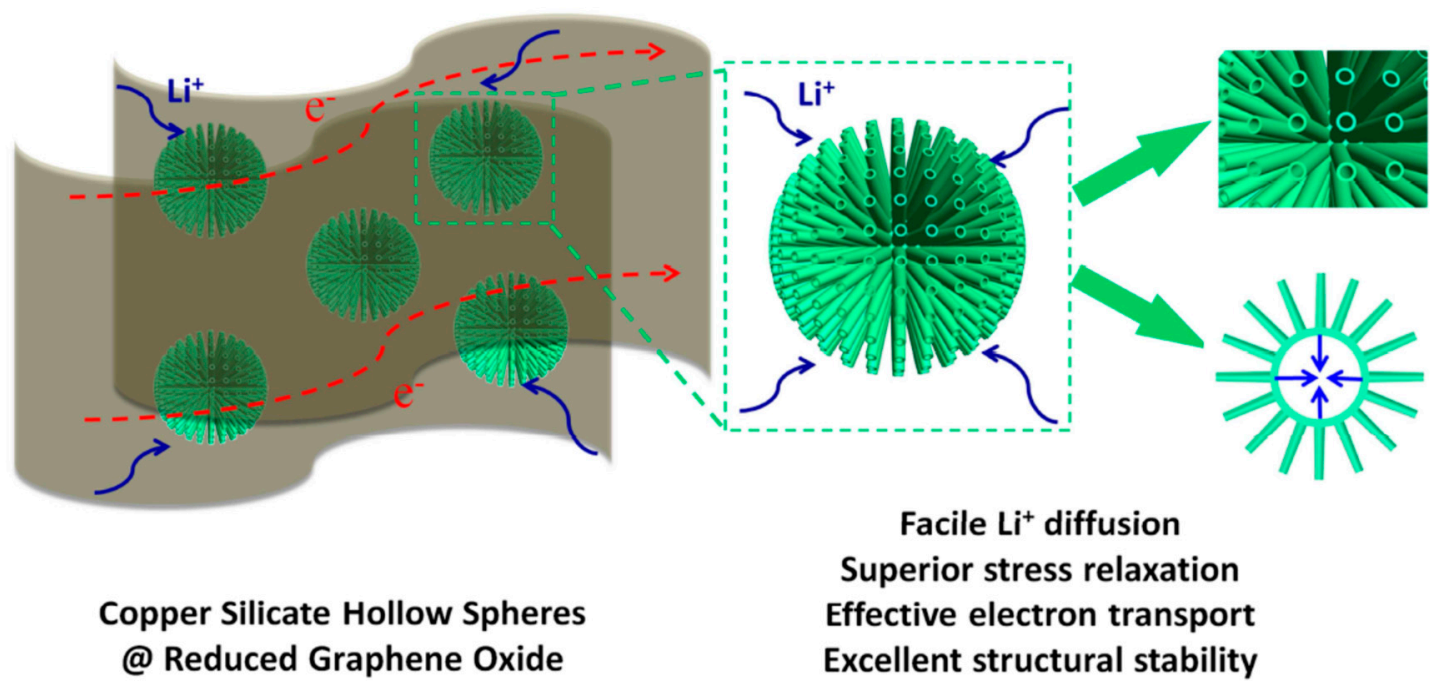

Figure 15. Schematic illustration of the copper silicate hydrate (CSH) hollow spheres encapsulated in reduced graphene oxide (RGO) (CSH/RGO) composite with facile $\mathrm{Li}^{+}$diffusion [183].

Another interesting anode material is a tin oxide-based nanostructure material having a high theoretical capacity of $780 \mathrm{mAh} \mathrm{g}^{-1}$. However, huge volume change leads to pulverization and drop in the conductivity and electrochemical reversibility. Several studies showed that the electrochemical performance of $\mathrm{SnO}_{2}$ could be improved by using $\mathrm{SnO}$ /graphene composites, in which the volume change in $\mathrm{SnO}_{2}$ could be controlled by self-restacking of graphene [190-192]. Xu et al. [193] improved the conductivity and stability of $\mathrm{SnO}_{2}$ by preparing a composite using fluorine and graphene. It is believed that fluorine can increase the conductivity and graphene can increase stability. The derived fluorine-doped tin oxide (FTO) nanocrystal and reduced graphene oxide (RGO) (FTO/RGO) composite exhibited much higher capacity than that of the individual $\mathrm{SnO}_{2}, \mathrm{SnO}_{2} /$ reduced graphene oxide $\left(\mathrm{SnO}_{2} / \mathrm{RGO}\right)$, fluorine-doped tin oxide (FTO), and FTO/RGO composite, as given in Table 1.

Table 1. Capacities of $\mathrm{SnO}_{2}, \mathrm{SnO}_{2} / \mathrm{RGO}, \mathrm{FTO}$, and $\mathrm{FTO} / \mathrm{RGO}$ during charge and discharge processes at a current density of $100 \mathrm{mAg}^{-1}$ [193].

\begin{tabular}{ccccc}
\hline Sample & $\mathrm{SnO}_{2}$ & $\mathrm{SnO}_{2} / \mathrm{RGO}$ & FTO & FTO/RGO \\
\hline 1st discharge capacity $\left(\mathrm{mAh} \mathrm{g}^{-1}\right)$ & 787 & 1536 & 1168 & 2108 \\
\hline 200th discharge capacity $\left(\mathrm{mAh} \mathrm{g}^{-1}\right)$ & 201 & 821 & 265 & 1439 \\
\hline Capacity retention after 200th & $26 \%$ & $53 \%$ & $23 \%$ & $68 \%$ \\
\hline
\end{tabular}

The specific capacity of FTO/RGO was much higher compared to that of its individual components. Comparison of charge transfer resistance (Rct) and contact resistance (Rf) of the $\mathrm{SnO}_{2}, \mathrm{SnO}_{2} / \mathrm{RGO}$, FTO, and FTO/RGO samples confirmed that the Rf value of FTO/RGO was much lower compared to that of its individual components. The authors claimed that the thinner growth of the SEI layer at the electrode-electrolyte interface of the FTO/RGO samples reduced the contact resistance.

Fast charging and discharging could be achieved by graphene doping [194]. For instance, N-doped graphene electrodes exhibited a very high capacity of $1043 \mathrm{mAh} \mathrm{g}^{-1}$ and B-doped graphene electrode exhibited $1549 \mathrm{mAh} \mathrm{g}^{-1}$ with higher coulombic efficiency and cycle performance in comparison with undoped graphene. The doped $\mathrm{N}$-doped and B-doped graphene can be quickly charged and discharged for a very short time of $1 \mathrm{~h}$ to several tens of seconds, showing high rate capability and excellent long-term cyclability at the same time [169]. Niobium oxide $\left(\mathrm{Nb}_{2} \mathrm{O}_{5}\right)$ is considered as another promising anode material in a lithium-ion battery for its advantage of preventing the formation of SEI at higher operation potentials. Also, the $\mathrm{Nb}_{2} \mathrm{O}_{5}$ materials exhibited high rate capability and excellent cycle durability [195]. However, these materials exhibited low ion diffusion and charge transfer [196]. 
Yan et al. [197] showed that $\mathrm{Nb}_{2} \mathrm{O}_{5}$ in a carbon matrix showed enhanced rate performance and cycle durability, especially in the oxygen-deficient $\mathrm{Nb}_{2} \mathrm{O}_{5}$, such as $\mathrm{Nb}_{2} \mathrm{O}_{5-\mathrm{x}}$. The carbon matrix in $\mathrm{Nb}_{2} \mathrm{O}_{5-\mathrm{x}}$ shielded the volume change during charging and discharge processes. Also, the carbon matrix increases the conductivity, which in turn enhances rate performance and cycle durability [197].

Wu et al. [198] fabricated $\mathrm{SnO}_{2}$ quantum dots loaded on the sulfur-doped reduced graphene oxide that could retain their tiny sizes during $\mathrm{Li}$ insertion/extraction and thus reduce the volume expansion. Defects in the structure introduced by the sulphur dopant allow ease of charge transfer and $\mathrm{Li}^{+}$ion diffusion. The specific capacity at $100 \mathrm{mAg}^{-1}$ was $897 \mathrm{mAh} \mathrm{g}^{-1}$ and $88 \%$ of original capacity was maintained after 500 cycles at $500 \mathrm{mAg}^{-1}$. Sheng et al. [199] have constructed $\mathrm{MnO}_{2}$ nanosheets with the sizes of 50-100 nm anchored between the graphene oxide sheets to form a densely stacked graphene/ $\mathrm{MnO}(\mathrm{G} / \mathrm{MnO})$ architecture with some micropores $(0.4-0.8 \mathrm{~nm})$ in the graphene sheet. The graphene confinements in $\mathrm{G} / \mathrm{MnO}$ enhance the electrical conductivity and reduce the charge transfer impedance through fast $\mathrm{Li}^{+}$ion diffusion and low charge transfer resistance. The capacity and rate capability derived from this graphene/MnO hybrid system are $1000 \mathrm{mAh} \mathrm{g}^{-1}$ at $0.1 \mathrm{Ag}^{-1}$, and $604 \mathrm{mAh} \mathrm{g}^{-1}$ at $2 \mathrm{Ag}^{-1}$, respectively, which is much higher than those reported for $\mathrm{MnO}\left(777 \mathrm{mAh} \mathrm{g}^{-1}\right.$ at $0.1 \mathrm{Ag}^{-1}, 343 \mathrm{mAh} \mathrm{g}^{-1}$ at $\left.2 \mathrm{Ag}^{-1}\right)$, graphene $\left(648 \mathrm{mAh} \mathrm{g}^{-1}\right.$ at $0.1 \mathrm{~A} \mathrm{~g}^{-1}, 282 \mathrm{~mA} \mathrm{~h} \mathrm{~g}^{-1}$ at $\left.2 \mathrm{Ag}^{-1}\right)$ and $\mathrm{MnO} /$ graphene ( $804 \mathrm{mAh} \mathrm{g}^{-1}$ at $0.1 \mathrm{Ag}^{-1}, 453 \mathrm{mAhg}^{-1}$ at $2 \mathrm{~A} \mathrm{~g}^{-1}$ ) [200-202]. The volumetric capacity of $\mathrm{G} / \mathrm{MnO}$ is 2.27 times higher than $\mathrm{MnO} /$ graphene and 5.40 times higher than graphene. $\mathrm{G} / \mathrm{MnO}$, $\mathrm{MnO} /$ graphene, and graphene exhibited volumetric capacity of $2288 \mathrm{~mA} \mathrm{~h} \mathrm{~cm}{ }^{-3}, 1008 \mathrm{mAh} \mathrm{cm}^{-3}$, and $424 \mathrm{mAh} \mathrm{cm}^{-3}$, respectively [199]. The higher capacity and rate capability are due to the densely stacked graphene/ $\mathrm{MnO}(\mathrm{G} / \mathrm{MnO})$ architecture with some micropores, which offers easy diffusion for ion transport. In addition, the cycle stability of $\mathrm{G} / \mathrm{MnO}$ is much higher than $\mathrm{MnO}$, graphene, and $\mathrm{MnO} /$ graphene. There is a change in thickness of the $\mathrm{G} / \mathrm{MnO}-800$ electrode of about $18 \%$, which is lower than that of pure $\mathrm{MnO}(106 \%)$. Regarding the expansion/contraction during the charge-discharge process, $\mathrm{MnO}$ nanosheets preferentially expand and shrink and were maintained by confinement of the graphene sheets as illustrated by TEM imaging before and after lithiation (Figure 16). However, there is an inevitable initial capacity loss (initial Coulombic efficiency of $65 \%$ ) due to electrolyte decomposition and formation of the SEI layer. A detailed study reported the structure evaluation by TEM analysis for $\mathrm{CeO}_{2}$ /graphene composites during lithiation and delithiation processes, revealing that during the lithiation processes, $\mathrm{Li}_{2} \mathrm{O}$ layers were formed on the surfaces of the $\mathrm{CeO}_{2}$ and graphene sheets and most of these layers disappeared during delithiation. The leftover $\mathrm{Li}_{2} \mathrm{O}$ layers on $\mathrm{CeO}_{2}$ and the graphene sheets could form stable SEI layers, which leads to capacity loss [188]. 


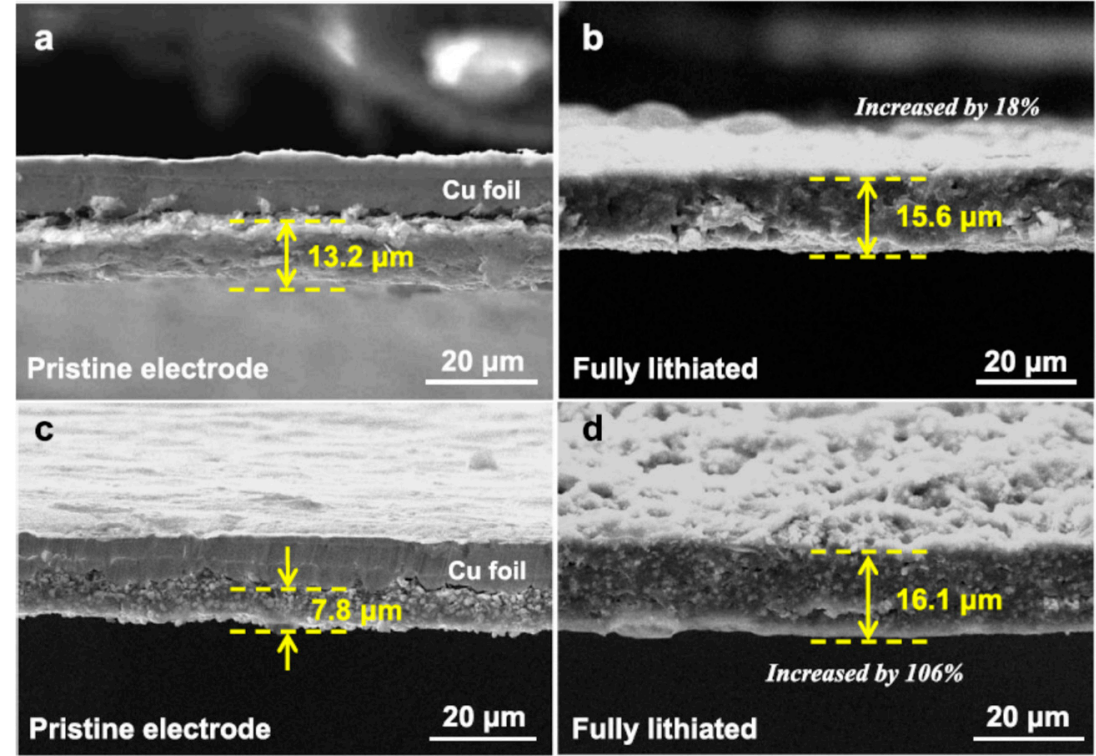

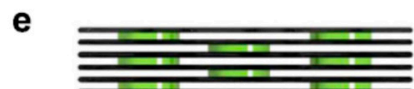

$\mathrm{G} / \mathrm{MnO}$

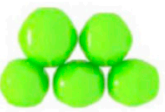

$\mathrm{MnO}$
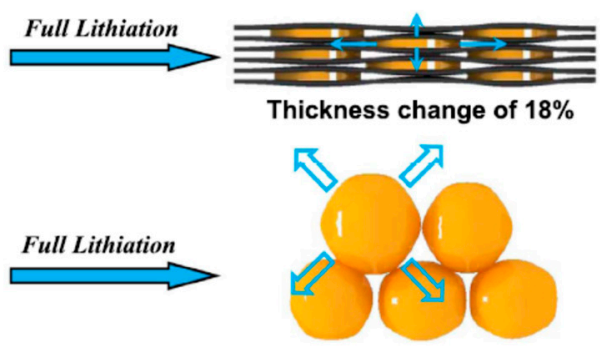

Thickness change of $106 \%$

Figure 16. Cross-sectional SEM images of the G/MnO-800 and $\mathrm{MnO}$ electrodes: (a) G/MnO-800 and (c) $\mathrm{MnO}$; Fully lithiated state: (b) G/MnO-800 and (d) MnO). (e) Schematic illustration of the thickness change for the $\mathrm{G} / \mathrm{MnO}-800$ and $\mathrm{MnO}$ during the full lithiation process [199].

Xiao et al. [203] constructed MnO-graphene core-shell nanowires, in which graphene was coated on $\mathrm{MnO}$, which exhibited comparable electrochemical performance as that of the densely stacked graphene/ $\mathrm{MnO}(\mathrm{G} / \mathrm{MnO})$ architecture constructed by Sheng et al. [199] with reversible capacities of $1185 \mathrm{mAh} \mathrm{g}^{-1}$ at $50 \mathrm{mAg}^{-1}$, rate capability $\left(884 \mathrm{mAh} \mathrm{g}^{-1}\right.$ at $500 \mathrm{mAg}^{-1}$ and $508 \mathrm{mAh} \mathrm{g}^{-1}$ at $\left.3 \mathrm{~A} \mathrm{~g}^{-1}\right)$, high initial coulombic efficiency $(86.3 \%)$, and long-term cyclic stability as long as 500 cycles at $1 \mathrm{~A} \mathrm{~g}^{-1}$, $15 \%$ higher than the initial capacity (Figure 17) [203].

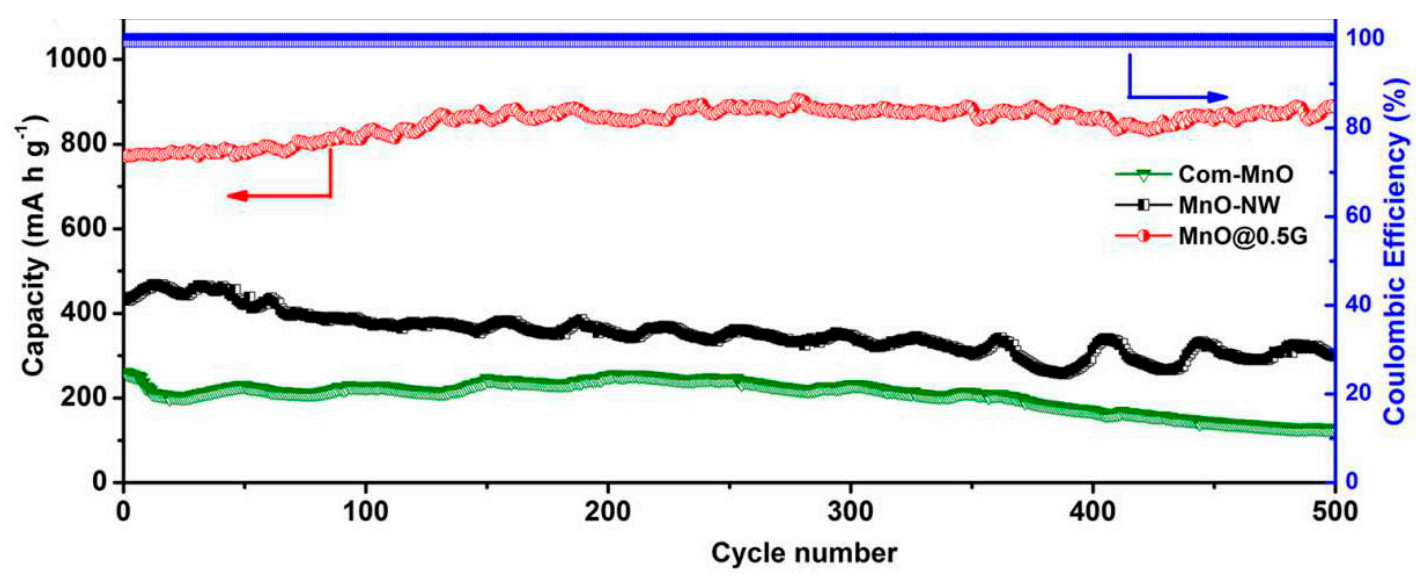

Figure 17. Cycling performance of $\mathrm{MnO}$-graphene core-shell nanowires [203]. 
$\mathrm{N}$-doped carbon $\left(\mathrm{C}_{3} \mathrm{~N}\right)$ with excess nitrogen $\left(\mathrm{C}_{2.67} \mathrm{~N}\right)$ is a promising material for use in LIBs with a theoretical capacity of $837.06 \mathrm{mAh} \mathrm{g}^{-1}$ [204]. The excess $\mathrm{C}$ in $\mathrm{C}_{3} \mathrm{~N}\left(\mathrm{C}_{3.33} \mathrm{~N}\right)$ exhibited a high reversible capacity of $840.35 \mathrm{mAh} \mathrm{g}^{-1}$ with fast charging-discharging rate [205]. $\mathrm{C}_{3} \mathrm{~N} /$ graphene has a theoretical capacity of $1079 \mathrm{mAh} \mathrm{g}^{-1}$ and exhibits good electric conductivity with high stability [206].

Magnetite $\left(\mathrm{Fe}_{3} \mathrm{O}_{4}\right)$ has been considered as an anode material due to its abundance, low-cost, and eco-friendly characteristics. The theoretical capacity of $\mathrm{Fe}_{3} \mathrm{O}_{4}$ is $926 \mathrm{mAh} \mathrm{g}^{-1}$ and the electronic conductivity is $2 \times 10^{4} \mathrm{Sm}^{-1}$. However, huge volume changes during $\mathrm{Li}^{+}$ions insertion/extraction processes were observed in $\mathrm{Fe}_{3} \mathrm{O}_{4}$, which leads to rapid capacity loss [207]. Zhou et al. [208] found that porous $\mathrm{Fe}_{3} \mathrm{O} @ \mathrm{C}$ nanospheres performed as a high-performance anode for a lithium-ion battery. Yang et al. [209] constructed nanoparticles of $\mathrm{Fe}_{3} \mathrm{O}_{4}$ interconnected by carbon nanotubes that were sandwiched by rGO layers to form a network $\left(\mathrm{Fe}_{3} \mathrm{O}_{4} / \mathrm{CNTs} / \mathrm{rGO}\right)$ by a facile route without any binders. This composite network exhibited a reversible capacity of $540 \mathrm{mAh} \mathrm{g}^{-1}$ at a very high current density of $10 \mathrm{~A} \mathrm{~g}^{-1}$, and a stable capacity of $1080 \mathrm{mAh} \mathrm{g}^{-1}$ after 450 cycles at $1 \mathrm{~A} \mathrm{~g}^{-1}$ ). The faster transportation of $\mathrm{Li}^{+}$ions and electrons in the $\mathrm{Fe}_{3} \mathrm{O}_{4} / \mathrm{CNTs} / \mathrm{rGO}$ composite network resulted in superior rate performance as evidenced from the electrochemical impedance spectrum (EIS) of the commercial $\mathrm{Fe}_{3} \mathrm{O}_{4} \mathrm{NPs}$ and $\mathrm{Fe}_{3} \mathrm{O}_{4} / \mathrm{CNTs} / \mathrm{rGO}$ electrodes after the first cycle (Figure 18). The resistance values of the $\mathrm{Fe}_{3} \mathrm{O}_{4} / \mathrm{CNTs} / \mathrm{rGO}$ composite electrode are lesser than that of the commercial $\mathrm{Fe}_{3} \mathrm{O}_{4} \mathrm{NPs}$ electrode.

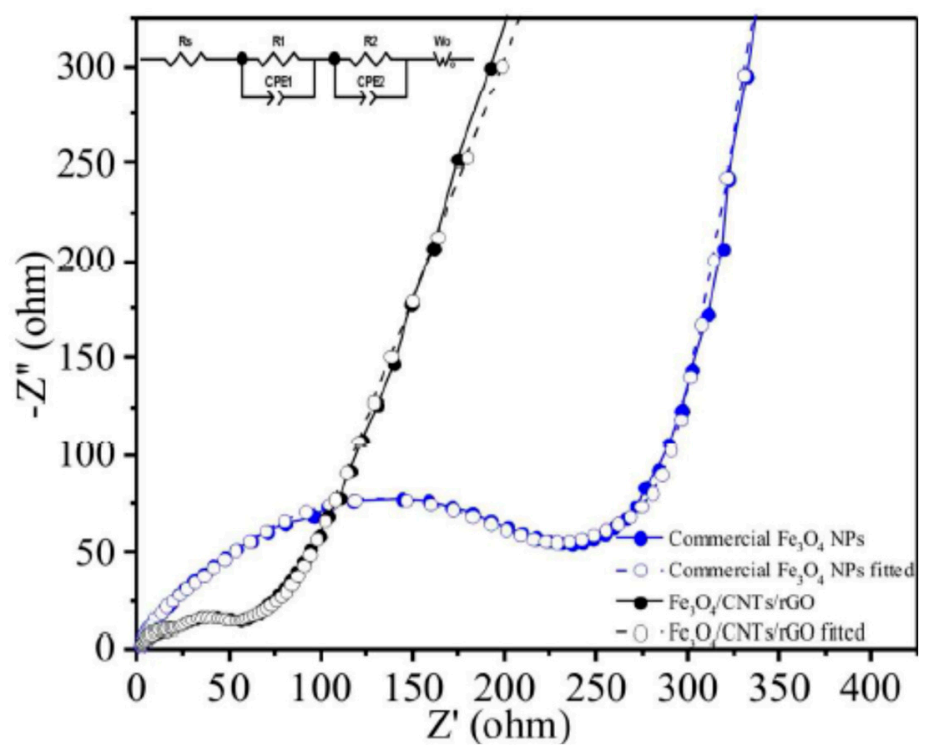

Figure 18. Electrochemical impedance spectrum (EIS) and fitting results of the $\mathrm{Fe}_{3} \mathrm{O}_{4} / \mathrm{CNTs} / \mathrm{rGO}$ composite and commercial $\mathrm{Fe}_{3} \mathrm{O}_{4}$ NPs electrodes [209].

$\mathrm{Fe}_{3} \mathrm{O}_{4}$ nanoparticles/graphene foam with a hierarchical structure with well-dispersed $\mathrm{Fe}_{3} \mathrm{O}_{4}$ nanoparticles on a graphene matrix exhibited a capacity of $1198 \mathrm{mAh} \mathrm{g}^{-1}$, which was higher than that of theoretical capacity value for $\mathrm{Fe}_{3} \mathrm{O}_{4}\left(926 \mathrm{mAh} \mathrm{g}^{-1}\right)$ and pure GF $\left(300 \mathrm{mAh} \mathrm{g}^{-1}\right)$ after 400 cycles [210]. The network-structured graphene minimizes the direct contact with positively-charged $\mathrm{Fe}_{3} \mathrm{O}_{4} \mathrm{NPs}$ that will control the aggregation of the NPs during charge-discharge processes. The hierarchical structure enhances electron/ion transport.

The theoretical capacity of a $\mathrm{Co}_{3} \mathrm{O}_{4}$ anode in LIB is $890 \mathrm{mAh} \mathrm{g}^{-1}$, involving eight electrons, and is much higher than that graphite, but is limited by its poor cycling stability resulting from huge volume change, as with other oxide anodes [211]. Yang et al. [212] constructed a $\mathrm{Co}_{3} \mathrm{O}_{4} /$ graphene sandwich-like hybrid electrode by direct electrophoretic deposition without using any binder. The $\mathrm{Co}_{3} \mathrm{O}_{4} / \mathrm{G}$ hybrid electrode showed initial discharge and charge capacities of 1303.9 and $946.0 \mathrm{mAh} \mathrm{g}^{-1}$, respectively, with initial Coulombic efficiency (CE) of $72.6 \%$ (Figure 17). The reversible discharge capacity of $\mathrm{Co}_{3} \mathrm{O}_{4} / \mathrm{G}$ hybrid electrode was $1113 \mathrm{mAh} \mathrm{g}^{-1}$ (100 cycles), which is much higher than that of $\mathrm{Co}_{3} \mathrm{O}_{4}$ 
electrode ( $583 \mathrm{mAh} \mathrm{g}^{-1}$ after 50 cycles). The higher electrochemical performance of the $\mathrm{Co}_{3} \mathrm{O}_{4} / \mathrm{G}$ hybrid electrode is due to: (i) Many voids formed by $\mathrm{Co}_{3} \mathrm{O}_{4}$ nanocubes embedded between graphene sheets, which can provide buffer space for huge volume expansion during material during cycling; (ii) improved electronic conductivity by flexible graphene; and (iii) higher energy density and less agglomeration as there are no binders or conductive additives. The nanocubes of $\mathrm{CoFe}_{2} \mathrm{O}_{4} /$ graphene composite ( $\mathrm{CoFe}_{2} \mathrm{O}_{4} / \mathrm{G}$ electrode) also exhibited comparable cycling performance and rate capability to that of the $\mathrm{Co}_{3} \mathrm{O}_{4} / \mathrm{G}$ hybrid electrode. The cycling performance of the $\mathrm{CoFe}_{2} \mathrm{O}_{4} / \mathrm{G}$ electrode was $1109 \mathrm{mAh} \mathrm{g}^{-1}$ after 100 cycles at $0.2 \mathrm{Ag}^{-1}$ and $835 \mathrm{mAh} \mathrm{g}^{-1}$ after 200 cycles at $1 \mathrm{Ag}^{-1}$ and rate capability was $420 \mathrm{mAh} \mathrm{g}^{-1}$ at $5 \mathrm{~A} \mathrm{~g}^{-1}$. The $\mathrm{CoFe}_{2} \mathrm{O}_{4} / \mathrm{G}$ electrode displayed better diffusion behavior of lithium ions than $\mathrm{CoFe}_{2} \mathrm{O}_{4}$ electrodes. The overall shape of the electrode material $\mathrm{CoFe}_{2} \mathrm{O}_{4} / \mathrm{G}$ electrode was well retained, as evidenced by TEM and HRTEM images of the $\mathrm{CoFe}_{2} \mathrm{O}_{4} / \mathrm{G}$ electrode after 200 cycles at $1 \mathrm{Ag}^{-1}$ (Figure 19) [212].
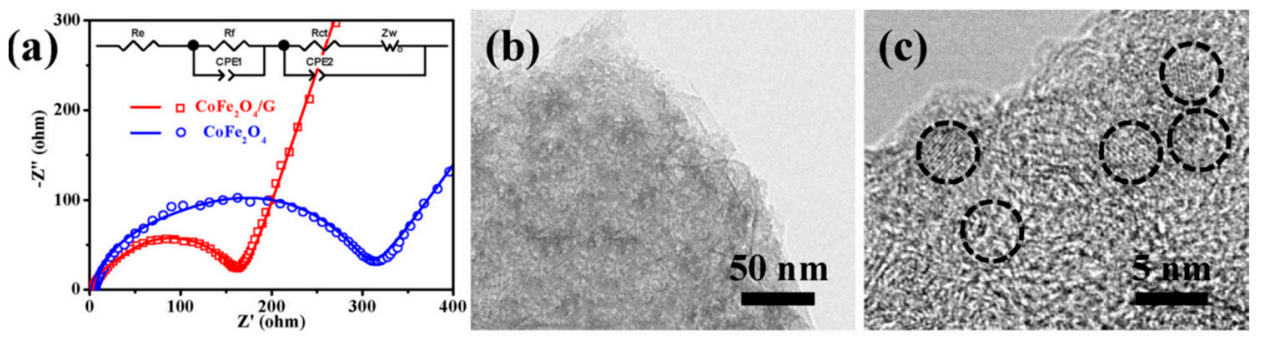

(d)

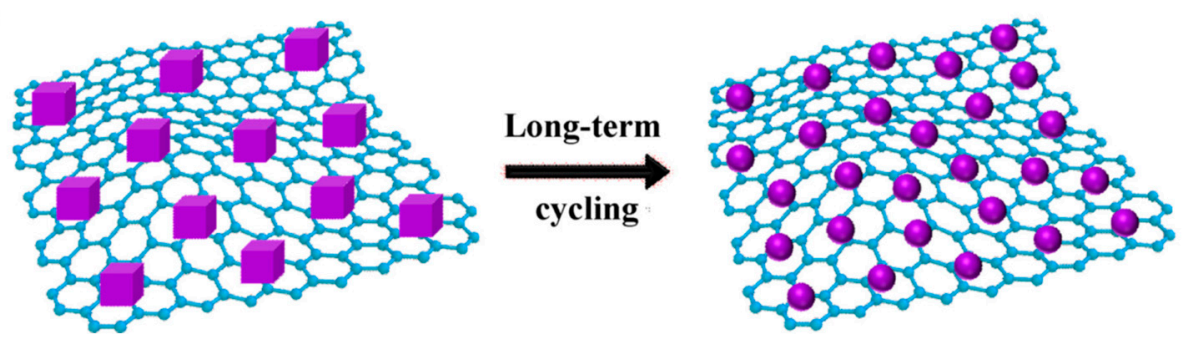

Figure 19. Nyquist plots of the $\mathrm{CoFe}_{2} \mathrm{O}_{4} / \mathrm{G}$ and $\mathrm{CoFe}_{2} \mathrm{O}_{4}$ electrodes (hollow symbols: measured data; continuous lines: fitting curves) (a); TEM image (b) and HRTEM image (c) of the $\mathrm{CoFe}_{2} \mathrm{O}_{4} / \mathrm{G}$ electrode after 200 cycles at $1 \mathrm{~A} \mathrm{~g}^{-1}$; The schematic illustration of the morphological and structural evolution of the $\mathrm{CoFe}_{2} \mathrm{O}_{4} / \mathrm{G}$ electrode (d) [212].

Comparison of two-dimensional (2D) graphene and 3D porous graphene showed that in 2D-graphene, there are strong van der Waals interactions between the nanosheets, which could hinder the reversible capacity [213-218]. However, in 3D porous graphene, there are defects and interconnected pores, which offer easy diffusion for ion transport and relief of volume expansion during the $\mathrm{Li}^{+}$ions intercalation/deintercalation process, thereby improving the capacity, rate capability, and stability $[213,215,219]$. Chemical etching and templating [218-220] are commonly used methods to prepare graphene with porous architecture. Zhu et al. [221] fabricated a three-dimensional porous graphene microspheres (3DGPM) anode with interconnected hollow pore structure by a template-sacrificing method. The 3DGPM has specific hollow micro-spherical structure. The presence of graphene spheres (diameter of 1-10 $\mu \mathrm{m}$ ) with interlinked hollow spherical embossed structure was confirmed by scanning electron microscopy. Hollow spherical graphene shells dispersed on graphene microspheres was confirmed by transmission electron microscopy. The multilayer reduced graphene on the boundary of graphene shells was presented by high-resolution TEM (Figure 20). 

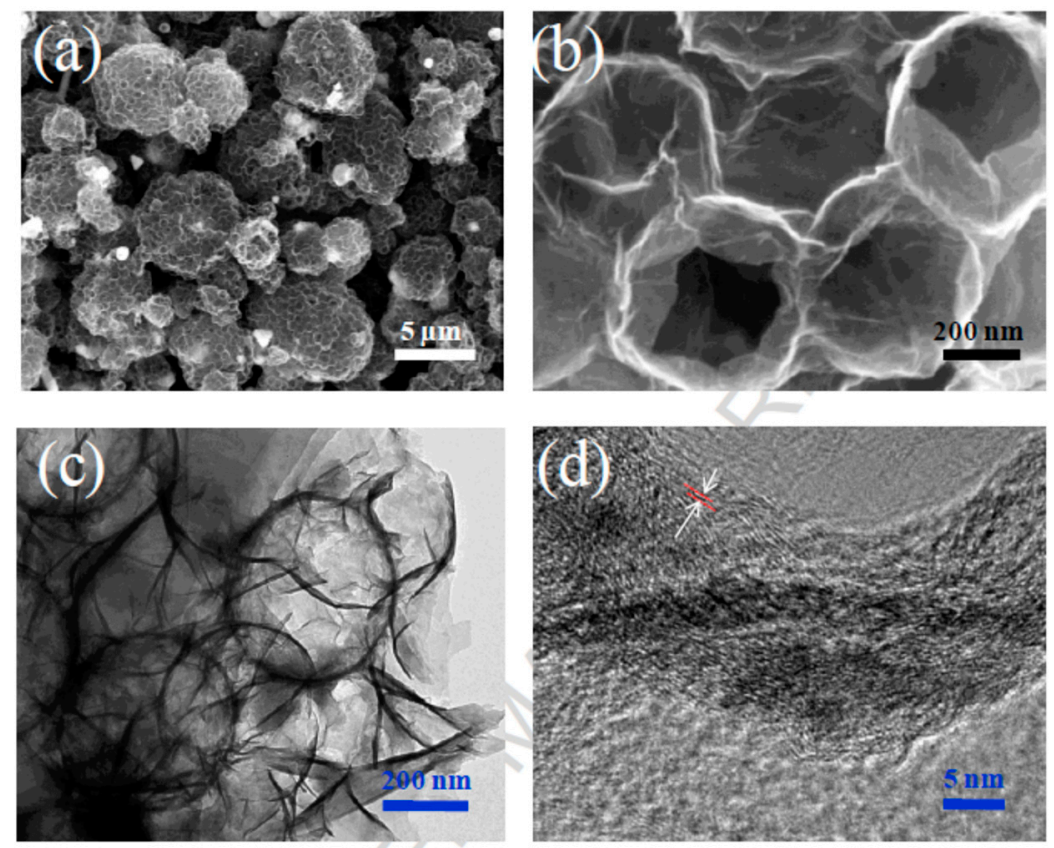

Figure 20. Morphologies of the 3DGPM: (a, b) SEM images; (c, d) TEM and HRTEM images [221].

The 3DGPM exhibited a reversible capacity of $551.4 \mathrm{mAh} \mathrm{g}^{-1}$ (at $100 \mathrm{~mA} \mathrm{~g}^{-1}$ ) and rate capability of $245.8 \mathrm{mAh} \mathrm{g}^{-1}$ (at $2 \mathrm{~A} \mathrm{~g}^{-1}$ ). The first discharge-charge capacities were 851.1 and $402.4 \mathrm{mAg}^{-1}$ (at $0.1 \mathrm{~A} \mathrm{~g}^{-1}$ ). The 500th discharge capacity was $245.8 \mathrm{mAh} \mathrm{g}^{-1}$ (at $2 \mathrm{~A} \mathrm{~g}^{-1}$ ). The charge transfer resistance (R1) of 3DGPM was $82.5 \Omega$, which was much lower than that of the RGO (258.3 $\Omega$ ) (Figure 21). The presence of specific hollow micro-spherical structure provides pathways for fast electron transfer during repeated cycling and offer voids for volume expansion [221].
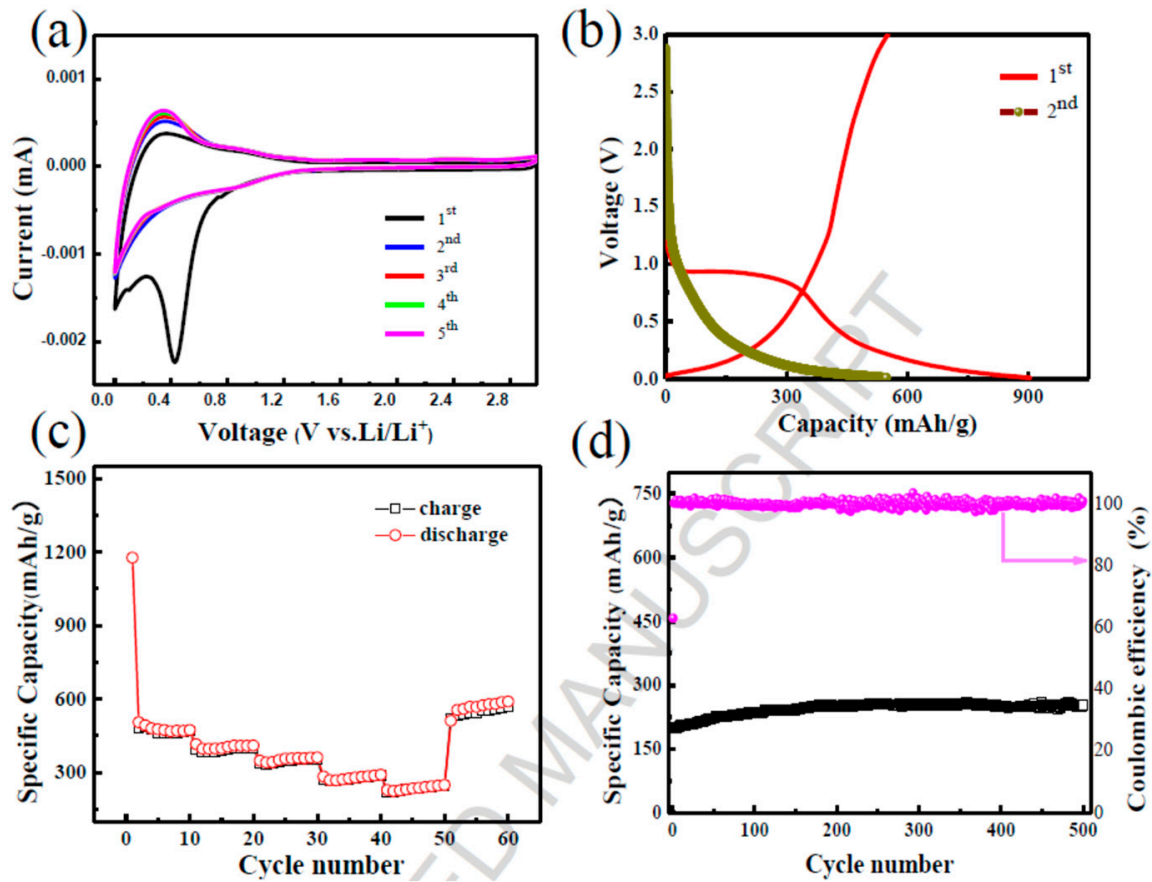

Figure 21. Quantitative analysis of lithium storage behavior of the 3DGPM. (a) CV curves; (b) Charge and discharge curves of the 3DGPM at $0.1 \mathrm{C}$; (c) rate capability at various current density; (d) capacity retention at $2 \mathrm{~A} \mathrm{~g}^{-1}$. [221]. 
Xing et al. [222] adopted graphitization of anthracite, followed by a modified Hummers method, and then rapid reduction at high temperature. This method resulted in continuous nanosheets with a hierarchical porous structure having micro/meso/macropores, with high specific surface area and large pore volume with enormous structural defects with a wide pore size distribution ranging from 1.0 to $25.1 \mathrm{~nm}$ (Figure 22).

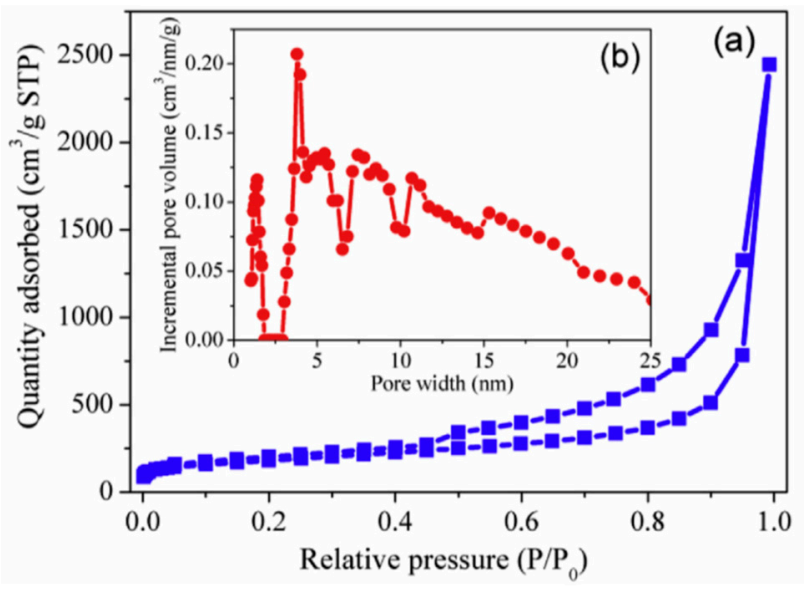

Figure 22. Nitrogen adsorption-desorption isotherm (a) and pore size distribution (b) of coal-based porous graphene (CPG) [222].

These porous graphene materials exhibited lower capacity compared to metal oxide-doped graphene but have higher cycling performance. The capacity and rate capability are $770 \mathrm{mAh} \mathrm{g}^{-1}$ (at $0.1 \mathrm{C}$ ), and $274 \mathrm{mAh} \mathrm{g}^{-1}(10 \mathrm{C})$ and $224 \mathrm{mAh} \mathrm{g}^{-1}(20 \mathrm{C})$, respectively. The cycling performance reached up to $98.0 \%$ (after 110 cycles), which is higher than that of a graphene anode $(95.7 \%)$, with near $100 \%$ efficiency was reported. The graphene orientation results in different properties in such a way that vertically-oriented graphene nanowalls (VGNWs) have three-dimensional network morphology with long and thin edges having a large specific surface area, which provides good electrical properties as well as structural stability [223]. Chemical vapor deposition (CVD) and plasma-enhanced chemical vapor deposition (PECVD) are used to synthesize vertically-oriented graphene nanowalls (VGNWs). Faster deposition growth at a lower temperature could be achieved by PECVD [224]. Yang et al. applied a plasma-based approach to fabricate VGNWs with tailored properties by adjusting the experimental conditions such as argon flow rate, growth temperature, RF power, and deposition times [225]. Under optimum conditions, the specific discharge capacity reaches $400 \mathrm{mAh} \mathrm{g}^{-1}$ in the first charge-discharge cycle and was lower than the graphene sheets prepared by thermally exfoliation of graphene oxide at $1050{ }^{\circ} \mathrm{C}$ [226], which have the specific capacity of $672 \mathrm{mAh} \mathrm{g}^{-1}$ at a current density of $0.2 \mathrm{mAcm}^{-2}$ and thermally reduced graphite oxide at $1050{ }^{\circ} \mathrm{C}$, which has the specific capacity of $835 \mathrm{mAh} \mathrm{g}^{-1}$ at a current density of $50 \mathrm{~mA} \mathrm{~g}^{-1}$ [227].

More than 20 years ago, the carbon anode enabled the Li-ion battery to become commercially viable and is still the material of choice for the anode. The electrochemical activity of carbon is the result of $\mathrm{Li}$ intercalation between the graphene planes offering good mechanical 2D stability, electrical conductivity, and Li transport. In this way, it is possible to store up to one $\mathrm{Li}$ atom per six C. A summary of the application of carbon anodes Li-ion batteries is presented in Table 2. 
Table 2. A summary of the applications of carbon anodes in Li-ion materials.

\begin{tabular}{|c|c|c|}
\hline Materials & Significant Applications/Findings observed & Ref. \\
\hline $\mathrm{ZnCo}_{2} \mathrm{O}_{4} / \mathrm{rGO}$ & $\begin{array}{l}\text { The electrochemical properties of } \mathrm{ZnCO}_{2} \mathrm{O}_{4} / \mathrm{rGO} \text { composite material } \\
\text { exhibited a raised cycling capability as high as } 1613 \mathrm{mAh} \mathrm{g}^{-1} \text { at } \\
500 \mathrm{~mA} \mathrm{~g}^{-1} \text { over } 400 \text { cycles }\end{array}$ & [228] \\
\hline Sn@G & $\begin{array}{l}\text { The 3D hybrid Sn@Graphene anode displays an elevated cycling } \\
\text { capability of } 1022 \mathrm{mAh} / \mathrm{g} \text { at } 0.2 \mathrm{C} \text { and } 270 \mathrm{mAh} / \mathrm{g} \text { at } 10 \mathrm{C} \text { along with } \\
\text { tremendously longer cycling stability at higher rates, such as } 682 \mathrm{mAh} / \mathrm{g} \\
\text { cycling stability at } 2 \mathrm{~A} / \mathrm{g} \text {. This is roughly about } 96.3 \% \text { even after } \\
1000 \text { cycles, which is perhaps the best rate capacity and lengthiest cycle } \\
\text { life ever testified for Sn-based battery anode for Li ions. }\end{array}$ & [229] \\
\hline $\mathrm{Ga}_{2} \mathrm{O}_{3} / \mathrm{rGO}$ & $\begin{array}{l}\text { The } \mathrm{Ga}_{2} \mathrm{O}_{3} / \mathrm{rGO} \text { nanocomposite has been proven to be a promising } \\
\text { electrode material for use as a Li-ion anode with superior performance. } \\
\text { This enhancement in performance is due to the electron transport } \\
\text { characteristics created due to the presence of controlled open porous, } \\
\text { crystal structure, and crystal morphology by doping with rGO. }\end{array}$ & [230] \\
\hline $\mathrm{GeO} / \mathrm{GO}$ & $\begin{array}{l}\text { A test carried to evaluate the performance of different materials for } \\
\text { lithium ion battery anodes revealed GO containing only } 51 \% \text { wt } \\
\text { germanium to exhibit good storage capacity }>1000 \mathrm{mAh} \mathrm{g}^{-1} \text { at } \\
250 \mathrm{~mA} \mathrm{~g}^{-1} \text {. }\end{array}$ & [168] \\
\hline $\begin{array}{l}\text { Graphene-like graphite } \\
\text { (GLG) }\end{array}$ & $\begin{array}{l}\text { GLG's discharge capacity above } 1 \mathrm{~V} \text { increases the oxygen percentage, } \\
\text { with successive discharge capacity reaching } 673 \mathrm{mAh} \mathrm{g}^{-1} \text {. Thus, GLG } \\
\text { can act as an ideal anode for Li-ion storage cells. }\end{array}$ & [231] \\
\hline $\mathrm{Co}_{3} \mathrm{Sn}_{2} @ \mathrm{Co}-\mathrm{NG}$ & $\begin{array}{c}\text { The } \mathrm{Co}_{3} \mathrm{Sn}_{2} @ \text { Co-NG hybrid nanocomposite shows an unexpected } \\
\text { reversible capacity of } 1615 \mathrm{mAh} / \mathrm{g} \text { at } 250 \mathrm{~mA} / \mathrm{g} \text { after } 100 \text { cycles when } \\
\text { used as an anode. These } \mathrm{Co}_{3} \mathrm{Sn}_{2} @ \text { Co-NG composites were able to } \\
\text { produce } 100 \% \text { coulombic efficiency. }\end{array}$ & [232] \\
\hline $\mathrm{CuMn}_{2} \mathrm{O}_{4} / \mathrm{G}$ & $\begin{array}{l}\text { These nanostructured } \mathrm{CuMn}_{2} \mathrm{O}_{4} / \text { graphene composites were able to } \\
\text { deliver a larger capacity of } 935 \mathrm{mAh} / \mathrm{g} \text { after } 150 \text { cycles, corresponding to } \\
\text { a current density of } 50 \mathrm{~mA} / \mathrm{g} \text {. Additionally, it was further confirmed } \\
\text { that } \mathrm{CuMn}{ }_{2} \mathrm{O}_{4} \text { composite changes into a nanosized } \mathrm{CuO}-\mathrm{MnO} \\
\text { composite material with a spongy porous structure during } \\
\text { discharge-charge processes. }\end{array}$ & [233] \\
\hline $\mathrm{ZnO} / \mathrm{rGO}$ & $\begin{array}{l}\mathrm{ZnO} / \mathrm{rGO} \text { as an anode material in a lithium-ion battery exhibits brilliant } \\
\text { cycling stability and improved charge capacity rates, because of its } \\
\text { doughnut-like } \mathrm{ZnO} \text { assembly. } \mathrm{ZnO} / \mathrm{rGO} \text { nanocomposite provides high } \\
\text { electrical conductivity due to its short diffusion length. }\end{array}$ & [234] \\
\hline 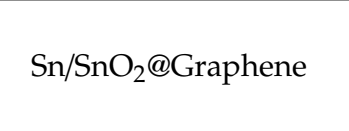 & $\begin{array}{l}\text { Improved initial capacity as high as } 2970.3 \mathrm{mAh}^{-1} \text { makes } \\
\mathrm{Sn} / \mathrm{SnO}_{2} @ \text { Graphene composites an ideal candidate for } \\
\text { high-performance electrodes for Li/Na-ion batteries. }\end{array}$ & [235] \\
\hline $\mathrm{Co}_{3} \mathrm{O}_{4} / \mathrm{rGO}$ & $\begin{array}{l}\mathrm{Co}_{3} \mathrm{O}_{4} / \mathrm{rGO} \text { composites are preferred materials for lithium ion batteries } \\
\text { due to their superior electrochemical behavior as an anode material. } \\
\text { This superior behaviour is as a result of the steady changes in } \\
\text { morphology that occur with respect to thicknesses of the material } \\
\text { during the process of cycling, thereby reducing the stress caused during } \\
\text { cycling by providing a smaller diffusion path length for Li-ions and } \\
\text { electrons. }\end{array}$ & [236] \\
\hline $3 \mathrm{DG} / \mathrm{Fe}_{2} \mathrm{O}_{3}$ & $\begin{array}{l}\text { The 3DG/Fe } \mathrm{F}_{2} \text {-based aerogel, when used as anode material for } \\
\text { lithium-ion battery, displayed an extremely large storage capacity of } \\
1129 \mathrm{mAh} / \mathrm{g} \text { at } 0.2 \mathrm{~A} / \mathrm{g} \text { after } 130 \text { cycles. This highly flexible anode } \\
\text { retained a storage capacity as high as } 98 \% \text { after } 1200 \text { cycles at } 5 \mathrm{~A} / \mathrm{g} \text {. }\end{array}$ & [237] \\
\hline
\end{tabular}


Table 2. Cont.

\begin{tabular}{|c|c|c|}
\hline Materials & Significant Applications/Findings observed & Ref. \\
\hline Graphene-Si aerogels & $\begin{array}{l}\text { Electrochemical investigations indicated that the fabricated graphene-Si } \\
\text { aerogels were capable of delivering } 104 \% \text { charging capacity at } 0.8 \mathrm{~A} / \mathrm{g} \text {. } \\
\text { Carbon nanotubes functionalized with silicon were utilized to achieve } \\
\text { capacities as high as } 1415 \mathrm{mAh} / \mathrm{g} \text { at a discharge rate of } 0.05 \mathrm{C} \text {. Thus, it is } \\
\text { expected that graphene-Si aerogels will play a noteworthy role in } \\
\text { lithium ion batteries. }\end{array}$ & [238] \\
\hline $\begin{array}{l}\text { Graphene nanoflakes } \\
\text { ink }\end{array}$ & $\begin{array}{l}\text { By optimizing the cell composition, the best battery behaviour of } 165 \\
\text { mAh } \mathrm{g}^{-1} \text { was achieved, corresponding to an energy density as high as } \\
190 \mathrm{Wh} \mathrm{kg}^{-1} \text { for an average of } 80 \text { cycles. }\end{array}$ & [74] \\
\hline $\mathrm{TiO}_{2}-\mathrm{B}-\mathrm{G}$ & $\begin{array}{l}\mathrm{TiO}_{2} \text {-B-graphene nanocomposite material doped with } 18.8 \mathrm{wt} \% \text { of } \\
\text { graphene exhibits promising electrochemical characteristics with charge } \\
\text { capacities reaching } 264 \text { and } 255 \mathrm{~mA} \mathrm{hg}^{-1} \text { at a current rate of } 1 \mathrm{C} \text {. The } \\
\text { storage capacity is as high as } 171 \mathrm{mAh} \mathrm{g}^{-1} \text { and was retained after } 100 \\
\text { cycles at } 5 \mathrm{C} \text {. The increase in graphene concentration above } 27.7 \mathrm{wt} \% \text {, } \\
\text { diminished the lithium storage properties due to the accumulation of } \\
\text { graphene structures. }\end{array}$ & [239] \\
\hline $\mathrm{Fe}_{2} \mathrm{~N} @ \mathrm{AC} @ \mathrm{rGO}$ & $\begin{array}{l}\text { The amorphous carbon }(\mathrm{AC}) \text { shell and graphene oxide (rGO) network } \\
\text { were able to provide long-term cyclic stability along with extraordinary } \\
\text { rate capability of } 303 \mathrm{mAh} \mathrm{g}^{-1} \text { at } 10 \mathrm{~A} \mathrm{~g}^{-1} \text {. }\end{array}$ & [240] \\
\hline
\end{tabular}

\section{Conclusions and Future Directions}

In this review, we have reviewed the utilization of carbon-based nanomaterials as potential anode materials for Li-ion batteries. Based on the literature survey, it was observed that the carbon-based nanomaterials are promising materials which can efficiently be used as anode materials for Li-ion battery applications. Various carbon-based materials, such as carbon nanotubes, carbon nanofibers, carbon xerogels, carbon nanosprings, and graphene, were used as efficient Li-ion battery anode materials. Although carbon-based nanomaterials are efficiently used as anode materials for Li-ion battery applications, to fulfill the need for high power electrochemical cells, there is a need to utilize higher surface area materials which should inherently have a higher reaction rate. The natural step is to look at nanomaterials with surface areas more than $5 \mathrm{~m}^{2} \mathrm{~g}^{-1}$ and up to several hundred $\mathrm{m}^{2} \mathrm{~g}^{-1}$. However, the increase in surface area will also increase the side-reactions and potentially reduce the safety of the cells. In addition, the nanomaterials in batteries show low density. Therefore, not all materials are appropriate to use at the nanolevel, just those that undergo the desired reaction in a highly selective manner. New material development for low-cost anodes is expected to endow both small and large batteries with superior rate capability, safety, and cycle performance.

Author Contributions: L.S.R., S.S., A.U. and R.S. collected the literature and wrote the review. L.S.R., R.-S.J., C.-T.H., S.S., A.U., R.S. and H.H.H. read and revised the paper.

Acknowledgments: The authors (Ahmad Umar and Hosameldin H. Hegazy) gratefully thank the Deanship of Scientific Research at King Khalid University for the financial support through research groups program under grant number (R.G.P.2/18/40).

Conflicts of Interest: The authors declare no conflicts of interest.

\section{References}

1. Ahmed, S.; Islam, M.T.; Karim, M.A.; Karim, N.M. Exploitation of renewable energy for sustainable development and overcoming power crisis in Bangladesh. Renew. Energy 2014, 72, 223-235. [CrossRef]

2. Perera, F. Pollution from Fossil-Fuel Combustion is the Leading Environmental Threat to Global Pediatric Health and Equity: Solutions Exist. Int. J. Environ. Res. Public Health 2018, 15, 16. [CrossRef] [PubMed]

3. Evangelos Kalamaras, M.; Maroto-Valer, M.; Shao, M.; Xuan, J.; Wang, H. Solar carbon fuel via photoelectrochemistry. Catal. Today 2018, 317, 56-75. [CrossRef] 
4. Chen, H.; Cong, T.N.; Yang, W.; Tan, C.; Li, Y.; Ding, Y. Progress in electrical energy storage system: A critical review. Prog. Nat. Sci. 2009, 19, 291-312. [CrossRef]

5. Wu, Y.; Holze, R. Electrocatalysis at Electrodes for Vanadium Redox Flow Batteries. Batteries $2018,4,47$. [CrossRef]

6. Hesse, H.C.; Schimpe, M.; Kucevic, D.; Jossen, A. Lithium-Ion Battery Storage for the Grid-A Review of Stationary Battery Storage System Design Tailored for Applications in Modern Power Grids. Energies 2017, 10, 2107. [CrossRef]

7. Shukla, A.K.; Kumar, T.P. Materials for next-generation lithium batteries. Curr. Sci. 2008, 94, 314-331.

8. Liu, C.; Neale, Z.G.; Cao, G. Understanding electrochemical potentials of cathode materials in rechargeable batteries. Mater. Today 2016, 19, 109-123. [CrossRef]

9. Chen, L.; Gu, Q.; Zhou, X.; Lee, S.; Xia, Y.; Liu, Z. New-concept Batteries Based on Aqueous Li1/Na1 Mixed-ion Electrolytes. Sci. Rep. 2013, 3,1-7. [CrossRef]

10. Fish, R.M.; Geddes, L.A. Conduction of Electrical Current to and Through the Human Body: A Review. ePlasty 2009, 9, 407-421.

11. Hiremath, M.; Derendorf, K.; Vogt, T. Comparative Life Cycle Assessment of Battery Storage Systems for Stationary Applications. Environ. Sci. Technol. 2015, 49, 4825-4833. [CrossRef]

12. Chu, Y.S.; Lister, T.E.; Cullen, W.G.; You, H.; Nagy, Z. Commensurate water monolayer at theRuO $\mathrm{R}_{2}(110) /$ water interface. Phys. Rev. Lett. 2001, 86, 3364-3367. [CrossRef]

13. Dondelinger, R.M. Batteries: From alkaline to zinc-air. Biomed. Instrum. Technol. 2004, 38, 100-110.

14. Wruck, W.J.; Reichman, B.; Bullock, K.R.; Kao, W.-H. Rechargeable Zn-Mn02 Alkaline Batteries. J. Electrochem. Soc. 1991, 138, 3560-3567. [CrossRef]

15. Gaines, L. The future of automotive lithium-ion battery recycling: Charting a sustainable course. Sustain. Mater. Technol. 2014, 1-2, 2-7. [CrossRef]

16. Garche, J. Advanced battery systems-The end of the lead-acid battery? Phys. Chem. Chem. Phys. 2001, 3, 356-367. [CrossRef]

17. Nowak, S.; Winter, M. The Role of Cations on the Performance of Lithium Ion Batteries: A Quantitative Analytical Approach. Acc Chem. Res. 2018, 51, 265-272. [CrossRef]

18. Manthiram, A.; Fu, Y.; Chung, S.-H.; Zu, C.; Su, Y.-S. Rechargeable Lithium-Sulfur Batteries. Chem. Rev. 2014, 114, 11751-11787. [CrossRef]

19. Xu, W.; Wang, J.; Ding, F.; Chen, X.; Nasybulin, E.; Zhang, Y.; Zhang, J.-G. Lithium metal anodes for rechargeable batteries. Energy Environ. Sci. 2014, 7, 513-537. [CrossRef]

20. Lee, J.-S.; Cao, S.T.K.R.; Choi, N.-S.; Liu, M.; Lee, K.T.; Cho, J. Metal-Air Batteries with High Energy Density: Li-Air versus Zn-Air. Adv. Energy Mater. 2011, 1, 34-50. [CrossRef]

21. Bauman, H.G.; Chilton, J.E.; Cook, G.M. New Cathode-Anode Couples using Nonaqueous Electrolyte; Lockheed Missiles and Space Co., Inc.: Palo Alto, CA, USA, 1963.

22. Tarascon, J.M.; Armand, M. Issues and challenges facing rechargeable lithium batteries. Nature 2001, 414, 359-367. [CrossRef]

23. Ohzuku, T.; Ueda, A.; Nagayama, M. Electrochemistry and structural chemistry of $\mathrm{LiNiO}_{2}(\mathrm{R} 3 \mathrm{~m})$ for 4 Volt secondary lithium cells. J. Electrochem. Soc. 1993, 140, 1862-1870. [CrossRef]

24. Zhuravlev, V.D.; PachuevK, A.V.; NefedovaL, V.; Ermakova, V. Solution-Combustion Synthesis of LiNi1/3Co1/3Mn1/3O2 as a Cathode Material for Lithium-Ion Batteries. Int. J. Self-Propag. High-Temp. Synth. 2018, 27, 154-161. [CrossRef]

25. Blomgren, G.E. The Development and Future of Lithium Ion Batteries. J. Electrochem. Soc. 2017, 164, A5019-A5025. [CrossRef]

26. Zelinsky, M.A.; Koch, J.M.; Young, K.-H. Performance Comparison of Rechargeable Batteries for Stationary Applications (Ni/MH vs. Ni-Cd and VRLA). Batteries 2018, 4, 1. [CrossRef]

27. Bernard, P.; Lippert, M. Nickel-Cadmium and Nickel-Metal Hydride Battery Energy Storage. Electrochem. Energy Storage Renew. Sources Grid Balanc. 2015, 223-251. [CrossRef]

28. MacLean, G.K.; Aiken, P.A.; Adams, W.A.; Mussivand, T. Comparison of rechargeable lithium and nickel/cadmium battery cells for implantable circulatory support devices. Artif. Organs 1994, 18, 331-334. [CrossRef]

29. Shen, W.X.; Chan, C.C.; Lo, E.W.C.; Chau, K.T. Estimation of battery available capacity under variable discharge currents. J. Power Sources 2002, 103, 180-187. [CrossRef] 
30. Sukhvinder, P.; Badwal, S.; Giddey, S.S.; Munnings, C.; Bhatt, A.I.; Hollenkamp, A.F. Emerging electrochemical energy conversion and storage technologies. Front. Chem. 2014, 2, 1-28. [CrossRef]

31. Gao, J.; Shi, S.-Q.; Li, H. Brief overview of electrochemical potential in lithium ion batteries. Chin. Phys. B 2016, 25, 018210. [CrossRef]

32. Girishkumar, G.; McCloskey, B.; Luntz, A.C.; Swanson, S.; Wilcke, W. Lithium-Air Battery: Promise and Challenges. J. Phys. Chem. Lett. 2010, 1, 2193-2203. [CrossRef]

33. Wu, Y.P.; Rahm, E.; Holze, R. Carbon Anode Materials for Lithium Ion Batteries. J. Power Sources 2003, 114, 228-236. [CrossRef]

34. Wang, Y.; He, P.; Zhou, H. A lithium-air capacitor-battery based on a hybrid electrolyte. Energy Environ. Sci. 2011, 4, 4994-4999. [CrossRef]

35. Xu, K. Nonaqueous Liquid Electrolytes for Lithium-Based Rechargeable Batteries. Chem. Rev. 2004, 104, 4303-4417. [CrossRef]

36. Malik, R.; Burch, D.; Bazant, M.; Ceder, G. Particle size dependence of the ionic diffusivity. Nano Lett. 2010, 10, 4123-4127. [CrossRef]

37. Poizot, P.; Laruelle, S.; Grugeon, S.; Dupont, L.; Tarascon, J.M. Nanosized transition-metal oxides as negative-electrode materials for lithium-ion batteries. Nature 2000, 407, 496-499. [CrossRef]

38. Bekaert, E.; Balaya, P.; Murugavel, S.; Maier, J.; Ménétrier, M. 6Li MAS NMR investigation of electrochemical lithiation of $\mathrm{RuO}_{2}$ : Evidence for an interfacial storage mechanism. Chem. Mater. 2009, 21, 856-861. [CrossRef]

39. Chandler, J.H.; Head, D.A.; Hubbard, M.E.; Neville, A.; Jayne, D.G.; Culmer, P.R. The impact of electrode resistance on the biogalvanic characterization technique. Physiol. Meas. 2017, 38, 101-115. [CrossRef]

40. Evans, J.W. Introduction and the Significance of Electrometallurgy. Ref. Module Mater. Sci. Mater. Eng. 2016, 1-13. [CrossRef]

41. da Silva, S.P.; da Silva, P.R.C. Alexandre Urbano e Jair Scarminio, Analysis of A Commercial Portable Lithium-Ion Battery Under Low Current Charge-discharge Cycles, Quim. Nova 2016, 39, 901-905. [CrossRef]

42. Zhang, H.; Zhao, H.; Khan, M.A.; Zou, W.; Xu, J.; Zhang, L.; Zhang, J. Recent progress in advanced electrode materials, separators and electrolytes for lithium batteries. J. Mater. Chem. A 2018, 6, 20564-20620. [CrossRef]

43. He, Y.; Matthews, B.; Wang, J.; Song, L.; Wang, X.; Wu, G. Innovation and challenges in materials design for flexible rechargeable batteries: From 1D to 3D. J. Mater. Chem. A 2018, 6, 735-753. [CrossRef]

44. Nitta, N.; Wu, F.; Lee, J.T.; Yushin, G. Li-ion battery materials: Present and future. Mater. Today 2015, 18, 252-264. [CrossRef]

45. Galushkin, N.E.; Yazvinskaya, N.N.; Galushkin, D.N. Mechanism of thermal runaway in lithium-ion cells. J. Electrochem. Soc. 2018, 165, A1303-A1308. [CrossRef]

46. Cabana, J.; Valdés-Solís, T.; Palacín, M.R.; Oró-Solé, J.; Fuertes, A.; Marbán, G.; Fuertes, A.B. Enhanced high rate performance of $\mathrm{LiMn}_{2} \mathrm{O}_{4}$ spinel nanoparticles synthesized by a hard-template route. J. Power Sources 2007, 166, 492-498. [CrossRef]

47. Jiang, C.; Hosono, E.; Zhou, H. Nanomaterials for lithium ion batteries. Nano Today 2006, 1, 28-33. [CrossRef]

48. Liu, X.H.; Zhong, L.; Huang, S.; Mao, S.X.; Zhu, T.; Huang, J.Y. Size-Dependent Fracture of Silicon Nanoparticles During Lithiation. ACS Nano 2012, 6, 1522-1531. [CrossRef]

49. Sankarasubramanian, S.; Krishnamurthy, B. A capacity fade model for lithium ion batteries including diffusion and kinetics. Electrochim. Acta 2012, 70, 248-254. [CrossRef]

50. Lüder, J.; Legrain, F.; Chen, Y.; Manzhos, S. Doping of active electrode materials for electrochemical batteries: An electronic structure perspective. MRS Commun. 2017, 7, 523-540. [CrossRef]

51. Wang, Y.; Li, H.; He, P. Eiji Hosonoa and Haoshen Zhou, Nano active materials for lithium-ion batteries. Nanoscale 2010, 2, 1294-1305. [CrossRef]

52. Wang, X.; Liu, D.; Weng, Q.; Liu, J.; Liang, Q.; Zhang, C. Cu/Li4Ti5O12 scaffolds as superior anodes for lithium-ion batteries. NPG Asia Mater. 2015, 7, 1-7. [CrossRef]

53. Courtel, F.M.; Duncan, H.; Abu-Lebdeh, Y.; Davidson, I.J. High capacity anode materials for Li-ion batteries based on spinel metal oxides $\mathrm{AMn}_{2} \mathrm{O}_{4}(\mathrm{~A}=\mathrm{Co}, \mathrm{Ni}$, and Zn). J. Mater. Chem. 2011, 21, 10206-10218. [CrossRef]

54. Khalajhedayati, A.; Pan, Z.; Rupert, T.J. Manipulating the interfacial structure of nanomaterials to achieve a unique combination of strength and ductility. Nat. Commun. 2016, 7, 1-8. [CrossRef]

55. Zhang, H.; Mao, C.; Li, J.; Chen, R. Advances in electrode materials for Li-based rechargeable batteries. RSC Adv. 2017, 7, 33789-33811. [CrossRef] 
56. Yu, Z.; Tetard, L.; Zhai, L.; Thomas, J. Supercapacitor electrode materials: Nanostructures from 0 to 3 dimensions. Energy Environ. Sci. 2015, 8, 702-730. [CrossRef]

57. Okubo, M.; Hosono, E.; Kim, J.; Enomoto, M.; Kojima, N.; Kudo, T.; Zhou, H.; Honma, I. Nanosize effect on high-rate Li-ion intercalation in $\mathrm{LiCoO}_{2}$ electrode. J. Am. Chem. Soc. 2007, 129, 7444-7452. [CrossRef]

58. Uchlyama, H.; Hosono, E.; Honma, I.; Zhou, H.; Imai, H. A nanoscale meshed electrode of single-crystalline SnO for lithium-ion rechargeable batteries. Electrochem. Commun. 2008, 10, 52-55. [CrossRef]

59. Robertson, A.D.; Robert Armstrong, A.; Bruce, P.G. Layered LixMn1-yCoyO ${ }_{2}$ intercalation electrodes influence of ion exchange on capacity and structure upon cycling. Chem. Mater. 2001, 13, 2380-2386. [CrossRef]

60. Fan, Y.; Zhang, Q.; Xiao, Q.; Wang, X.; Huang, K. High-performance lithium ion battery anodes based on carbon nanotube-silicon core-shell nanowires with controlled morphology. Carbon 2013, 59, $264-269$. [CrossRef]

61. Cheng, L.; Liu, H.J.; Zhang, J.J.; Xiong, H.M.; Xia, Y.Y. Nanosized $\mathrm{Li}_{4} \mathrm{Ti}_{5} \mathrm{O}_{12}$ Prepared by Molten Salt Method as an Electrode Material for Hybrid Electrochemical Supercapacitors. J. Electrochem. Soc. 2006, 153, A1472-A1477. [CrossRef]

62. Zukalova, M.; Prochazka, J.; Zukal, A.; Yum, J.H.; Kavan, L.; Graetzel, M. Organized Mesoporous TiO2 Films Stabilized by Phosphorus: Application for Dye-Sensitized Solar Cells. J. Electrochem. Soc. 2010, 157, H99-H103. [CrossRef]

63. Guo, Y.G.; Hu, J.S.; Wan, L.J. Nanostructured Materials for Electrochemical Energy Conversion and Storage Devices. Adv. Mater. 2008, 20, 2878. [CrossRef]

64. Liu, N.; Lu, Z.; Zhao, J.; McDowell, M.T.; Lee, H.-W.; Zhao, W.; Cui, Y. A pomegranate-inspired nanoscale design for large-volume-change lithium battery anodes. Nat. Nanotech. 2014, 9, 187-192. [CrossRef] [PubMed]

65. Nagamine, K.; Oh-Ishi, K.; Honma, T.; Komatsu, T. Formation mechanism of $\mathrm{LiFePO}_{4}$ in crystallization of lithium iron phosphate glass particles. J. Ceram. Soc. Jpn. 2012, 120, 193-198. [CrossRef]

66. Sun, Y.K.; Chen, Z.; Noh, H.-J.; Lee, D.-J.; Jung, H.-G.; Ren, Y.; Wang, S.; Yoon, C.S.; Myung, S.-T.; Amine, K. Nanostructured high-energy cathode materials for advanced lithium batteries. Nat. Mater. 2012, 11, 942-947. [CrossRef] [PubMed]

67. Oh, S.W.; Myung, S.; Oh, S.; Oh, K.H.; Amine, K.; Scrosati, B.; Sun, Y. Double carbon coating of $\mathrm{LiFePO}_{4}$ as high rate electrode for rechargeable lithium batteries. Adv. Mater. 2010, 22, 4842-4845. [CrossRef] [PubMed]

68. Lin, D.; Lu, Z.; Hsu, P.-C.; Lee, H.R.; Liu, N.; Zhao, J.; Wang, H.; Liu, C.; Cui, Y. A high tap density secondary silicon particle anode fabricated by scalable mechanical pressing for lithium-ion batteries. Energy Environ. Sci. 2015, 8, 2371-2376. [CrossRef]

69. Choi, N.S.; Chen, Z.; Freunberger, S.A.; Ji, X.; Sun, Y.K.; Amine, K.; Yushin, G.; Nazar, L.F.; Cho, J.; Bruce, P.G. Challenges facing lithium batteries and electrical double-layer capacitors. Angew. Chem. Int. Ed. Engl. 2012, 51, 9994-10024. [CrossRef]

70. Zhao, Y.; Wang, L.P.; Sougrati, M.T.; Feng, Z.; Leconte, Y.; Fisher, A.; Srinivasan, M.; Xu, Z. A Review on Design Strategies for Carbon Based Metal Oxides and Sulfides Nanocomposites for High Performance Li and Na Ion Battery Anodes. Adv. Energy Mater. 2017, 1601424. [CrossRef]

71. Yazami, R.; Touzain, P. A reversible graphite-lithium negative electrode for electrochemical generators. J. Power Sources 1983, 9, 365-371. [CrossRef]

72. Brandt, K. Historical development of secondary lithium batteries. Solid State Ionics 1994, 69, $173-183$. [CrossRef]

73. Iijima, S. Helical microtubules of graphitic carbon. Nature 1991, 354, 56-58. [CrossRef]

74. Hassoun, J.; Bonaccorso, F.; Agostini, M.; Angelucci, M.; Betti, M.G.; Cingolani, R.; Scrosati, B. An advanced lithium-ion battery based on a graphene anode and a lithium iron phosphate cathode. Nano Lett. 2014, 14, 4901-4906. [CrossRef]

75. Faraji, S.; Yildiz, O.; Rost, C.; Stano, K.; Farahbakhsh, N.; Zhu, Y.; Bradford, P.D. Radial growth of multi-walled carbon nanotubes in aligned sheets through cyclic carbon deposition and graphitization. Carbon 2017, 111, 411-418. [CrossRef]

76. Zhao, J.; Wei, L.; Yang, Z.; Zhang, Y. Continuous and low-cost synthesis of high-quality multi-walled carbon nanotubes by arc discharge in air. Phys. E Low-Dimens. Syst. Nanostruct. 2012, 44, 1639-1643. [CrossRef]

77. Faraji, S.; Stano, K.; Rost, C.; Maria, J.P.; Zhu, Y.; Bradford, P.D. Structural annealing of carbon coated aligned multi-walled carbon nanotube sheets. Carbon 2014, 79, 113-122. [CrossRef] 
78. Nakayama, A.; Numao, S.; Nakano, S.; Bandow, S.; Iijima, S. In-situ observation of structural change in MWCNTs under high-pressure $\mathrm{H}_{2}$ gas atmosphere. Diam. Relat. Mater. 2008, 17, 548-551. [CrossRef]

79. Bachtold, A.; Strunk, C.; Salvetat, J.P.; Bonard, J.M.; Forró, L.; Nussbaumer, T.; Schönenberger, C. Aharonov-Bohm oscillations in carbon nanotubes. Nature 1999, 397, 673-675. [CrossRef]

80. Koh, W.; Choi, J.I.; Donaher, K.; Lee, S.G.; Jang, S.S. Mechanism of Li adsorption on carbon nanotube-fullerene hybrid system: A first-principles study. ACS Appl. Mater. Interfaces 2011, 3, 1186-1194. [CrossRef]

81. Shen, J.M.; Xu, L.; Liu, Y.G.; Lu, C.L.; Hou, W.H.; Zhu, J.J. Wet chemistry self-seeded surface-deposition process toward amorphous carbon nanotubes and their electrochemical application. Chem. Mater. 2008, 20, 3034-3041. [CrossRef]

82. Zhou, J.; Song, H.; Fu, B.; Wu, B.; Chen, X. Synthesis and high-rate capability of quadrangular carbon nanotubes with one open end as anode materials for lithium-ion batteries. J. Mater. Chem. 2010, 20, 2794-2800. [CrossRef]

83. Chen, J.; Zhao, J.; Minett, A.; Liu, Y.; Crean, C.; Liu, H.K.; Wallace, G. Carbon nanotube network modified carbon fiber paper for Li-ion batteries. Energy Environ. Sci. 2009, 2, 393-396. [CrossRef]

84. Leitner, K.; Lerf, A.; Winter, M.; Besenhard, J.O.; Villar-Rodil, S.; Suárez-García, F.; Martínez-Alonso, A.; Tascón, J.M.D. Nomex-derived activated carbon fibers as electrode materials in carbon-based supercapacitors. J. Power Sources 2006, 153, 419-423. [CrossRef]

85. Nga, S.H.; Wang, J.; Guo, Z.P.; Chen, J.; Wang, G.X.; Liu, H.K. Single wall carbon nanotube paper as anode for lithium-ion battery. Electrochim. Acta 2005, 51, 23-28. [CrossRef]

86. Wang, Y.; Wu, M.; Jiao, Z.; Lee, J.Y. Sn@CNT and Sn@C@CNT nanostructures for superior reversible lithium ion storage. Chem. Mater. 2009, 21, 3210-3215. [CrossRef]

87. Maurin, G.; Bousquet, C.; Henn, F.; Bernier, P.; Almairac, R.; Simon, B. Electrochemical intercalation of lithium into multiwalledcarbon nanotubes. Chem. Phys. Lett. 1999, 312, 14-18. [CrossRef]

88. Maurin, G.; Bousquet, C.; Henn, F.; Bernier, P.; Almairac, R.; Simon, B. Electrochemical lithium interrelation into multiwalledcarbon nanotubes. Solid State Ionics 2000, 136-137, 1295-1299. [CrossRef]

89. Gao, B.; Kleinhammes, A.; Tang, X.P.; Bower, C.; Fleming, L.; Wu, Y.; Zhou, O. Electrochemical intercalation of single-walled carbon nanotubes with lithium. Chem. Phys. Lett. 1999, 307, 153-157. [CrossRef]

90. Leroux, F.; Méténier, K.; Gautier, S.; Frackowiak, E.; Bonnamy, S.; Béguin, F. Electrochemical insertion of lithium in catalytic multiwalled carbon nanotubes. J. Power Sources 1999, 81-82, 317-322. [CrossRef]

91. Yang, Z.; Wu, H.Q.; Simard, B. Charge-discharge characteristics of raw acid-oxidized carbon nanotubes. Electrochem. Commun. 2002, 4, 574-578. [CrossRef]

92. Pierard, N.; Fonseca, A.; Konya, Z.; Willems, I.; van Tendeloo, G.; Nagy, J.B. Production of short carbon nanotubes with open tips by ball milling. Chem. Phys. Lett. 2001, 335, 1-8. [CrossRef]

93. Xing, W.; Dunlap, R.; Dahn, J. Studies of lithium insertion in ball milled sugar carbons. J. Electrochem. Soc. 1998, 145, 62-70. [CrossRef]

94. Disma, F.; Aymard, L.; Dupont, L.; Tarascon, J. Effect of mechanical grinding on the lithium intercalation process in graphites and soft carbons. J. Electrochem. Soc. 1996, 143, 3959-3972. [CrossRef]

95. Frackowiak, E.; Gautier, S.; Gaucher, H.; Bonnamy, S.; Beguin, F. Electrochemical storage of lithium multiwalled carbon nanotubes. Carbon 1999, 37, 61-69. [CrossRef]

96. Li, M.; Wu, Y.; Zhao, F.; Wei, Y.; Wang, J.; Jiang, K.; Fan, S. Cycle and rate performance of chemically modified super-aligned carbon nanotube electrodes for lithium ion batteries. Carbon 2014, 69, 444-451. [CrossRef]

97. Gao, B.; Bower, C.; Lorentzen, J.D.; Fleming, L.; Kleinhammes, A.; Tang, X.P.; McNeil, L.E.; Wu, Y.; Zhou, O. Enhanced saturation lithium composition in ball-milled single-walled carbon nanotubes. Chem. Phys. Lett. 2000, 327, 69-75. [CrossRef]

98. Yang, S.; Huo, J.; Song, H.; Chen, X. A comparative study of electrochemical properties of two kinds of carbon nanotubes as anode materials for lithium ion batteries. Electrochim. Acta 2008, 53, 2238-2244. [CrossRef]

99. Wang, X.X.; Wang, J.N.; Su, L.F. Preparation and electrochemical performance of ultra-short carbon nanotubes. J. Power Sources 2009, 186, 194-200. [CrossRef]

100. Mi, C.H.; Cao, G.S.; Zhao, X.B. A nonGIC mechanism of lithium storage in chemical etched MWNTs. J. Electroanal. Chem. 2004, 562, 217-221. [CrossRef]

101. Eom, J.Y.; Kwon, H.S.; Liu, J.; Zhou, O. Lithium insertion into purified and etched multiwalled carbon nanotubes synthesized on supported catalysts by thermal CVD. Carbon 2004, 42, 2589-2596. [CrossRef] 
102. Maurin, G.; Henn, F.; Simon, B.; Colomer, J.F.; Nag, J.B. Lithium doping of multiwalled carbon nanotubes produced by catalytic decomposition. Nano Lett. 2001, 1, 75-79. [CrossRef]

103. Li, X.; Gu, H.; Liu, J.; Wei, H.; Qiu, S.; Fu, Y.; Lv, H.; Lu, G.; Wang, Y.; Guo, Z. Multiwalled carbon nanotubes composited with nanomagnetite for anodes in lithium ion batteries. RSC Adv. 2015, 5, 7237-7244. [CrossRef]

104. Yang, Z.H.; Wu, H.Q. Electrochemical intercalation of lithium into carbon nanotubes. Solid State Ionics 2001, 143, 173-180. [CrossRef]

105. Yang, Z.H.; Wu, H.Q. Electrochemical intercalation of lithium into raw carbon nanotubes. Mater. Chem. Phys. 2001, 71, 7-11. [CrossRef]

106. Wu, G.T.; Wang, C.S.; Zhang, X.B.; Yang, H.S.; Qi, Z.F.; He, P.M.; Li, W.Z. Structure and lithium insertion properties of carbon nanotubes. J. Electrochem. Soc. 1999, 146, 1696-1701. [CrossRef]

107. Wu, G.T.; Wang, C.S.; Zhang, X.B.; Yang, H.S.; Qi, Z.F.; Li, W.Z. Lithium insertion into CuO/carbon nanotubes. J. Power Sources 1998, 75, 175-179. [CrossRef]

108. Che, G.L.; Lakshmi, B.B.; Fisher, E.R.; Martin, C.R. Carbon nanotubule membranes for electrochemical energy storage and production. Nature 1998, 393, 346-349. [CrossRef]

109. Mukhopadhyay, I.; Hoshino, N.; Kawasaki, S.; Okino, F.; Hsu, W.K.; Touhara, H. Electrochemical Li insertion in B-doped multiwalledcarbon nanotubes. J. Electrochem. Soc. 2002, 149, A39-A44. [CrossRef]

110. Lee, R.S.; Kim, H.J.; Fischer, J.E.; Thess, A.; Smalley, R.E. Conductivity enhancement in single-walled carbon nanotube bundles doped with $\mathrm{K}$ and Br. Nature 1997, 388, 255-257. [CrossRef]

111. Claye, A.; Fischer, J.E.; Metrot, A. Kinetics of alkali insertion in single-wall carbon nanotubes: An electrochemical impedance spectroscopy study. Chem. Phys. Lett. 2000, 330, 61-67. [CrossRef]

112. Claye, A.; Rahman, S.; Fischer, J.E.; Sirenko, A.; Sumanasekera, G.U.; Eklund, P.C. In situ Raman scattering studies of alkali-doped single-wall carbon nanotubes. Chem. Phys. Lett. 2001, 333, 16-22. [CrossRef]

113. Cao, K.; Jin, T.; Yang, L.; Jiao, L. Recent progress in conversion reaction metal oxide anodes for Li-ion batteries. Mater. Chem. Front. 2017, 1, 2213-2242. [CrossRef]

114. Ko, S.; Lee, J.I.; Yang, H.S.; Park, S.; Jeong, U. Mesoporous CuO particles threaded with CNTs for high-performance lithium-ion battery anodes. Adv. Mater. 2012, 24, 4451-4456. [CrossRef]

115. Yang, Z.; Li, Z.; Wu, H.; Simard, B. Effects of doped copper on electrochemical performance of the raw carbon nanotubes anode. Mater. Lett. 2003, 57, 3160-3166. [CrossRef]

116. Winter, M.; Besenhard, J.O. Electrochemical lithiation of tin and tin-based intermetallics and composites. Electrochim. Acta 1999, 45, 31-50. [CrossRef]

117. Chen, W.X.; Lee, J.Y.; Liu, Z. The nanocomposites of carbon nanotube with $\mathrm{Sb}$ and $\mathrm{SnSb}_{0.5}$ as Li-ion battery anodes. Carbon 2003, 41, 959-966. [CrossRef]

118. Guo, Z.P.; Zhao, Z.W.; Liu, H.K.; Dou, S.X. Electrochemical lithiation and de-lithiation of MWNT-Sn/SnNi nanocomposites. Carbon 2005, 43, 1392-1399. [CrossRef]

119. Eom, J.Y.; Park, J.W.; Kwon, H.S.; Rajendran, S. Electrochemical insertion of lithium into multiwalled carbon nanotube/silicon composites produced by ball milling. J. Electrochem. Soc. 2006, 153, A1678-A1684. [CrossRef]

120. Xie, J.; Varadan, V.K. Synthesis and characterization of high surface area tin oxide/functionalized carbon nanotubes composite as anode materials. Mater. Chem. Phys. 2005, 91, 274-280. [CrossRef]

121. Yang, S.; Song, H.; Yi, H.; Liu, W.; Zhang, H.; Chen, X. Carbon nanotube capsules encapsulating $\mathrm{SnO}_{2}$ nanoparticles as an anode material for lithium ion batteries. Electrochim. Acta 2009, 55, 521-527. [CrossRef]

122. Shu, J.; Li, H.; Yang, R.Z.; Shi, Y.; Huang, X.J. Cage-like carbon nanotubes/Si composite as anode material for lithium ion batteries. Electrochem. Commun. 2006, 8, 51-54. [CrossRef]

123. Dai, J.X.; Li, S.F.Y.; Siow, K.S.; Gao, Z.Q. Synthesis and characterization of the hollandite-type $\mathrm{MnO}_{2}$ as a cathode material in lithium batteries. Electrochim. Acta 2000, 45, 2211-2217. [CrossRef]

124. Wu, M.S.; Chiang, P.C. Synthesis of manganese oxide electrodes with interconnected nanowire structure as an anode material for rechargeable lithium ion batteries. J. Phys. Chem. B 2005, 109, 23279-23284. [CrossRef] [PubMed]

125. Jin, X.B.; Zhou, W.Z.; Zhang, S.W.; Chen, G.Z. Nanoscale microelectrochemical cells on carbon nanotubes. Small 2007, 3, 1513-1517. [CrossRef] [PubMed]

126. Reddy, A.L.M.; Shaijumon, M.M.; Gowda, S.R.; Ajayan, P.M. Coaxial $\mathrm{MnO}_{2} /$ carbon nanotube array electrodes for high-performance lithium batteries. Nano Lett. 2009, 9, 1002-1006. [CrossRef] [PubMed] 
127. Xia, H.; Lai, M.; Lu, L. Nanoflaky $\mathrm{MnO}_{2}$ /carbon nanotube nanocomposites as anode materials for lithium-ion batteries. J. Mater. Chem. 2010, 20, 6896-6902. [CrossRef]

128. Yoon, S.H.; Park, C.W.; Yang, H.; Korai, Y.; Mochida, I.; Baker, R.T.K.; Rodriguez, N.M. Novel carbon nanofibers of high graphitization as anodic materials for lithium ion secondary batteries. Carbon 2004, 42, 21-32. [CrossRef]

129. Wang, T.; Shi, S.; Li, Y.; Zhao, M.; Chang, X.; Wu, D.; Wang, H.; Peng, L.; Wang, P.; Yang, G. Study of microstructure change of carbon nanofibers as binder-free anode for high-performance lithium-ion batteries. ACS Appl. Mater. Interfaces 2016, 8, 33091-33101. [CrossRef] [PubMed]

130. Yuan, X.; Chao, Y.J.; Ma, Z.F.; Deng, X. Preparation and characterization of carbon xerogel (CX) and CX-SiO composite as anode material for lithium-ion battery. Electrochem. Commun. 2007, 9, 2591-2595. [CrossRef]

131. Wu, X.L.; Liu, Q.; Guo, Y.G.; Song, W.G. Superior storage performance of carbon nano springs as anode materials for lithium-ion batteries. Electrochem. Commun. 2009, 11, 1468-1471. [CrossRef]

132. Shao, J.; Zhang, J.; Jiang, J.; Zhou, G.; Qu, M. $\alpha-\mathrm{Fe}_{2} \mathrm{O}_{3} @ \mathrm{CNSs}$ nanocomposites as superior anode materials for lithium-ion batteries. Electrochim. Acta 2011, 56, 7005-7011. [CrossRef]

133. Yang, Z.; Ren, J.; Zhang, Z.; Chen, X.; Guan, G.; Quiu, L.; Zhang, Y.; Peng, H. Recent advancement of nanostructured carbon for energy applications. Chem. Rev. 2015, 115, 5159-5223. [CrossRef] [PubMed]

134. Raccichini, R.; Varzi, A.; Passerini, S.; Scrosati, B. The role of graphene for electrochemical energy storage. Nat. Mater. 2015, 14, 271. [CrossRef] [PubMed]

135. Chen, K.; Song, S.; Liu, F.; Xue, D. Structural design of graphene for use in electrochemical energy storage devices. Chem. Soc. Rev. 2015, 44, 6230-6257. [CrossRef] [PubMed]

136. de las Casas, C.; Li, W.-Z. A review of application of carbon nanotubes for lithium ion battery anode material. J. Power Sources 2012, 208, 74-85. [CrossRef]

137. Wang, G.; Leng, X.; Han, S.; Shao, Y.; Wei, S.; Liu, Y.; Lian, J.; Jiang, Q. How to improve the stability and rate performance of lithium-ion batteries with transition metal oxide anodes. J. Mater. Res. 2017, 32, 16-36. [CrossRef]

138. Li, X.; Zhi, L. Graphene hybridization for energy storage applications. Chem. Soc. Rev. 2018, 47, 3189-3216. [CrossRef] [PubMed]

139. Gerouki, A.; Goldner, M.A.; Goldner, R.B.; Haas, T.E.; Liu, T.Y.; Slaven, S. Density of States Calculations of Small Diameter Single Graphene Sheets. J. Electrochem. Soc. 1996, 143, L262-L263. [CrossRef]

140. Yoo, E.J.; Kim, J.; Hosono, E.; Zhou, H.-S.; Kudo, T.; Honma, I. Large reversible Li storage of graphene nanosheet families for use in rechargeable lithium ion batteries. Nano Lett. 2008, 8, 2277-2282. [CrossRef]

141. Lee, W.S.V.; Peng, E.; Loh, T.A.J.; Huang, X.; Xue, J.M. Few-layer $\mathrm{MoS}_{2}$-anchored graphene aerogel paper for self-supported electrode materials. Nanoscale 2016, 8, 8042-8047. [CrossRef]

142. Jiang, L.; Lin, B.; Li, X.; Song, X.; Xia, H.; Li, L.; Zeng, H. Monolayer MoS2-graphene hybrid aerogels with controllable porosity for lithium-ion batteries with high reversible capacity. ACS Appl. Mater. Interfaces 2016, 8, 2680-2687. [CrossRef]

143. He, J.; Li, P.; Lv, W.; Wen, K.; Chen, Y.; Zhang, W.; Li, Y.; Qin, W.; He, W. Three-dimensional hierarchically structured aerogels constructed with layered $\mathrm{MoS}_{2}$ /graphene nanoparticles as self-supported anodes for high-performance lithium ion batteries. Electrochim. Acta 2016, 215, 12-18. [CrossRef]

144. Wang, J.; Liu, J.; Luo, J.; Liang, P.; Chao, D.; Lai, L.; Lin, J.; Shen, Z. MoS 2 architectures supported on graphene foam/carbon nanotube hybrid films: Highly integrated frameworks with ideal contact for superior lithium storage. J. Mater. Chem. A 2015, 3, 17534-17543. [CrossRef]

145. Zhang, L.; Fan, W.; Liu, T. A flexible self-supported defect-rich $\mathrm{MoS}_{2} /$ graphene/carbon nanotube hybrid paper as a binder-free anode for high-performance lithium ion batteries. RSC Adv. 2015, 5, 43130-43140. [CrossRef]

146. Wang, C.; Wan, W.; Huang, Y.; Chen, J.; Zhou, H.H.; Zhang, X.X. Hierarchical MoS $_{2}$ nanosheet/active carbon fiber cloth as a binder-free and self-supported anode for lithium-ion batteries. Nanoscale 2014, 6, 5351-5358. [CrossRef] [PubMed]

147. Wu, M.; Zhan, J.; Wu, K.; Li, Z.; Wang, L.; Geng, B.; Wang, L.; Pan, D. Metallic 1T MoS 2 nanosheet arrays were vertically grown on activated carbon fiber cloth for enhanced Li-ion storage performance. J. Mater. Chem. A 2017, 5, 14061-14069. [CrossRef]

148. Johansson, B. Security aspects of future renewable energy systems a short overview. Energy 2013, 61, 598-605. [CrossRef] 
149. Zhu, J.; Zhu, T.; Zhou, X.; Zhang, Y.; Lou, X.W.; Chen, X.; Zhang, H.; Hng, H.H.; Yan, Q. Facile synthesis of metal oxide/reduced graphene oxide hybrids with high lithium storage capacity and stable cyclability. Nanoscale 2011, 3, 1084-1089. [CrossRef]

150. Goriparti, S.; Miele, E.; Angelis, F.D.; Fabrizio, E.D.; Zaccaria, R.P.; Capiglia, C. Review on recent progress of nanostructured anode materials for Li-ion batteries. J. Power Sources 2014, 257, 421-443. [CrossRef]

151. Yu, S.-H.; Feng, X.; Zhang, N.; Seok, J.; Abruña, H.D. Understanding Conversion-Type Electrodes for Lithium Rechargeable Batteries. Acc Chem. Res. 2018, 51, 273-281. [CrossRef]

152. Wen, W.; Wu, J.M.; Jiang, Y.Z.; Lai, L.L.; Song, J. Pseudocapacitance-enhanced Li-ion microbatteries derived by a TiN@ $\mathrm{TiO}_{2}$ nanowire anode. Chem 2017, 2, 404-416. [CrossRef]

153. Huang, H.; Gao, S.; Wu, A.M.; Cheng, K.; Li, X.N.; Gao, X.X.; Zhao, J.J.; Dong, X.L.; Cao, G.Z. Fe 3 N constrained inside $\mathrm{C}$ nanocages as an anode for Li-ion batteries through post-synthesis nitridation. Nano Energy 2017, 31, 74-83. [CrossRef]

154. Zhang, G.; Xiao, X.; Li, B.; Gu, P.; Xue, H.; Pang, H. Transition metal oxides with one-dimensional/ one-dimensional-analog nanostructures for advanced supercapacitors. J. Mater. Chem. A 2017, 5, 8155-8186. [CrossRef]

155. Peng, L.; Xiong, P.; Ma, L.; Yuan, Y.; Zhu, Y.; Chen, D.; Luo, X.; Lu, J.; Amine, K.; Yu, G. Holey two-dimensional transition metal oxide nanosheets for efficient energy storage. Nat. Commun. 2017, 8, 1-10. [CrossRef]

156. Zhang, Y.; Li, L.; Su, H.; Huang, W.; Dong, X. Binary metal oxide: Advanced energy storage materials in supercapacitors. J. Mater. Chem. A 2015, 3, 43-59. [CrossRef]

157. Majeed, A.; Ullah, W.; Anwar, A.W.; Nasreen, F.; Sharif, A.; Mustafa, G.; Khan, A. Graphene-metal oxides/hydroxide nanocomposite materials: Fabrication advancements and supercapacitive performance. J. Alloys Compd. 2016, 671, 1-10. [CrossRef]

158. Bharathidasan, P.; Kim, D.W.; Devaraj, S.; Sivakumar, S.R. Supercapacitive characteristics of carbon-based graphene composites. Electrochim. Acta 2016, 204, 146-153. [CrossRef]

159. Wu, Z.; Li, L.; Yan, J.; Zhang, X. Materials design and system construction for conventional and new-concept supercapacitors. Adv. Sci. 2017, 4, 1600382. [CrossRef]

160. Cheng, Q.; Okamoto, Y.; Tamura, N.; Tsuji, M.; Maruyama, S.; Matsuo, Y. Graphene-like-graphite as fast chargeable and high-capacity anode materials for lithium ion batteries. Sci. Rep. 2017, 7, 14782. [CrossRef]

161. Fong, R.; von Sacken, U.; Dahn, J.R. Studies of Lithium Intercalation into Carbons Using Nonaqueous Electrochemical Cells. J. Electrochem. Soc. 1990, 137, 2009-2013. [CrossRef]

162. Wang, G.; Shen, X.; Yao, J.; Park, J. Graphene nanosheets for enhanced lithium storage in lithium ion batteries. J. Carbon 2009, 47, 2049-2053. [CrossRef]

163. Lin, J.; Peng, Z.; Xiang, C.; Ruan, G.; Yan, Z.; Natelson, D.; Tour, J.M. Graphene Nanoribbon and Nanostructured $\mathrm{SnO}_{2}$ Composite Anodes for Lithium Ion Batteries. J. ACS Nano 2013, 7, 6001-6006. [CrossRef] [PubMed]

164. Rehman, W.u.; Xu, Y.; Sun, X.; Ullah, I.; Zhang, Y.; Li, L. Bouquet-like Mn2SnO4 nanocomposite engineered with graphene sheets as an advance lithium-ion battery anode. ACS Appl. Mater. Interfaces 2018, 10, 17963-17972. [CrossRef] [PubMed]

165. Song, Y.; Cao, Y.; Wang, J.; Zhou, Y.N.; Fang, F.; Li, Y.; Gao, S.P.; Gu, Q.F.; Hu, L.; Sun, D. Bottom-up Approach Design, Band Structure, and Lithium Storage Properties of Atomically Thin $\gamma$-FeOOH Nanosheets. ACS Appl. Mater. Interfaces 2016, 8, 21334-21342. [CrossRef]

166. Wang, J.; Polleux, J.; Lim, J.; Dunn, B. Pseudocapacitive Contributions to Electrochemical Energy Storage in $\mathrm{TiO}_{2}$ (Anatase) Nanoparticles. J. Phys. Chem. C 2007, 111, 14925-14931. [CrossRef]

167. Qi, H.; Cao, L.; Li, J.; Huang, J.; Xu, Z.; Cheng, Y.; Kong, X.; Yanagisawa, K. High pseudocapacitance in $\mathrm{FeOOH} / \mathrm{rGO}$ composites with superior performance for high rate anode in Li-ion battery. ACS Appl. Mater. Interfaces 2016, 8, 35253-35263. [CrossRef] [PubMed]

168. Medvedev, A.G.; Mikhaylov, A.A.; Grishanov, D.A.; Yu, D.Y.W.; Gun, J.; Sladkevich, S.; Lev, O.; Prikhodchenko, P.V. $\mathrm{GeO}_{2}$ thin film deposition on graphene oxide by the hydrogen peroxide route: Evaluation for lithium ion battery anode. ACS Appl. Mater. 2017, 9, 9152-9160. [CrossRef]

169. Wu, Z.-S.; Ren, W.; Xu, L.; Li, F.; Cheng, H.-M. Doped Graphene Sheets As Anode Materials with Superhigh Rate and Large Capacity for Lithium Ion Batteries. ACS Nano 2011, 5, 5463-5471. [CrossRef] [PubMed]

170. Geim, A.K.; Novoselov, K.S. The rise of graphene. Nat. Mater. 2007, 6, 183-191. [CrossRef] 
171. Wang, S.; Yang, B.; Chen, H.; Ruckenstein, E. Reconfiguring graphene for high-performance metal-ion battery anodes. Energy Storage Mater. 2019, 16, 619-624. [CrossRef]

172. Al-Hassan, M.R.; Sen, A.; Zaman, T.; Mostari, M.S. Emergence of graphene as a promising anode material for rechargeable batteries: A review. Mater. Today Chem. 2019, 11, 225-243. [CrossRef]

173. Dong, Y.; Wu, Z.-S.; Ren, W.; Cheng, H.M.; Bao, X. Graphene: A promising 2D material for electrochemical energy storage. Sci. Bull. 2017, 62, 724-740. [CrossRef]

174. Wang, Y.; Zhang, H.J.; Lu, L.; Stubbs, L.P.; Wong, C.C.; Lin, J. Designed Functional Systems from Peapod-Like Co@Carbon to $\mathrm{Co}_{3} \mathrm{O}_{4} @$ Carbon Nanocomposites. ACS Nano 2010, 4, 4753-4761. [CrossRef]

175. Agostini, M.; Brutti, S.; Hassoun, J. High voltage Li-ion battery using exfoliated graphite/graphene nanosheets anode. ACS Appl. Mater. Interfaces 2016, 8, 10850-10857. [CrossRef] [PubMed]

176. Koo, B.; Xiong, H.; Slater, M.D.; Prakapenka, V.B.; Balasubramanian, M.; Podsiadlo, P.; Johnson, C.S.; Rajh, T.; Shevchenko, E.V. Hollow Iron Oxide Nanoparticles for Application in Lithium Ion Batteries. Nano Lett. 2012, 12, 2429-2435. [CrossRef] [PubMed]

177. Jiang, J.; Li, Y.Y.; Liu, J.P.; Huang, X.T.; Yuan, C.Z.; Lou, X.W. Recent Advances in Metal Oxide-Based Electrode Architecture Design for Electrochemical Energy Storage. Adv. Mater. 2012, 24, 5166-5180. [CrossRef]

178. Ding, S.J.; Zhang, D.Y.; Wu, H.B.; Zhang, Z.C.; Lou, X.W. Synthesis of MicroMicrosized SnO $_{2} @ C a r b o n$ Hollow Spheres with Enhanced Lithium Storage Properties. Nanoscale 2012, 4, 3651-3654. [CrossRef]

179. Zhang, K.; Han, P.; Gu, L.; Zhang, L.; Liu, Z.; Kong, Q.; Zhang, C.; Dong, S.; Zhang, Z.; Yao, J.; et al. Synthesis of nitrogen-doped $\mathrm{MnO} / g r a p h e n e$ nanosheets hybrid material for lithium ion batteries. ACS Appl. Mater. Interfaces 2012, 4, 658. [CrossRef]

180. Wang, J.; Zhang, C.; Jin, D.; Xie, K.; Wei, B. Synthesis of ultralong MnO/C coaxial nanowires as freestanding anodes for high-performance lithium ion batteries. J. Mater. Chem. A 2015, 3, 13699-13705. [CrossRef]

181. Zhou, X.S.; Dai, Z.H.; Liu, S.H.; Bao, J.C.; Guo, Y.G. Ultrauniform SnOx/carbon Nanohybrids toward Advanced Lithium-ion Battery Anodes. Adv. Mater. 2014, 26, 3943-3949. [CrossRef]

182. Dong, C.; Guo, L.; He, Y.; Qian, Y.; Chen, Y.; Xu, L. Sandwich-like Ni $2_{2}$ P Nanoarray/Nitrogen-Doped Graphene Nanoarchitecture as a High-Performance Anode for Sodium and Lithium Ion Batteries. Energy Storage Mater. 2018, 15, 234-241. [CrossRef]

183. Wei, X.; Tang, C.; Wang, X.; Zhou, L.; Wei, Q.; Yan, M.; Sheng, J.; Hu, P.; Wang, B.; Mai, L. Copper Silicate Hydrate Hollow Spheres Constructed by Nanotubes Encapsulated in Reduced Graphene Oxide as Long-life Lithium-ion Battery Anode. Appl. Mater. Interfaces 2015, 7, 26572-26578. [CrossRef] [PubMed]

184. Atabaki, M.M.; Kovacevic, R. Graphene Composites as Anode Materials in Lithium-Ion Batteries. Electron. Mater. Lett. 2013, 9, 133-153. [CrossRef]

185. Badway, F.; Plitz, I.; Grugeon, S.; Laruelle, S.; Dolle, M.; Gozdz, A.S.; Tarascon, J.M. Metal oxides as negative electrode materials in Li-ion cells. Electrochem Solid State Lett. 2002, 5, A115-A118. [CrossRef]

186. Cai, D.; Lian, P.; Zhu, X.; Liang, S.; Yang, W.; Wang, H. High specific capacity of $\mathrm{TiO}_{2}$-graphene nanocomposite as an anode material for lithium-ion batteries in an enlarged potential window. Electrochim. Acta 2012, 74, 65-72. [CrossRef]

187. Tung, V.C.; Allen, M.J.; Yang, Y.; Kaner, R.B. High-throughput solution processing of large-scale graphene. Nat. Nanotech. 2009, 4, 25. [CrossRef] [PubMed]

188. Su, Q.; Chang, L.; Zhang, J.; Du, G.; Xu, B. In Situ TEM Observation of the Electrochemical Process of Individual $\mathrm{CeO}_{2} /$ Graphene Anode for Lithium Ion Battery. J. Phys. Chem. C 2013, 117, 4292-4298. [CrossRef]

189. Zhou, X.S.; Yin, Y.X.; Wan, L.J.; Guo, Y.G. A Robust Composite of $\mathrm{SnO}_{2}$ Hollow Nanospheres Enwrapped by Graphene as a High-capacity Anode Material for Lithium-ion Batteries. J. Mater. Chem. 2012, 22, 17456-17459. [CrossRef]

190. Chen, Y.; Song, B.H.; Chen, R.M.; Lu, L.; Xue, J.M. A Study of the Superior Electrochemical Performance of 3 $\mathrm{nm} \mathrm{SnO}_{2}$ Nanoparticles Supported by Graphene. J. Mater. Chem. A 2014, 2, 5688-5695. [CrossRef]

191. Zhou, X.S.; Wan, L.J.; Guo, Y.G. Binding SnO2 Nanocrystals in Nitrogen-doped Graphene Sheets as Anode Materials for Lithiumilon Batteries. Adv. Mater. 2013, 25, 2152-2157. [CrossRef]

192. Arnaiza, M.; Botasa, C.; Carriazoa, D.; Mysyka, R.; Mijangosb, F.; Rojoa, T.; Ajuriaa, J.; Goikolea, E. Reduced graphene oxide decorated with $\mathrm{SnO}_{2}$ nanoparticles asnegative electrode for lithium ion capacitors. Electrochim. Acta 2018, 284, 542-550. [CrossRef] 
193. Xu, H.; Shi, L.; Wang, Z.; Liu, J.; Zhu, J.; Zhao, Y.; Zhang, M.; Yuan, S. Fluorine-Doped Tin Oxide Nanocrystal/Reduced Graphene Oxide Composites as Lithium Ion Battery Anode Material with High Capacity and Cycling Stability. ACS Appl. Mater. Interfaces 2015, 7, 27486-27493. [CrossRef]

194. Ullaha, S.; Denis, P.A.; Sato, F. Beryllium doped graphene as an efficient anode material for lithium-ion batteries with significantly huge capacity: A DFT study. Appl. Mater. Today 2017, 9, 333-340. [CrossRef]

195. Wei, M.; Wei, K.; Ichihara, M.; Zhou, H. Nb2O5 nanobelts: A lithium intercalation host with large capacity and high rate capability. Electrochem. Commun. 2008, 10, 980-983. [CrossRef]

196. Viet, A.L.; Reddy, M.V.; Jose, R.; Chowdari, B.V.R.; Ramakrishna, S. Nanostructured $\mathrm{Nb}_{2} \mathrm{O}_{5}$ Polymorphs by Electrospinning for Rechargeable Lithium Batteries. J. Phys. Chem. C 2010, 114, 664-671. [CrossRef]

197. Yan, L.; Chen, G.; Zhou, M.; Luo, H. Oxygen-deficient Niobium Oxide in Carbon Matrix as Anode for Lithium-Ion Battery. ECS Trans. 2015, 66, 277-283. [CrossRef]

198. Wu, K.; Shi, B.; Qi, L.; Mi, Y.; Zhao, B.; Yang, C.; Wang, Q.; Tang, H.; Lu, J.; Liu, W.; Zhou, H. SnO 2 uantum dots@3D sulfur-doped reduced graphene oxides as active and durable anode for lithium ion batteries. Electrochim. Acta 2018, 291, 24-30. [CrossRef]

199. Sheng, L.; Liang, S.; Wei, T.; Chang, J.; Jiang, Z.; Zhang, L.; Zhou, Q.; Zhou, J.; Jiang, L.; Fan, Z. Space-confinement of $\mathrm{MnO}$ nanosheets in densely stacked graphene: Ultra-high volumetric capacity and rate performance for lithium-ion batteries. Energy Storage Mater. 2018, 12, 94-102. [CrossRef]

200. Zhang, Y.; Chen, P.; Gao, X.; Wang, B.; Liu, H.; Wu, H.; Liu, H.; Dou, S. Nitrogen-doped graphene ribbon assembled core-sheath MnO@graphene scrolls as hierarchically ordered 3D porous electrodes for fast and durable lithium storage. Adv. Funct. Mater. 2016, 26, 7754-7765. [CrossRef]

201. Liu, J.; Chen, X.; Kim, J.; Zheng, Q.; Ning, H.; Sun, P.; Huang, X.; Liu, J.; Niu, J.; Braun, P.V. High volumetric capacity three-dimensionally sphere-caged secondary battery anodes. Nano Lett. 2016, 16, 4501-4507. [CrossRef]

202. Ju, H.S.; Hong, Y.J.; Cho, J.S.; Kang, Y.C. Strategy for yolk-shell structured metal oxide-carbon composite powders and their electrochemical properties for lithium ion batteries. Carbon 2016, 100, 137-144. [CrossRef]

203. Xiao, Z.; Ning, G.; Ma, X.; Zhao, L.; Yu, Y.; Wang, H. Hydrothermal assembly of MnO-graphene core-shell nanowires with superior anode performance. Carbon 2019, 142, 461-467. [CrossRef]

204. Liu, Q.; Xiao, B.; Cheng, J.-B.; Li, Y.-C.; Li, Q.-Z.; Li, W.-Z.; Xu, X.-F.; Yu, X.-F. Carbon Excess C3N: A Potential Candidate as Li-Ion Battery Material. ACS Appl. Mater. Interfaces 2018, 10, 37135-37141. [CrossRef] [PubMed]

205. Bhauriyal, P.; Mahata, A.; Pathak, B. Graphene-like carbon-nitride monolayer: a potential anode material for Na-and K-ion batteries. J. Phys. Chem. C 2018, 122, 2481-2489.

206. Wang, Y.; Jiao, Z.; Ma, S.; Guo, Y. Probing $\mathrm{C}_{3} \mathrm{~N} /$ Graphene heterostructures as anode materials for Li-ion batteries. J. Power Sources 2019, 413, 117-124. [CrossRef]

207. Yoon, T.; Chae, C.; Sun, Y.K.; Zhao, X.; Kunge, H.H.; Lee, J.K. Bottom-up in situ formation of $\mathrm{Fe}_{3} \mathrm{O}_{4}$ nanocrystals in a porous carbon foam for lithium-ion battery anodes. J. Mater. Chem. 2011, 21, 17325-17330. [CrossRef]

208. Zhou, Z.; Xie, W.; Li, S.; Jiang, X.; He, D.; Peng, S.; Ma, F. Facile Synthesis of Porous $\mathrm{Fe}_{3} \mathrm{O}_{4} @ \mathrm{C}$ Nanospheres as High-Performance Anode for Lithium-Ion Battery. J. Solid State Electrochem. 2015, 19, 1211-1215. [CrossRef]

209. Yang, Y.; Li, J.; Chen, D.; Zhao, J. A facile electrophoretic deposition route to the $\mathrm{Fe}_{3} \mathrm{O}_{4} / \mathrm{CNTs} / \mathrm{rGO}$ composite electrode as a binder-free anode for lithium ion battery. ACS Appl. Mater. Interfaces 2016, 8, 26730-26739. [CrossRef]

210. Zhang, N.; Yan, X.; Huang, Y.; Li, J.; Ma, J.; Ng, D.H.L. Electrostatically assembled magnetite nanoparticles/graphene foam as a binder-free anode for lithium ion battery Langmuir. Langmuir 2017, 33, 8899-8905. [CrossRef]

211. Li, C.; Yin, X.; Chen, L.; Li, Q.; Wang, T. Synthesis of Cobalt Ion-Based Coordination Polymer Nanowires and Their Conversion into Porous $\mathrm{Co}_{3} \mathrm{O}_{4}$ Nanowires with Good Lithium Storage Properties. Chem.-Eur. J. 2010, 16, 5215-5221. [CrossRef]

212. Yang, Y.; Huang, J.; Zeng, J.; Xiong, J.; Zhao, J. Direct Electrophoretic Deposition of Binder-Free $\mathrm{Co}_{3} \mathrm{O}_{4} /$ Graphene Sandwich-Like Hybrid Electrode as Remarkable Lithium Ion Battery Anode. ACS Appl. Mater. Interfaces 2017, 9, 32801-32811. [CrossRef] [PubMed]

213. Bulusheva, L.G.; Stolyarova, S.G.; Chuvilin, A.L.; Shubin, Y.V.; Asanov, I.P.; Sorokin, A.M.; Gunov, M.S.M.; Zhang, S.; Dong, Y.; Chen, X.H.; et al. Creation of nanosized holes in graphene planes for improvement of rate capability of lithium-ion batteries. Nanotechnology 2018, 29, 134001. [CrossRef] 
214. Bulbula, S.T.; Lu, Y.; Dong, Y.; Yang, X.Y. Hierarchically porous graphene for batteries and supercapacitors. New J. Chem. 2018, 42, e5634-e5655. [CrossRef]

215. Cao, H.L.; Zhou, X.F.; Zheng, C.; Liu, Z.P. Metal etching method for preparing porous graphene as high performance anode material for lithium-ion batteries. Carbon 2015, 89, 41-46. [CrossRef]

216. Zhao, X.; Hayner, C.M.; Kung, M.C.; Kung, H.H. Flexible holey graphene paper electrodes with enhanced rate capability for energy storage applications. ACS Nano 2011, 5, 8739-8749. [CrossRef] [PubMed]

217. Zhao, D.D.; Wang, L.; Yu, P.; Zhao, L.; Tian, C.G.; Zhou, W.; Zhang, L.; Fu, H.G. From graphite to porous graphene-like nanosheets for high rate lithium-ion batteries. Nano Res. 2015, 8, 2998-3010. [CrossRef]

218. Fan, Z.J.; Yan, J.; Ning, G.Q.; Wei, T.; Zhi, L.J.; Wei, F. Porous graphene networks as high performance anode materials for lithium ion batteries. Carbon 2013, 60, 558-561. [CrossRef]

219. Ma, C.L.; Zhao, Y.; Li, Y. A facile solution-free etching preparation of porous graphene nanosheets with high performances for lithium storage. Chem. Eng. J. 2017, 320, 283-289. [CrossRef]

220. Tang, C.; Li, B.Q.; Zhang, Q.; Zhu, L.; Wang, H.F.; Shi, J.L.; Wei, F. CaO-templated growth of hierarchical porous graphene for high-Power lithium-sulfur battery applications. Adv. Funct. Mater. 2016, 26, 577-585. [CrossRef]

221. Zhu, B.; Liu, X.; Li, N.; Yang, C.; Ji, T.; Yan, K.; Chi, H.; Zhang, X.; Sun, F.; Sun, D.; et al. Three-dimensional porous graphene microsphere for high performance anode of lithium ion batteries. Surface Coat. Technol. 2019, 360, 232-237. [CrossRef]

222. Xing, B.; Zeng, H.; Huang, G.; Zhang, C.; Yuan, R.; Cao, Y.; Chen, Z.; Yu, J. Porous graphene prepared from anthracite as high-performance anode materials for lithium-ion battery applications. J. Alloys Compd. 2019, 779, 202-211. [CrossRef]

223. Levchenko, I.; Ostrikov, K.; Mariotti, D. The production of self-organized carbon connections between Ag nanoparticles using atmospheric microplasma synthesis. Carbon 2009, 47, 344-347. [CrossRef]

224. Ostrikov, K.; Levchenko, I.; Xu, S. Computational plasma nanoscience: Where plasma physics meets surface science. Comput. Phys. Commun. 2007, 177, 110-113. [CrossRef]

225. Yang, Q.; Wu, J.; Li, S.; Zhang, L.; Fu, J.; Huang, F.; Cheng, Q. Vertically-oriented graphene nanowalls: Growth and application in Li-ion batteries. Diam. Relat. Mater. 2019, 91, 54-63. [CrossRef]

226. Guo, P.; Song, H.H.; Chen, X.H. Electrochemical performance of graphene nanosheets as anode material for lithium- ion batteries. Electrochem. Commun. 2009, 11, 1320-1324. [CrossRef]

227. Xiang, H.F.; Li, Z.D.; Xie, K.; Jiang, J.Z.; Chen, J.J.; Lian, P.C.; Wu, J.S.; Yu, Y.; Wang, H.H. Graphene sheets as anode materials for Li- ion batteries: Preparation, structure, electrochemical properties and mechanism for lithium storage. RSC Adv. 2012, 2, 6792-6799. [CrossRef]

228. Ren, H.; Wang, W.; Woo Joo, S.; Sun, Y.; Gu, C. Preparation of $\mathrm{ZnCo}_{2} \mathrm{O}_{4} @$ reduced graphene oxide nanocomposite for high-capacity Li-ion battery anodes. Mater. Res. Bull. 2018, 111, 34-42. [CrossRef]

229. Qin, J.; He, C.; Zhao, N.; Wang, Z.; Shi, C.; Liu, E.-Z.; Li, J. Graphene Networks Anchored with Sn@Graphene as Lithium Ion Battery Anode. ACS Nano 2014, 8, 1728-1738. [CrossRef]

230. Patil, S.B.; Kim, I.Y.; Gunjakar, J.L.; Oh, S.M.; Eom, T.; Kim, H.; Hwang, S.-J. Phase Tuning of Nanostructured Gallium Oxide via Hybridization with Reduced Graphene Oxide for Superior Anode Performance in Li-Ion Battery: An Experimental and Theoretical Study. ACS Appl. Mater. Interfaces 2015, 7, 18679-18688. [CrossRef]

231. Matsuo, Y.; Taninaka, J.; Hashiguchi, K.; Sasaki, T.; Cheng, Q.; Okamoto, Y.; Tamura, N. Effect of oxygen contents in graphene-like graphite anodes on their capacity for lithium ion battery. J. Power Sources 2018, 396, 134-140. [CrossRef]

232. Mahmood, N.; Zhang, C.; Liu, F.; Zhu, J.; Hou, Y. Hybrid of $\mathrm{Co}_{3} \mathrm{Sn}_{2} @ \mathrm{Co}$ Nanoparticles and Nitrogen-Doped Graphene as a Lithium Ion Battery Anode. ACS Nano 2013, 7, 10307-10318. [CrossRef] [PubMed]

233. Li, L.; Jiang, G.; Ma, J. CuMn $\mathrm{O}_{4}$ /graphene nanosheets as excellent anode for lithium-ion battery. Mater. Res. Bull. 2018, 104, 53-59. [CrossRef]

234. Kim, C.; Kim, J.W.; Kim, H.; Kim, D.H.; Choi, C.; Jung, Y.S.; Park, J. Graphene Oxide Assisted Synthesis of Self-assembled Zinc Oxide for Lithium-Ion Battery Anode. Chem. Mater. 2016, 28, 8498-8503. [CrossRef]

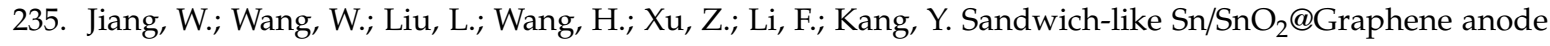
composite assembled by fortissimo penetration of $\gamma$-ray and interlamellar limitation of graphene oxide. J. Alloys Compd. 2019, 779, 856-862. [CrossRef] 
236. Jiang, Y.; Yan, X.; Mei, P.; Zhang, Y.; Xiao, W.; Tang, H. Electrochemical reconstruction induced high electrochemical performance of $\mathrm{Co}_{3} \mathrm{O}_{4}$ /reduced graphene oxide for lithium ion batteries. J. Alloys Compd. 2018, 764, 80-87. [CrossRef]

237. Jiang, T.; Bu, F.; Feng, X.; Shakir, I.; Hao, G.; Xu, Y. Porous Fe2O3 Nano frameworks Encapsulated within Three-Dimensional Graphene as High-Performance Flexible Anode for Lithium-Ion Battery. ACS Nano 2017, 11, 5140-5147. [CrossRef]

238. Hu, X.; Jin, Y.; Zhu, B.; Liu, Z.; Xu, D.; Guan, Y.; Liu, F. Tuning density of Si nanoparticles on graphene sheets in graphene-Si aerogels for stable lithium ion batteries. J. Colloid Interface Sci. 2018, 532, 738-745. [CrossRef] [PubMed]

239. Wang, J.-F.; Zhang, J.-J.; He, D.-N. Flower-like $\mathrm{TiO}_{2}-\mathrm{B}$ particles wrapped by graphene with different contents as an anode material for lithium-ion batteries. NanoStruct. NanoObjects 2018, 15, 216-223. [CrossRef]

240. Ding, R.; Zhang, J.; Zhang, J.; Li, Z.; Wang, C.; Chen, M. Core-shell Fe2N@amorphous carbon nanocomposite-filled 3D graphene framework: An additive-free anode material for lithium-ion batteries. Chem. Eng. J. 2019, 360, 1063-1070. [CrossRef]

(C) 2019 by the authors. Licensee MDPI, Basel, Switzerland. This article is an open access article distributed under the terms and conditions of the Creative Commons Attribution (CC BY) license (http://creativecommons.org/licenses/by/4.0/). 